NBER WORKING PAPER SERIES

\title{
BLACK LIVES MATTER PROTESTS AND RISK AVOIDANCE: THE CASE OF CIVIL UNREST DURING A PANDEMIC
}

\author{
Dhaval M. Dave \\ Andrew I. Friedson \\ Kyutaro Matsuzawa \\ Joseph J. Sabia \\ Samuel Safford \\ Working Paper 27408 \\ http://www.nber.org/papers/w27408 \\ NATIONAL BUREAU OF ECONOMIC RESEARCH \\ 1050 Massachusetts Avenue \\ Cambridge, MA 02138 \\ June 2020, Revised January 2021
}

Sabia acknowledges research support from the Center for Health Economics \& Policy Studies (CHEPS) at San Diego State University, including grant support received from the Charles Koch Foundation and the Troesh Family Foundation. We thank Kasey Buckles, Andrea Velásquez and seminar participants at the Colorado School of Public Health and University of Maryland Baltimore County for helpful advice on previous versions of the paper, as well as Drew McNichols, Alicia Marquez, Cameron Milani, James Curry, Calvin Bryan, Erich Kevari, Connor Redpath, and Melinda Mueller for outstanding research assistance. The views expressed herein are those of the authors and do not necessarily reflect the views of the National Bureau of Economic Research.

NBER working papers are circulated for discussion and comment purposes. They have not been peer-reviewed or been subject to the review by the NBER Board of Directors that accompanies official NBER publications.

(C) 2020 by Dhaval M. Dave, Andrew I. Friedson, Kyutaro Matsuzawa, Joseph J. Sabia, and Samuel Safford. All rights reserved. Short sections of text, not to exceed two paragraphs, may be quoted without explicit permission provided that full credit, including (C) notice, is given to the source. 
Black Lives Matter Protests and Risk Avoidance: The Case of Civil Unrest During a Pandemic Dhaval M. Dave, Andrew I. Friedson, Kyutaro Matsuzawa, Joseph J. Sabia, and Samuel Safford NBER Working Paper No. 27408

June 2020, Revised January 2021

JEL No. H75

\section{ABSTRACT}

Sparked by the killing of George Floyd in police custody, the 2020 Black Lives Matter (BLM) protests brought a new wave of attention to the issue of inequality within criminal justice. However, some policymakers warned that such protests should be curtailed due to public health risks of infectious disease contagion. The current study finds that this epidemiological argument rests on an incorrect counterfactual that ignores economic incentives for risk-avoiding behaviors. We use newly collected data on BLM protests and anonymized cell phone data from SafeGraph, Inc. to estimate the impacts of BLM protests on (i) stay-at-home behavior, and (ii) foot-traffic to restaurants/bars, retail establishments, and business service locations. Event-study analyses provide strong evidence that net stay-at-home behavior increased following protest onset, consistent with the hypothesis that non-protesters shifted their activity in response to the perceived heightened risk of contagion and protest-related violence. Moreover, we find that the types of activities that were averted by BLM protests were potentially riskier for disease spread than outdoor civil rights protests: restaurant and bar-going and retail shopping. These riskavoiding responses to protests, coupled with mask-wearing by protesters, explain why BLM protests did not reignite community-level COVID-19 growth. Together, our findings highlight the pitfalls of ignoring general equilibrium effects in assessing the net economic impacts of civil rights protests.

\author{
Dhaval M. Dave \\ Department of Economics \\ Bentley University \\ 175 Forest Street, AAC 195 \\ Waltham, MA 02452-4705 \\ and IZA \\ and also NBER \\ ddave@bentley.edu \\ Andrew I. Friedson \\ Department of Economics \\ University of Colorado Denver \\ Lawrence Street Center 460T \\ Campus Box 181 \\ P.O. Box 173364 \\ Denver, CO 80217-3364 \\ andrew.friedson@ucdenver.edu \\ Kyutaro Matsuzawa \\ Center for Health Economics and Policy Studies \\ San Diego State University \\ San Diego, CA \\ qmatsuzawa@gmail.com
}

Joseph J. Sabia

Department of Economics

San Diego State University

Center for Health Economics

\& Policy Studies

5500 Campanile Drive

San Diego, CA 92182

and IZA \& ESSPRI

jsabia@sdsu.edu

Samuel Safford

Center for Health Economics \& Policy Studies

San Diego, CA

safford.samuel@gmail.com 


\section{Introduction}

On May 25, George Floyd, a 46-year-old black man, was killed by a member of the Minneapolis Police Department when an officer used his knee to pin Floyd's neck to the ground for over eight minutes (Hill et al. 2020). The death, which resulted in the officer being charged with murder, touched off a series of protests in cities around the United States, with protesters demanding, among other things, policing reform (Taylor 2020). However, these protests came during a second national crisis, the COVID-19 pandemic, a deadly infectious disease whose spread is facilitated by close contact. ${ }^{1}$ This led both public health experts and policymakers to contend that exercise of the constitutional right to assemble during a pandemic would generate substantial public health costs (Bacon 2020; Goldberg 2020; Harmon and Rojas 2020). For example, Dr. Anthony Fauci, the director of the National Institute of Allergy and Infectious Diseases remarked on the protests, "I get very concerned, as do my colleagues in public health, when they see these kinds of crowds” (Resnick 2020). ${ }^{2}$

However, this epidemiological argument assumes a counterfactual that ignores economic incentives for risk-avoiding behaviors by non-participants and fails to consider the behaviors in which protesters (and non-protesters) would have engaged in the absence of a civil rights rally. Economists have long studied risk compensating behavior, the key insight being that individuals

\footnotetext{
${ }^{1}$ One of the main tactics for controlling the spread of COVID-19 was social distancing: avoiding large public gatherings, and maintaining at least 6 feet of distance between individuals (Australian Government Department of Health. 2020; Public Health England. 2020; Public Health Agency of Canada. 2020; White House 2020). In fact, one of the steps that many states and localities have taken to slow community transmission is to impose restrictions on indoor and outdoor gatherings.

${ }^{2}$ This sentiment was not uncommon amongst top public health officials and practitioners, a similar sentiment was expressed by Ashish Jha, Dean of the Brown University School of Public Health, who remarked "Do I worry that mass protests will fuel more cases? Yes, I do.” (Powell 2020). Some public health experts also pointed out that the goals of the protests may be worth the costs (Powell 2020; Simon 2020).
} 
will adjust their risk taking behavior based on their perceived exposure to risk. ${ }^{3}$ For example, in the sphere of public health, economists have demonstrated that changes in perceived risk due to availability of HIV treatments changes risky sexual behavior (Lakdawalla, Sood and Goldman 2006). ${ }^{4}$ The centrality of risk perceptions for preventative health behaviors has also been established in the context of vaccinations, with studies finding that the perceived probability of infection and severity of the disease are a significant predictor of flu vaccine uptake (Mullahy 1999; Brewer et al. 2007; Tsuitsui et al. 2012; Carman and Kooreman 2014). Moreover, early evidence suggests that in the context of the COVID-19 pandemic, even in the absence of mitigation policies, individuals privately adjusted their daily activities to avoid risk as the disease became more prevalent and the environment riskier (Cronin and Evans 2020; Gupta et al. 2020).

In addition to generating health-related risk avoidance, BLM protests could also generate violence-related risk avoidance, due to perceived fears of violent behaviors by police or protesters (Kim 2020). A recent, closely applicable literature exists on crime, in which individuals are found to spend more time indoors as local criminal activity increases, avoiding risk exposure by changing their mix of daily activities (Bennett et al. 2007; Stafford et al. 2007; Roman and Chalfin 2008; Janke, Propper and Shields 2016; Yu and Lippert 2016; Stolzenberg, D’Alessio and Flexon 2019).

Finally, claims of pandemic spread by public health officials ignored counterfactual behaviors in which protesters and non-protesters would have been engaged in the absence of protest gatherings. For instance, outdoor gatherings involving mask wearing among young

\footnotetext{
${ }^{3}$ The general principle of individuals disliking and finding margins by which to reduce risk is far older, dating back at least to the concept of a "risk premium" or willingness to pay to swap risky assets for riskless ones (Pratt 1964; Arrow 1971).

${ }^{4}$ Another related literature explores ex ante moral hazard, wherein individuals protected from financial risk due to insurance take on riskier behaviors. See for example Chiappori (2000); Cohen and Dehejia (2004); Klick and Stratmann (2007); or Dave and Kaestner (2009).
} 
adults may be less risky for infectious disease spread than indoor restaurant/bar-going or retail shopping (Fisher et al. 2020).

In this study, we document compelling evidence that failing to account for risk avoiding behavior in response to the 2020 Black Lives Matter (BLM) protests resulted in public health officials and policymakers incorrectly forecasting the public health costs of these civil rights protests. Using newly collected data on BLM protests in 315 of the largest U.S. cities, merged to daily anonymized smartphone tracking data from SafeGraph Inc., we find that BLM protests led to risk avoidance due to (i) public health risks and perceived violence risks. First, difference-indifferences regressions show that the onset of BLM protests led to increases in rates of full-time stay-at-home behavior and median hours spent at home among local residents. We find that the increase in stay at home behavior is largest when (i) local COVID-19 growth prior to the death of George Floyd was relatively higher, (ii) state mask mandates were not in place, and (iii) there were reports of violence at the civil rights rallies. These findings are consistent with local nonrallygoers responding to the increased risks of infectious disease spread and protest-related violence (i.e., by police or protesters) by increasing time spent at home.

In addition, our examination of point-of-interest smartphone data provide strong evidence that the activities supplanted by BLM protests were higher risk activities for infectious disease spread than outdoor rallies. Specifically, event-study analyses show that the onset of BLM protests was associated with a substantial net decline in foot traffic at restaurants/bars and retail establishments, which are indoor activities that are more conducive to disease spread. ${ }^{5}$

We find that these important risk avoiding actions (by protest participants and nonparticipants), in conjunction with any mask-wearing by rally attendees, resulted in no net

\footnotetext{
${ }^{5}$ We cannot attribute these reductions in activities to solely protesters or solely protest avoiders.
} 
increase in community-level COVID-19 spread following BLM protests. Together, our findings highlight the dangers of public health officials and policy makers ignoring general equilibrium effects in assessing the net economic impacts of community-based social activism.

\section{Background}

\subsection{Features of the 2020 Black Lives Matter Protests}

On May 25, 2020 George Floyd was arrested for trying to use a counterfeit twenty-dollar bill to purchase cigarettes. During the course of the arrest, one of the officers involved, Derek Chauvin, who is white, restrained George Floyd by pinning him to the ground by his neck with his knee. Despite George Floyd complaining that he was unable to breathe, Derek Chauvin continued to restrain George Floyd in that position for 8 minutes and 46 seconds, during which he became unresponsive and stopped breathing (Hill et al. 2020; Furber et al. 2020; State of Minnesota 2020).

News of the killing sparked immediate protest of policing behavior, with the first protest taking place in Minneapolis on the next day, May 26, 2020. ${ }^{6}$ The death of George Floyd also sparked widespread protests in large cities nationwide. Figure 1 shows both the gradual diffusion of the protests, with 286 cities (documented to have a municipal population of at least 100,000) seeing protests by June 16, 2020. The vast majority of these cities saw protests lasting

\footnotetext{
${ }^{6}$ The recent Black Lives Matter protests are not the first time that the killing of an individual has led to large scale protests with regards to issues of unequal treatment by law enforcement on the basis of race. The Black Lives Matter movement traces back to 2013 and events surrounding the death of Trayvon Martin (Black Lives Matter 2020), but the larger issue of racial justice within law enforcement in the United States is substantially older.
} 
more than 3 days (72 percent) and about one-third were attended by at least 1,000 people, according to media reports.

While many protests remained continuously peaceful, some included violence. There were several high-profile instances of looting in cities such as Chicago, Minneapolis and Los Angeles (Khazan 2020, Peterson 2020), as well a number of instances of police use of force against protesters, including pepper spray, tear gas, and rubber bullets (Kim 2020). Some of the police violence was in the course of enforcing citywide curfews which were enacted in some cities in response to the large protests.

\subsection{COVID-19 and Social Distancing}

The main vector for transmitting COVID-19 is believed to be respiratory droplets, which are emitted during respiratory expulsion such as breathing, speaking, coughing or sneezing (Centers for Disease Control and Prevention 2020a, Fineberg 2020). The disease was able to circulate rapidly in part due to its ability to spread from asymptomatic carriers, allowing individuals to infect others without knowing that they have done so or even that they themselves are infected (Bai et al. 2020; Pan et al. 2020; Rothe et al. 2020).

To combat the pandemic, governments took on two types of strategies. The first was a set of public health recommendations for social behavior within the population. Specifically, government health agencies have recommended frequent hand washing, mask-wearing in public and social distancing - avoiding public spaces and when in public spaces maintaining distance (usually at least 6 feet) between oneself and others (World Health Organization 2020; Centers for Disease Control 2020b). The second set of policies have involved public encouragement and enforcement of social distancing by shutting down public spaces, such as school closures, public 
gathering bans, and blanket shelter-in-place orders. These policies have been the subject of a growing literature that has shown meaningful increases in distancing behavior and meaningful decreases in disease infection growth rates following the enactment of shelter-in-place orders, suggesting that the strategy of social distancing (and its associated enforcement policies) was largely successful at slowing the spread of the disease (Courtemanche et al. 2020a,b; Dave et al. 2020a,b,c; Friedson et al. 2020; Sears et al. 2020).

\subsection{Protests and Behavior}

Large scale protests could impact net social distancing behavior (and disease transmission) through two key populations, those who attended the protests and those who did not. Correctly measuring the public health costs due to the protests depends on understanding the behavior of these populations as well as their respective sizes and demographics.

\subsubsection{Protest Attendee Behavior}

A protest is an activity that is difficult to socially distance. Attendees of the protests, be they protesters or police tend to congregate around points of interest (such as a seat of government) in close proximity. While attendees can utilize some compensatory behaviors to prevent spreading infection, such as wearing masks, maintaining distance from each other, and staying home if they feel ill, it is difficult at such an event to completely avoid human contact. Many activities that are common at protests, such as chanting or shouting can exacerbate the spread of respiratory droplets (Wei and Li 2016). Additionally, many forms of crowd dispersal used by law enforcement to break up protests such as pepper spray or tear gas illicit coughing, 
which increases the likelihood that an infected individual will spread disease (Xi et al. 2009; Rothenberg et al. 2016; Wei and Li 2016).

It is also important to consider the outside option for a protest attendee. People who attended protests may have otherwise been at home, but also may have otherwise been at work, or at public leisure activities such as bars or restaurants. It is further possible that protesters engaged in additional social distancing behavior during non-protest hours, creating a net increase in social distancing. Overall, it is difficult to know theoretically if attending a protest increased or decreased the average attendee's social distancing and disease transmission behavior.

\subsubsection{Protest Avoider Behavior}

The population who did not attend the large protests could have their behavior altered by the presence of local protests and the new risk environment presented by these events. To the extent that the protests were seen as dangerous (due to the protesters or the police being potentially violent, or due to the risk of disease transmission at or near the protests), then individuals might choose to remain home due to the additional risk to their person or property. This would be consistent with previous literature showing a link between crime and reduced outdoor physical activity, where individuals avoid going outside due to additional perceived risk (Bennett et al. 2007; Stafford et al. 2007; Roman and Chalfin 2008; Janke, Propper and Shields 2016; Yu and Lippert 2016; Stolzenberg, D’Alessio and Flexon 2019). ${ }^{7}$

There is also the possibility that non-attendees may have remained due to increased costs to activities rather than increased risks. For example, time costs from traffic congestion or from

\footnotetext{
${ }^{7}$ Exposure to violent crime itself increases risk aversion (Brown et al. 2019, Jakiela and Ozier 2019), so to the extent that protests included violence it is possible that individuals gained an additional appetite for social distancing.
} 
routing around streets closed off due to protests could have made remaining home more attractive. Also, if businesses were closed, either due to destruction from looting or as a preventative measure to avoid looting, this would have decreased the number of options for out of the home activities, increasing the likelihood that individuals would stay home.

\section{Data}

\subsection{Urban Protests}

Our data on protests are collected from May 25, 2020, the day George Floyd was killed, through July 7, 2020 from 315 U.S. cities with municipal populations estimated at 100,000 or more in 2019 (U.S. Census Bureau 2019). Searches for protests were carried out by the Center for Health Economics \& Policy Studies (CHEPS) at San Diego State University using internet searches for local and national news articles, reports from local police departments, and communications from mayors' and governors’ offices. Of the 315 largest U.S. cities under study, we document that 286 cities saw a protest while 29 did not. Figure 1 documents the geographic dispersion of these protests over time, beginning on May 26, the first day following George Floyd's death. The first large U.S. cities to experience protests were Minneapolis, Minnesota (May 26), the city where George Floyd was killed, followed by Memphis, Tennessee (May 27), and Los Angeles, California (May 27). On May 28, 14 additional cities held protests, followed by 49 additional cities on May 29, 88 cities on May 30, 49 on May 31, and 82 in the month of June.

Appendix Figure 1 shows the geographic distribution of the "control" cities without

protests (in black) as compared to the treatment cities (in red). Included among geographically 
diverse large cities without a Black Lives Matter protest were Glendale, Arizona, Hialeah, Florida, and Sugar Land, Texas.

In Appendix Figure 2, we explore heterogeneity across protests by showing protests which were accompanied by mainstream media reports of violence (which may include looting or arrests) (blue) as compared to those that were consistently described as only peaceful (yellow). Of the 286 cities with protests, 134 cities (46.9 percent) had a protest that was accompanied by reports of violence.

We also explore differences in protests with regards to persistence. Appendix Figure 3 compares large cities that had protests continue for three or more days (blue) to cities that held protests on only one or two days (yellow). We find that 74.5 percent of treatment cities (213 of 286 cities) held protests for 3 or more days.

In Appendix Figure 4, we show which cities included large protests, with media reports of crowd sizes exceeding over 1,000 individuals. Such protests could increase the risk of COVID-19 spread via the large reductions in social distancing among protest attendees. These larger protests are depicted in blue and comprise 47.2 percent of all protest cities.

Finally, in Appendix Figure 5, we map our 286 “protest cities” into their primary 203 counties (black) and 42 secondary counties (grey) using the crosswalk created by Simplemaps, which compiles up-to-date geographic information from the U.S. Geological Survey and U.S. Census Bureau. ${ }^{8}$ We do this for two reasons. First, our primary analyses of social distancing and COVID-19 case growth will be at the county-level given data availability of both of these outcomes. Second, using the county as our geographic unit of observation will allow us to capture potentially important spillover effects from local protesters who (i) travel beyond city

\footnotetext{
${ }^{8}$ The crosswalk is available at: https://simplemaps.com/data/us-cities
} 
limits to attend the events and (ii) perhaps travel back home where the coronavirus may be spread. Supplemental analysis will widen this ring to include secondary counties associated with primary counties, as well as include other border counties of the primary county where the protest took place.

\subsection{Social Distancing}

Our data on social distancing are drawn from SafeGraph, Inc., which provides an anonymized population movement dataset of nearly 45 million smartphone devices aggregated to the census block, county, and state levels. ${ }^{9}$ These data have been used by the Centers for Disease Control and Prevention (Lasry et al. 2020) and by COVID-19 scholars examining social distancing in the United States (Andersen et al. 2020; Dave et al. 2020a,b,c; Friedson et al. 2020; Abouk and Heydari 2020; Gupta et al. 2020).

Our social distancing analysis spans a period of 30 days from May 15, 2020 through June 13, 2020, which envelopes the date of George Floyd's death (May 25) and the outbreak of urban protests (May 26). Our analysis focuses on 208 primary counties which map to the 315 cities with a municipal population of 100,000 . The average population of these counties is 779,565 . In supplemental analyses, we add 42 "secondary" counties, to which large cities extended, to the treatment group. Moreover, we also conduct analyses augmenting the treatment group to include 739 border counties outside of the city limits to ensure that our results do not fail to capture important spillovers of protests.

We capture various dimensions of social distancing based on the Social Distancing Metrics (SDM) and Points-of-Interest (POI) data derived from SafeGraph. In the SDM, the base

\footnotetext{
${ }^{9}$ SafeGraph data, and a detailed description of these data, are available at: https://www.safegraph.com/dashboard/covid19-shelter-in-place
} 
unit of observation is represented by the cellular device, and each device is assigned a "home" according to a common nighttime location. ${ }^{10}$ We construct three measures at the daily level, capturing stay-at-home behaviors within a county. The first measure, Stay-at-Home Full-Time, captures the percent of the county population who remain at home for the entire day. We estimate that in our sample, 35.6 percent of respondents remained at home full-time. The other two measures proxy for social distancing behavior at the intensive margin: Median Hours at Home and Median Percent Time Spent at Home. On average, county-level respondents in our urban sample remained at home for a median of 12.5 hours and for 89.6 percent of the time on a given day. ${ }^{11}$

Panels (a) through (c) of Appendix Figure 6A shows trends in stay-at-home behaviors over the analysis period for our primary counties. We find that despite the intra-week variance in social distancing, there is an overall downward trend for all three measures. We see that, comparing to our earlier sample period (e.g. the first five days of our sample), less people are staying at home and spending time at home during our later sample period (e.g. after June $1^{\text {st }}$ ).

In order to assess how the protests may have affected mobility and foot-traffic patterns, we turn to the POI data. With the POI data, the base unit of observation is a "point of interest", often a business establishment. An establishment is identified with a location and type, using six-digit North American Industry Classification System (NAICS) industry codes, and we observe the number of cellphone pings at that establishment each day. We aggregate these data

\footnotetext{
${ }^{10}$ The "home" location is defined as a 153-meter by 153-meter location where the cellphone pinged most frequently during the evening and nighttime hours between $6 \mathrm{pm}$ and $7 \mathrm{am}$ over a 6-week baseline period.

${ }^{11}$ The measure Median Hours at Home is based on summed observed minutes at home throughout the day, regardless of whether or not these time episodes are contiguous. Because time during which a smartphone is turned off is not counted towards measured time spent at home, this measure is not sensitive to protesters potentially turning off their phones during the protests as a result of concern for potential digital surveillance or tracking by law enforcement. Irrespective of whether protesters are leaving their phones on or off during protesting activities, their activity would be appropriately reflected as a decrease in the median number of hours spent at home during the day.
} 
across establishment types, focusing largely on restaurants and bars, retail services, and business services, and construct measures of the count of pings from distinct cellular devices at each business type in a given county on each day. In addition to providing an alternate metric for social distancing activity to those derived from the SDM, these variables also provide complementary information on the types of activities that individuals may engage in or eschew when they shift their stay-at-home behaviors.

\subsection{COVID-19 Case and Death Growth}

Finally, we measure county-level COVID-19 cumulative case and death growth using data published by The New York Times. ${ }^{12}$ For our COVID-19 analysis period, May 15, 2020 through July 7, 2020, we estimate an average of 710.4 COVID-19 cases per 100,000 population and 40.4 COVID-19 deaths per 100,000 population in our sample. Our COVID-19 dependent variable measures the difference in the natural log in the cumulative number of COVID-19 cases (or death)s on a given day and the natural log of the number of cases (or deaths) on the previous day (see also, Courtemanche et al. 2020; Dave et al. 2020b). The mean of these measures over our sample period is 0.021 for cases and 0.012 for deaths.

In Panel (a) and Panel (b) of Appendix Figure 6B, we show the trend in COVID-19 cases and COVID-19 deaths for the full sample of counties, respectively. We show that the slope is almost linear for much of the sample period, but generally over the last week observed, there is an upward inflection in trajectory for both cases and deaths.

\section{Methods}

${ }^{12}$ These data are available at: https://github.com/nytimes/covid-19-data 
The main objective of this study is to estimate how mass protests across the U.S. following the death of George Floyd impacted social distancing behaviors and in turn affected the growth in COVID-19 cases and deaths. Our research design capitalizes on variation in the differential outbreak of these protests over time across "treated" cities in conjunction with “never-treated” large city controls that did not experience any protests over the sample period.

We begin by pooling our sample of 208 primary counties, which include the largest 315 U.S. cities with a municipal population of at least 100,000 across 30 days and estimate a difference-in-differences model of the following form:

$$
S D_{\mathrm{cst}}=\gamma_{0}+\sum_{j=0}^{8} \gamma_{j} \text { Protest }_{\mathrm{ct}}^{j}+\mathbf{X}_{\mathrm{ct}} \beta_{1}+\mathbf{Z}_{\mathrm{st}} \beta_{2}+\alpha_{\mathrm{c}}+\tau_{\mathrm{t}}+\varepsilon_{\mathrm{sct}}
$$

where $S D_{\text {cst }}$ is one of our six measures of social distancing in county $c$ in state $s$ on day $t$, capturing stay-at-home behaviors and foot-traffic patterns either from the SDM or the POI. For the POI-based foot-traffic measures, we use the inverse hyperbolic sine transformation. ${ }^{13}$ Protest $_{\mathrm{ct}}^{j}$ represents a set of mutually exclusive indicators set equal to 1 if county c saw a large city protest $j$ days from day $t$, and captures any dynamics in social distancing behaviors following the protest outbreak. In addition, $\mathbf{X}_{\mathrm{ct}}$ is a vector of county-level time-varying controls including average temperature (in degrees Celsius) and an indicator for whether any measurable precipitation fell. ${ }^{14} \mathbf{Z}_{\mathrm{st}}$ is a vector of state-level time-varying controls including the natural log of COVID-19 testing rates, an indicator for whether the state had a shelter-in-place order (SIPO) in effect, an indicator for whether the state had a mask mandate in place, and indicators for whether the state permitted reopening of (i) restaurants or bars, (ii) retail stores (beyond curbside pickup),

\footnotetext{
${ }^{13}$ The inverse hyperbolic sine approximates the natural log, is interpreted in a similar manner, but has the advantage of retaining zeroes (Bellemare and Wichman 2020).

${ }^{14}$ These data are available at: ftp://ftp.ncdc.noaa.gov/
} 
(iii) pet or personal care services (such as barbershops, nail salons and tattoo parlors), or (iv) entertainment activities (such as drive-in movie theatres, state parks, and public pools). ${ }^{15}$ In addition, $\alpha_{c}$ is a county fixed effect, and $\tau_{t}$ is a day fixed effect. All regressions are weighted by the county population and standard errors are clustered at the county-level.

The parameters of interest, $\gamma_{j}$, capture the net effects of the protests on stay-at-home behaviors and mobility outside the home operating through all — reinforcing and counteracting, direct and indirect — behavioral pathways. In our main tables on social distancing, we present post-protest effects for various time windows up to 8 or more days following its outbreak.

Drawing insights from our estimates of how the protests have affected social distancing behaviors, we next examine effects of the protests on the growth in COVID-19 cases by using data from May 15, 2020 through July 7, 2020 (54 days) and estimating the following specification:

$$
\text { COVID Growth }_{\mathrm{cst}, \mathrm{t}-1}=\gamma_{0}+\sum_{j=0}^{35} \gamma_{j} \text { Protest }_{\mathrm{ct}}^{j}+\mathbf{X}_{\mathrm{ct}} \beta_{1}+\mathbf{Z}_{\mathrm{st}} \beta_{2}+\alpha_{\mathrm{c}}+\tau_{\mathrm{t}}+\varepsilon_{\mathrm{sct}}
$$

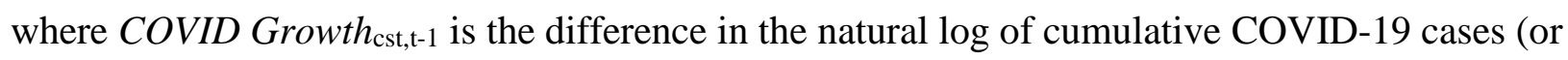
deaths) in county $c$ on day $t$ and day $t-1$, that is day-over-day COVID-19 case growth. Because we have additional data on cases, we are able to estimate case effects up to 35 or more days following the day of the protest, a period well beyond the median incubation period of COVID19 (5.1 days) (Lauer et al. 2020) when we would expect case divergence if there were an effect

\footnotetext{
${ }^{15}$ Data for COVID-19 testing are available from COVID tracking project (see: https://covidtracking.com). Data for SIPO enactment are available in Mervosh et al. (2020) and Dave et al. (2020a). Data on reopening policies are compiled by our own searches of official county websites, county court records, local news agencies, and gubernatorial executive orders and proclamations.
} 
from the protest gathering - as seen in studies of mitigation policies (Friedson et al. 2020; Dave et al. 2020a, b, c; Courtemanche et al. 2020a, b).

Our difference-in-differences estimates of protest effects will only be unbiased in the absence of (i) endogenous protests, that is, protests starting because of differential COVID-19 case growth, and (ii) unmeasured county-specific unobservables that could be correlated with protests and with COVID-19 case growth.

We take two approaches to assess the common trends assumption. First, we conduct an event-study analysis, decomposing the estimated protest effect into coefficients up to 7 days prior to the outbreak of the event and up to 10 (for social distancing) or 35 days (for cases) following the onset of protests. This will provide a descriptive test for whether protests are endogenous to the outcomes under study or correlated with differential trends in outcomes across the treated and non-treated counties. Second, in a robustness check, we test the sensitivity of estimates from equations (1) and (2) to additional controls for time-varying unmeasured factors. We include county-specific linear time trends, which may capture (i) differences in the trajectory of the COVID-19 epidemic across counties, and (ii) unobserved time-varying heterogeneity at the county level such as enforcement of local mitigation policies or outreach to historically marginalized populations. In alternate specifications, we also control for state-by-day fixed effects to capture time-variant common shocks across counties within the same state.

Next, we allow for spillover effects of protests by augmenting our analysis sample to include 42 "secondary" counties to which cities may extend. In addition, in supplemental analysis, we also augment our treatment group to include 739 border counties to the treatment counties. We then re-estimate equations (1) and (2), turning the protest variable on for all "treated" counties (primary, secondary, and non-secondary border counties) when a primary 
county has its protest. This will allow us to capture those protesters who may travel from neighboring jurisdictions to participate and potentially spread COVID-19 back in their home counties. In these regressions, standard errors are clustered at the level of the 208 "primary counties” associated with each group of border counties.

Finally, we examine heterogeneity in the impact of urban protests across several key dimensions of the protests and moderators of transmission risk, and estimate the following specification interacting the post-protest time windows with the relevant characteristic:

$$
\begin{aligned}
& \text { SD }_{\mathrm{cst}}=\gamma_{0}+\sum_{j=0}^{8} \gamma_{j} \text { Protest }_{\mathrm{ct}}^{j} * \mathrm{~T}_{\mathrm{c}}+\mathbf{X}_{\mathrm{ct}} \beta_{1}+\mathbf{Z}_{\mathrm{st}} \beta_{2}+\alpha_{\mathrm{c}}+\tau_{\mathrm{t}}+\varepsilon_{\mathrm{cst}} \\
& \text { COVID Growth } \mathrm{cst}=\gamma_{0}+\sum_{j=0}^{35} \gamma_{j} \text { Protest }_{\mathrm{ct}}^{j} * \mathrm{~T}_{\mathrm{c}}+\mathbf{X}_{\mathrm{ct}} \beta_{1}+\mathbf{Z}_{\mathrm{st}} \beta_{2}+\alpha_{\mathrm{c}}+\tau_{\mathrm{t}}+\varepsilon_{\mathrm{cst}}
\end{aligned}
$$

where $T_{c}$ measures particular characteristics of the protest that could differentially affect social distancing and COVID-19 case (or death) growth. These include (i) Violent ${ }_{c}$, an indicator for whether the protest was accompanied by media reports of violence (i.e. arrests, use of tear gas, looting), (ii) Persistent $c$, an indicator for whether the protest lasted for at least three days, (iii) Protest Size $_{c}$, an indicator for whether the protest was reported to consist of over 1,000 individuals on at least one day of the protest, (iv) Curfews, an indicator for whether the city’s mayor issued a curfew order at some point during the protest period, and (v) Mask Mandates, an indicator for whether the state had a mask mandate in place as of May $25^{\text {th }}$, the day of George Floyd's death. ${ }^{16}$ In addition, in a series of auxiliary analysis, we explore whether there were

\footnotetext{
1646.9 percent of all treatment cities (and 58.7 percent of all treatment counties) had a protest that was accompanied by media reports of violence; and 71.9 percent of all treatment cities (and 83.2 percent of all treatment counties) had a protest that lasted for three or more days; 47.2 percent of all treatment cities (and 58.7 percent of all treatment counties) had a protest with reported attendance exceeding 1,000 persons; 52.9 percent of treatment cities (and 47.6
} 
heterogeneous effects by whether the onset of protests occurred early in calendar time (on May 26,27 , or 28 ) or later, by whether the city municipal population size was greater than 500,000 individuals, and by the racial composition of the county (whether the county population exceeded the mean share of non-Hispanic whites, based on the treated counties). Finally, we assess if the protests had differential effects on stay-at-home behaviors and COVID-19 case growth depending on the county's baseline trajectory of COVID-19 cases.

\section{Results}

Our main findings are shown in Figures 2 and 3 and Tables 1 through 5. In Tables 1 and 2, and in Panels (a) through (c) of Figures 2 and 3, we present the net effects of protest onset on mobility, drawn from SafeGraph's anonymized geotagged cell-phone data. Key estimates of the heterogeneity analyses with respect to these social distancing measures are presented in Table 3. Then, in Table 4 and Panel (d) of Figure 3, we present and discuss how the mass protests affected COVID-19 case growth. Finally, in Table 5 and Appendix Figure 10 we present and discuss the relationship between the protests and COVID-19 deaths. Auxiliary analyses addressing specific issues are presented in the Appendix.

\subsection{Mass Protests and Social Distancing}

Panels (a) through (c) in Figure 2 visually present the conditional event study analyses for our three measures of stay-at-home behaviors from the SDM data. Panel (a) plots the trend difference between the treated and non-treated counties, pre- and post-protest outbreak, for the

percent of all treatment counties) had a protest that was accompanied by a city curfew; and 39.4 percent of treatment cities (and 46 percent of treatment counties) had a mask mandate in place as of the day of George Floyd's death. 
percent of respondents staying at home throughout the day. ${ }^{17}$ Panels (b) and (c) repeat this exercise for intensity measures, respectively capturing the median percent of time spent at home daily and the median daily hours spent at home.

These analyses underscore three key points. First, it is validating that we find no evidence that stay-at-home behaviors trended differently in treatment and control counties before the outbreak of the protests. Trends between the treated and non-treated counties essentially move in lock-step, reflected in the flat differential trends over the pre-protest periods. This instills a degree of confidence that the timing of the protests is exogenous to trends in social distancing.

Second, where there are social distancing effects, they only appear to materialize after the onset of the protests. Specifically, after the outbreak of an urban protest, we find, on average, an increase in stay-at-home behaviors in the primary county encompassing the city. That overall social distancing behavior increases after the mass protests is notable, as this finding contrasts with the general secular decline in sheltering-at-home taking place across the sample period (see Appendix Figure 6A). Our findings suggest that any direct decrease in social distancing among the subset of the population participating in the protests is more than offset by increasing social distancing behavior among those who may choose to shelter-at-home and circumvent public places while the protests are underway. This latter behavioral pathway is consistent with studies that find perceived safety concerns, crime, and violence to be significant barriers to participation in physical activity and spending time outdoors (Janke, Propper and Shields 2016; Roman and Chalfin 2008; Foster and Giles-Corti 2008). Moreover, to the extent that the killing of George

\footnotetext{
${ }^{17}$ Estimates plotted in Figure 2 are conditional on state-level log testing rates, indicators for shelter-in-place policies and reopening policies, county-level average temperature and an indicator for precipitation on the given day, and day and county fixed effects.
} 
Floyd, and the ensuing civil unrest and mass protests, also impacted residents' mental health and stress, this may further lead to decreased activity levels and an increase in stay-at-home behaviors. $^{18}$

Third, the event study analyses shown in Panels (a) through (c) of Figure 2 point to some dynamics in the response of stay-at-home behaviors. The rise in social distancing emerges after about three days following the start of protests. Effects get stronger over the next few days and peak within a week following the protests, before leveling off and showing some signs of decline. Hence, the effects of the protests on social distancing appear to be somewhat transitory and may fade over the longer-run, possibly as the scope of the protests and any associated violence abate.

Panels (a) through (c) in Figure 3 depict corollary trends in POI-derived foot-traffic at restaurants and bars, retail establishments, and business service establishments, enveloping the start of protests in treated counties related to non-treated counties. It is validating that dynamics from the event study analysis of these complementary mobility measures largely mirror those discussed above, supporting our general finding that social distancing behavior actually rose for the average affected resident and did so only after the start of the protests. The increase in stayat-home behaviors is accompanied by a decrease in foot-traffic at restaurants and bars, retail locations, and to some extent business service establishments. The more and longer that an individual interacts with others, the higher is the risk of COVID-19 transmission. Thus, it appears, on the net, that not only are individuals in an impacted county more likely to stay at home following protest onset, but they are also reducing their engagement in activities that may

\footnotetext{
18 Studies have causally linked crime and violence to poor mental health (Cornaglia, Feldman and Leigh, 2014; Dustmann and Fasani 2015; Wang and Yang 2013; Rubin et al. 2005).
} 
involve greater interactions and be construed as relatively risky. ${ }^{19}$ In addition to the behavioral pathways noted above, the reduction in foot-traffic at these establishments may also be compounded by business closures near protest sites, thereby reducing options for out-of-home activities. While this would be a distinct supply-side mechanism underlying the increase in social distancing behaviors, this channel and the behavioral pathways are not mutually exclusive. We view them as reinforcing links in the causal chain through which protests may be eliciting the average resident to stay at home more.

The patterns evident in Figures 2 and 3 (panels a through c) presage our main estimates of the average net effect of the protests on each of the social distancing outcomes, based on equation (1) and reported in Tables 1 and 2. We present estimates both with and without controls as a gauge of the extent to which the presence and timing of the protests are correlated with other observables. Our preferred estimates are from the saturated models that include COVID-19 testing rates and other predictors of social distancing, though it is reassuring that the results not very sensitive to these controls.

Panel I presents results for primary counties that include the large cities under study. As shown in column (2) of Table 1, we find an increase in the percent of county residents staying at home full-time following protest onset, with the effect getting progressively stronger and statistically significant after the third day. Within 4 to 7 days, there is about a 0.69 percentage point daily increase (1.9 percent increase relative to the mean) in residents remaining at home all day. The magnification of the effect over the first few days likely reflects dynamics in the behavioral response with protests gaining momentum and numbers, occurring on consecutive or multiple days, and being accompanied by more reports of violence in certain cities - dimensions

\footnotetext{
${ }^{19}$ The CDC notes that activities where mask use and social distancing become difficult to maintain, in particular going out to restaurants and bars, are riskier than other activities (Fisher et al. 2020)
} 
that we return to below in assessing heterogeneity in the response. Estimates from the intensity measures of staying at home follow a similar pattern, indicating on average a 0.45 percentage point increase in the median percent of time spent at home and a 0.18 hour increase in the median time spent at home (0.5 to 1.4 percent relative to the mean), within 4-7 days of the start of the protests. ${ }^{20}$ There is also evidence that social distancing effects level off or decline following about a week after the protests, which could suggest either that the impact of the protests are fading, or are cyclical depending on when future protests are organized. ${ }^{21}$

Turning to estimates reported in Panel I in Table 2, we also find a significant reduction in foot-traffic at restaurants and bars and at retail locations, with discernible effects materializing around two to three days following the onset of the protests. The decline in these out-of-home activities becomes steadily larger over time, with foot-traffic at restaurants and bars falling by about five percent, and that at retail locations falling by about four percent, following a week since the commencing of the protests. There are some suggestive decreases in mobility surrounding business services, though the estimates are imprecise and not statistically different from zero. Together, these findings suggest that protests may supplant activities that are higher risk for COVID-19 spread than outdoor gatherings with copious mask-wearing.

One concern with our findings is that our estimated social distancing effects may not fully capture any direct reduction in stay-at-home behaviors driven by the sub-population of protesters if protesters are being drawn from outside the city. This is partly addressed by our focus on the primary county - which encompasses the city - as the unit of analysis. However, in

\footnotetext{
${ }^{20}$ Results are robust to controlling for county-specific linear time trends though less precisely estimated (see Appendix Table 1A), and are also robust to the inclusion of state-by-day fixed effects (Appendix Table 1B).

${ }^{21}$ Data from Google Trends show that search queries on Google related to "protest”, "protest today”, "George Floyd protest", and "Black Lives Matter protest" peaked between May 31 and June 2, five to eight days since the start of the early protests. Similarly, searches related to "protest violence" and "protest looting" peaked between May 31 and June 1.
} 
Panel II of Tables 1 and 2, we widen the spatial unit to include both primary and secondary counties for cities that partly cross over into another county. Models reported in Appendix Table 2 further expand the geographic cluster to include counties that border the treated primary county (county that encloses the protest city). To the extent that protests in cities are drawing participants from their larger parent counties or from other surrounding counties, our estimates will capture both the direct social distancing effects on resident protesters in these counties as well as behavioral effects on other non-participating residents. The estimates remain similar across both samples as we broaden the geographical unit to capture non-local protesters.

\subsection{Heterogeneity in the Effects of the Protests on Social Distancing}

Given consistent indications that the mass protests appear to have increased net stay-athome behaviors - potentially reflecting an overriding behavioral effect among non-participants — we next assess whether this average response differs across relevant characteristics of the protests. We present these results in Table 3, based on equation (3a) that interacts a specific dimension of the protest with the post-protest timing windows.

If the increase in social distancing among non-participating residents is induced by safety and related concerns, then one would expect protests that are persistent (ongoing for 3 or more days) or that have turned violent to generate a stronger response. In Panel I, we specifically assess treatment effects across protests which have turned violent as compared to those that have not. We generally find increases in the percent of residents staying at home full-time and time spent at home for both sets of protests, however, for protests that are accompanied by media reports of violence we find larger estimates for the effect of the protest on distancing behaviors. 
In Panel II, we specifically assess treatment effects across protests which are longer lasting as compared to those that last only one or two days. In cases when protests are longer lasting, we find that within 4-7 days after the onset of the first protest, the percent of residents staying at home all day increases by 0.71 percentage points, which then falls to 0.52 percentage points after seven days; both estimates are statistically significant. In contrast, effects in counties where the protests are not persistent are smaller (0.38 percentage points within 4-7 days and 0.45 percentage point after 7 days) and are statistically indistinguishable from zero.

Panel III considers differences in the social distancing response based on the size of the protest. Specifically, we compare treatment effects across cities where the protest size exceeded 1,000 protesters vs. those that drew smaller protests. Larger protests may be perceived as being more disruptive and carrying a larger threat of violence. While there are significant increases in social distancing in both cases, there are indications that the increase is larger when protests draw a greater number of participants.

In response to protests that had turned violent and disruptive or in anticipation of such, some cities have issued nighttime curfews. In Panel IV, we assess whether these curfews may be "mechanically" driving the increase in sheltering-at-home that we find. In addition to their direct intended effects, curfews could also signal to residents the potential for the eruption of violence, and may further elicit a behavioral response due to this information signal. We find increases in staying-at-home behaviors across both cities with and without curfews, though effect magnitudes are expectedly larger when the city has imposed a curfew order at some point during the protest period. ${ }^{22}$

\footnotetext{
${ }^{22}$ In supplementary analyses (see Appendix Table 4), we also assess whether there were heterogeneous effects across other dimensions. Panel I of Appendix Table 4 considers differential effects based on whether the protests occurred early in calendar time, within the first 3 days after the death of George Floyd. These protests were arguably spontaneous, unanticipated, and exogenous to any considerations of COVID-19. We find significantly
} 
Finally, in Panel V, we consider heterogeneity in the social distancing behaviors based on whether the state had a mask mandate in place as of the date of George Floyd's death. ${ }^{23}$ Nonparticipating residents may perceive a higher risk of community transmission if their county is not covered by mandated facial coverings, and may respond more strongly to the protest crowds in terms of their compensatory behaviors. Pattern of results reported in Panel V largely supports this interpretation, with larger increases in stay-at-home behaviors materializing in counties that are not covered by a mask mandate.

Perceived risk of leaving one's home and engaging in external activities is likely to be correlated with COVID infections in the resident county. We therefore also stratify our analyses across county terciles based on the county's baseline (2 weeks prior to the death of George Floyd) growth in COVID-19 cases in order to assess whether the protests elicited a different response in areas that were experiencing more rapid vs. more contained infection spread (Appendix Table 5). These analyses indicate that counties which were experiencing relatively higher growth in COVID cases and were on a relatively steep upward trajectory of their outbreak cycle also witnessed the largest increase in net stay-at-home behaviors following the onset of protests. This is again consistent with non-attendees possibly perceiving a higher risk of COVID19 infection in these areas with faster COVID growth due to the protests and large gatherings, and choosing to stay home.

\footnotetext{
larger increases in social distancing following these earlier protests. Many of the early protests also occurred among the larger cities. In Panel II, we specifically decompose the treatment effect into separate effects across larger cities ( $\geq 500,000$ population) and smaller cities. While we find significant effects across the board, the effect magnitudes are generally higher for protests occurring in larger cities. Given that the protests were united against police brutality and racial bias in policing, and conjoined with the Black Lives Matter movement, we also assess whether responses in social distancing differed across the racial composition of the county (Panel III). We do not find any consistent or meaningful differences across our three social distancing outcomes across counties with a larger ( $\geq$ weighted mean of 56 percent among treated counties) share of non-Hispanic whites vs. those with a smaller share. ${ }^{23}$ Our results are virtually unchanged if we alternately characterize the potential heterogeneity based on whether a mask mandate was in place when the first protest started in each city (results available upon request). Our reported estimates in all Tables and Figures are also fully robust to controlling for state adoption of mask mandates.
} 
In summary we find that overall the onset of mass protests has led to an increase in social distancing, on the net, which is consistent with a counteracting response among non-protesting residents who may be avoiding venturing out as the protests are underway, possibly due to perceived safety concerns. The behavioral response may also reflect a diminution of economic and business activity. For instance, if retail outlets and restaurants are closed as a precautionary measure in anticipation of violence and disruption from the protests, then this would reduce the demand for out-of-home mobility. If these behavioral pathways are at play, it is reasonable to expect stronger responses when the protests are bigger in scope, persistent, and violent. The estimates in Table 3 largely confirm these patterns. ${ }^{24}$

Nevertheless, we also generally find an increase in social distancing behaviors across all margins. This is not altogether surprising given the geographic diffusion of the protests, including the national media attention. Hence, even if a protest in a given city is not violent, large, or sustained, there are likely spillovers from media reports of violence and disruptions from other cities; in this case, we would expect some behavioral response since there is a nonzero probability that a given protest could turn violent in the future. ${ }^{25}$

\subsection{Mass Protests and COVID-19 Case Growth}

\footnotetext{
${ }^{24}$ Appendix Figure 7 presents event study graphs for each of the margins considered in Table 2. They largely confirm flat differential trends prior to the onset of the protests, and increases in stay-at-home behaviors up to 7 days post-protest which subsequently diminish in magnitude after this time.

${ }^{25}$ Consequently, for similar analyses for our foot-traffic measures, we find decreases in these activities across the board and little indication of heterogeneous responses (Appendix Table 4). This may also be due to the activity measures centered on establishments (restaurants and bars, retail stores, and business service establishments). That is, part of the social distancing effects likely reflects temporary business closures in counties that host the protests. In this case, there may be little heterogeneity in this response channel if there is little variation in the distribution of closures across different treated counties (for instance, if businesses were boarded up around most protest sites in advance as a precautionary measure).
} 
Our findings thus far do not indicate that the protests on net led residents to spend more time outside their homes. If anything, we find consistent evidence of an increase in social distancing behaviors on average, and in particular a decrease in activities that are likely highrisk. Prima facie, given this increase in sheltering-at-home and decrease in mobility, we would not expect any strong increases in COVID-19 case growth. However, a key concern has been that local protesters, who are entering locations with high potential for transmission, may then travel back home and spread the virus to others. In this case, it is possible that we may see an increase in COVID-19 case growth, as a result of community spread from this subset of population (protest participants) for whom there was by definition an increase in out-of-home mobility and reduced social distancing.

Panel (d) in Figure 3 presents the event study analysis for daily growth in confirmed cases. Trends between the treated and non-treated counties are virtually identical prior to the protests. This is reassuring and suggests that the timing of the protests is not correlated with trends in COVID-19 case growth or unobservable determinants of case growth. We find no significant divergence in the trends after the protests. While there is some suggestive decrease in the daily growth rates in cases after 35 or more days subsequent to the start of the protests, the estimates are statistically insignificant and also fairly small in magnitude.

Estimates in Table 4, based on equations (2) and (3b), confirm these findings. In no case do we find any significant or substantial increase in the growth in COVID-19 caseload (Panel I). Our point estimates are close to zero and our confidence intervals are tight enough to rule out, with 95 percent confidence, an increase in daily case growth exceeding 0.27 percent in a county after five weeks following the onset of protests. 
These results are robust to widening the geographic unit of analysis to include primary and secondary counties (Panel II) and border counties (Appendix Table 6); hence, accounting for potential spillovers over a larger spatial unit as protesters travel back home does not alter our results. Our estimates are also robust to controlling for county-specific linear trends (Appendix Table 7A). The trends help to account for unobserved factors driving the exponential growth trajectory of COVID-19 transmissions, and effects in these models are identified off deviations from this trend growth. These controls may also be important in controlling for heterogeneity across counties in the timing of coronavirus outbreak as well as for heterogeneity in growth of COVID-19 testing. Moreover, in Appendix Table 7B (Panel I), we show that our results are not impacted by the inclusion of state-by-day fixed effects, which control for all unmeasured timevarying state level factors and rely only on counties within the same state for counterfactual comparisons. Finally, as reported in Panel III, we do not find any evidence of differential effects on case growth across specific dimensions of the protest (violent protests, persistent protests, size of protests, or the existence of curfews). ${ }^{26}$ Heterogeneity across additional margins are assessed in Appendix Tables 8 and 9, which also do not indicate any significant or consistent differences. ${ }^{27}$ One concern regarding the lack of any strong effects for COVID-19 case growth is that the post-protest sample period might not be sufficiently long enough as of yet to detect a

\footnotetext{
${ }^{26}$ Appendix Figure 8 presents the event study graphs for COVID-19 case growth across these margins. If anything, there is a very slight declining trend in case growth following protest onset where we also generally found a relatively larger increase in social distancing; all effects however are small and statistically insignificant.

${ }^{27}$ Specifically, in Appendix Table 8, we assess heterogeneous effects across: whether the protests occurred early in calendar time (Panel I); larger vs. smaller cities (Panel II); and racial composition of the county (Panel III). There are no indications of any significant or substantial increase in the growth of COVID-19 cases across any of these margins, by three or more weeks following the start of the protests. Appendix Table 9 reports differential effects for county terciles divided across the county's baseline (2 weeks prior to the death of George Floyd) growth rate in COVID-19 cases. While none of the estimates are statistically significant, it is interesting that the largest negative point estimates are found for the upper tercile of counties that were experiencing the highest baseline growth in the spread of the infection, the same group which also experienced the largest net increase in stay-at-home behaviors subsequent to the onset of the protests (see Appendix Table 5).
} 
resurgence or increase in the infection rates. While this is a possibility, we also note that our sample includes at least 35 days of data following the early protests that took place in 242 cities (during the first five days following George Floyd's death), at least 30 days of data following protests in 268 cities, and at least 28 days of data for 280 cities that experienced protests (during the first week following George Floyd's death). The median incubation period for COVID-19 is 5.1 days, with 75 percent of all infected individuals experiencing symptoms within 6.7 days and 97.5 percent within 11.5 days (Lauer et al. 2020). Prior work has uncovered strong effects of shelter-in-place orders on confirmed cases within five to ten days following the adoption of the policy (Friedson et al. 2020; Dave et al. 2020 a, b; c; Courtemanche et al. 2020a, b). Further, other work in economics has detected secondary spread of COVID-19 from travel due to spring break at a 2-week time horizon (Mangrum and Niekamp 2020). Hence, if there are any meaningful changes in COVID-19 cases as a result of the mass protests, our post-protest window is long enough to be able to capture them.

We also estimate separate protest effects for each of the early protest cities (cities experiencing protests on May 28 or earlier), in order to assess whether our finding of no significant or substantial effects on COVID-19 cases is masking any meaningful changes for certain cities. We employ a synthetic control approach to generate a counterfactual for each primary county (Abadie et al. 2010), with the donor pool comprising counties where no large city held any protest during the sample period or where the first protest occurred much later (less than five days prior to the end of the sample, a period not long enough to generate substantial effects on COVID-19 cases given the disease's incubation period) (Lauer et al. 2020; Friedson et al. 2020; Dave et al. 2020a). Analyses for the 13 counties for which pre-treatment COVID-19 
case levels and trends were well-matched are visually presented in Appendix Figure $9 .^{28}$ Cases are expectedly trending upwards across all of these counties and their synthetic controls.

However, with the exception for Maricopa County, Arizona, we find essentially no evidence that protests contributed to significant or substantial increases in COVID-19 during the period following protest onset, consistent with our main difference-in-differences findings in Table $4 .^{29}$

Finally, we assess the sensitivity of these estimates to different sources of timing-based identification. As our research design is capitalizing on variation in the timing of the protests across cities, in conjunction with cities that did not experience any protests, the estimated treatment effect is identified off the many sub-experiments comparing: 1) counties with early and later-occurring protests with counties containing large cities that did not experience any protests; 2) counties witnessing early protests with counties where protests occurred later; and 3) counties with later-occurring protests compared to counties with early onset of protests as controls (Goodman-Bacon 2018). With dynamic treatment effects, as there appear to be for social distancing outcomes and which also may be likely with COVID-19 cases, using counties with early protests as a control for the treated later-protesting counties may underestimate the treatment effect. $^{30}$ In Appendix Table 10, we draw on subsets of the treated counties to identify

\footnotetext{
${ }^{28}$ We match on the COVID-19 confirmed case rate (per 100,000 population) for each of the pre-protest days. We focus on protest counties where the quality of the pre-treatment match was good, as measured by the mean squared prediction error over the pre-protest period. For four of the early protest counties (Hennepin, MN; San Bernardino, CA; Los Angeles, CA; and Solano, CA), the quality of the pre-treatment match, between the county and its synthetically generated counterfactual from the donor pool, was quite poor. Thus, estimated post-protest effects for these counties are not regarded as credible.

${ }^{29}$ The effect size for Maricopa County implies an increase of 33.2 COVID-19 cases per 100,000 population within 13 days following the start of protests on May 28. The permutation-based p-value for this estimate is 0.067 . The pvalues for the effects for other protest counties shown in Appendix Figure 9, that show COVID-19 case increases relative to their synthetic control (Jefferson, Texas and Shelby, Tennessee), were never shown to have estimated effects that were statistically distinguishable from zero at conventional levels, with p-values ranging from 0.53 to 0.67 .

${ }^{30}$ This is because the trajectory in outcomes for counties with the early protests, at the time when other counties witness their own protests at a later point in time, may still be affected by the "treatment" (that is, by the early protests). In this context, it may be better to compare treated early-protesting counties with yet untreated laterprotesting counties or never-protesting counties, and compare treated later-protesting counties with never-protesting
} 
our effects, in turn excluding counties with late-occurring protests, counties with early-occurring protests, and counties that saw no protests from the sample. These results confirm that there is no discernible change in the growth of COVID-19 cases, among early- or later-protesting counties, even after three or more weeks subsequent to the onset of protests, irrespective of which counties form the counterfactual. ${ }^{31}$

\subsection{Mass Protests and COVID-19 Death Growth}

Finally, we investigate the relationship between the protests and deaths due to COVID-

19. Given the lack of relationship between the protests and COVID-19 cases demonstrated in the previous section, it is unlikely that a relationship between the protests and COVID-19 deaths exists. Thus, in light of the above findings, these analyses serve dually as a check on the consistency of our previous results as well as an investigation of a more objective measure of COVID-19 infections that is less plagued with measurement error in confirmed case counts and selection into testing.

The event study specification is shown in Appendix Figure 10, which much like the COVID-19 case event study in panel (d) of Figure 3 shows little relationship between the timing of the protests and deaths due to COVID-19. The trend in the results is largely flat, with a slight (but noisy) decrease in mortality at the end of the sample period. These results are consistent with the estimated coefficients reported in Table 5, which shows small and statistically insignificant estimates for primary counties (Panel I), as well as for primary and secondary

counties (Goodman-Bacon 2018). At the same time, however, counties with large cities that did not contain any protests may be different than counties that contained cities with protests. This suggests that it may also be important draw on variation just among the protest counties, excluding the "never protesters" from contributing any identifying variation (Dave et al. 2020b).

31 This is consistent with the results presented in Appendix Table 8 (Panel I), which separated out the effects across counties that saw the early wave of protests during the first three days following the death of George Floyd. 
counties (Panel II) ${ }^{32}$ Similar to the above findings on cases, results reported in Panel III largely do not show any evidence of differential or consistent effects on case growth across specific dimensions of the protest (violent protests, persistent protests, size of protests, or the existence of curfews).

\section{Conclusions}

This study demonstrates that the 2020 Black Lives Matter protests were associated with substantial increases in behavior consistent with risk avoidance. Event-study analyses show that following BLM protests (i) stay-at-home behavior among local residents increased in response to perceived threats of violence (i.e., from police or protesters) and infectious disease spread, and (ii) rallies supplanted activities that were higher risk for infectious disease spread than attending an outdoor protest, i.e. foot traffic at restaurants, bars, and retail establishments.

These findings provide strong evidence of risk avoidance behaviors in response to BLM protests. The findings are, in the main, consistent with evidence of behavioral responses to perceived safety risks amongst the general population, who in the presence of crime or violence choose to remain home more often (Bennett et al. 2007; Stafford et al. 2007; Chalfin 2008; Janke, Propper and Shields 2016; Yu and Lippert 2016; Stolzenberg, D’Alessio and Flexon 2019). While BLM protests were constitutionally protected speech and not criminal activities, they may still be viewed as dangerous by non-attendees due to the occasional presence of violence, including police response to these protests, and elicit avoidance behavior. Additionally, non-attendees may have perceived a higher risk of COVID-19 infection due to the protests, which could also have generated avoidance behavior.

\footnotetext{
${ }^{32}$ Estimates are also robust to controlling for county-specific linear trends (Panel II in Appendix Table 7A) and state-by-day fixed effects (Panel II in Table 7B).
} 
There are other hypotheses consistent with our findings as well. For example, nonattendees may have increased stay-at-home behavior in order to avoid additional traffic congestion or street closures, or due to lack of available activities from businesses closures near protest sites. It is also possible that the protests lowered foot traffic at business locations by directly siphoning off customers who participated the protest in lieu of engaging in economic activity.

We also empirically examine the linkage between the 2020 Black Lives Matter protests and the spread of COVID-19, which was a point of concern among public health officials and the media (Bacon 2020; Goldberg 2020; Harmon and Rojas 2020). While it is likely that the protests caused a decrease in social distancing behavior among protest attendees, we demonstrate that effect of the protests on the net social distancing behavior of the entire population residing in counties with large urban protests was positive. Likewise, while it is possible that the protests caused an increase in the spread of COVID-19 among those who attended the protests, we demonstrate that the protests had little effect on the spread of COVID-19 for the entire population of the counties with protests during the more than five weeks following protest onset. ${ }^{33}$ In most cases, the estimated longer-run effect (post-30 days) was negative, though not statistically distinguishable from zero. ${ }^{34}$

The key conclusion from this research is that understanding of human behavior, in particular with regards to how humans behave in the presence of risk needs to be included in

\footnotetext{
${ }^{33}$ It is also possible that the result of suggestive lower spread of COVID-19 relative to non-protesting cities is due in part to characteristics of the protesters. For example, protest attendees may have mitigated the spread of COVID-19 via infection countermeasures such as wearing masks. The attendees may further be a selected subpopulation of younger individuals who if infected have less severe symptoms (Liao et al. 2020) and thus may never get tested and not show up in the official COVID-19 numbers.

${ }^{34}$ Our results do not necessarily extrapolate to imply that large outdoor gatherings per se are safe. In the case of the protests that we study, compensatory behavioral responses among the non-participating subpopulation appear to be driving the net effects that we find in the overall population.
} 
public health and public policy discussions. The net change in behavior in this case was substantial, and failure to account for the general equilibrium effects would lead to skewed benefit-cost analyses. Our findings thus highlight the importance of understanding the behavior of all relevant populations when conducting analysis in the realm of social science in general, and public health in particular: the most visible portion of the population is not always the primary driver of the outcome of interest. 


\section{References}

Abadie, A., Diamond, A. and Hainmueller, J. (2010). "Synthetic Control Methods for Comparative Case Studies: Estimating the Effect of California's Tobacco Control Program.” Journal of the American Statistical Association 105 (490): 493-505.

Abouk, R, and Heydari, B. (2020). "The Immediate Effect of COVID-19 Policies on Social Distancing Behavior in the United States.” Retrieved from SSRN: https://ssrn.com/abstract=3571421

Andersen, M., Maclean, J.C., Pesko, M.F., and Simon, K.I. (2020). "Effect of a Federal Paid Sick Leave Mandate on Working and Staying at Home: Evidence from Cellular Device Data.” NBER Working Paper No. 27138.

Arrow, K.J., 1971. “The theory of risk aversion.” Essays in the theory of risk-bearing, pp.90120.

Australian Government Department of Health. 2020. "Social Distancing for Coronavirus (COVID-19).” Available at: https://www.health.gov.au/news/health-alerts/novelcoronavirus-2019-ncov-health-alert/how-to-protect-yourself-and-others-fromcoronavirus-covid-19/social-distancing-for-coronavirus-covid-19

Bacon, John. (2020, May 31). “Coronavirus updates: George Floyd protests could fuel COVID cases, Trump postpones G7 summit” USA Today.

Bai, Yan, Lingsheng Yao, Tao Wei, Fei Tian, Dong-Yan Jin, Lijuan Chen, and Meiyun Wang. 2020. "Presumed asymptomatic carrier transmission of COVID-19." JAMA, 323(14): 1406-1407.

Bellemare, Marc F., and Casey J. Wichman. 2020. "Elasticities and the inverse hyperbolic sine transformation." Oxford Bulletin of Economics and Statistics, 82(1): 50-61.

Bennett, G.G., McNeill, L.H., Wolin, K.Y., Duncan, D.T., Puleo, E. and Emmons, K.M., 2007. Safe to walk? Neighborhood safety and physical activity among public housing residents. PLoS medicine, 4(10).

Black Lives Matter. 2020. “About Black Lives Matter” Available at: https://blacklivesmatter.com/about/

Brewer, N. T., Chapman, G. B., Gibbons, F. X., Gerrard, M., McCaul, K. D., \& Weinstein, N. D. (2007). Meta-analysis of the relationship between risk perception and health behavior: the example of vaccination. Health Psychology, 26(2), 136.

Brown, R., Montalva, V., Thomas, D. and Velásquez, A., 2019. "Impact of violent crime on risk aversion: Evidence from the Mexican drug war.” Review of Economics and Statistics, 101(5), pp.892-904. 
Carman, K. G., \& Kooreman, P. (2014). Probability perceptions and preventive health care. Journal of Risk and Uncertainty, 49(1), 43-71.

Centers for Disease Control and Prevention. 2020a. “Coronavirus Disease 2019 (COVID-19): How It Spreads.” Available at: https://www.cdc.gov/coronavirus/2019-ncov/preventgetting-sick/how-covidspreads.html?CDC_AA_refVal=https\%3A\%2F\%2Fwww.cdc.gov\%2Fcoronavirus\%2F20 19-ncov\%2Fprepare\%2Ftransmission.html

Centers for Disease Control. 2020b. "COVID-19 How to Protect Yourself and Others.” Available at: https://www.cdc.gov/coronavirus/2019-ncov/prevent-gettingsick/prevention.html

Chiappori, P.A., 2000. “Econometric models of insurance under asymmetric information.” In Handbook of insurance (pp. 365-393). Springer, Dordrecht.

Cohen, A. and Dehejia, R., 2004. "The effect of automobile insurance and accident liability laws on traffic fatalities.” The Journal of Law and Economics, 47(2), pp.357-393.

Cornaglia, F., Feldman, N.E. and Leigh, A., 2014. "Crime and Mental Well-being.” Journal of Human Resources, 49(1), pp.110-140.

Courtemanche, Charles, Joseph Garuccio, Anh Le, Joshua C. Pinkston, and Aaron Yelowitz. 2020a. "Strong Social Distancing Measures In The United States Reduced The COVID19 Growth Rate.” Health Affairs, in press.

Courtemanche, Charles J., Joseph Garuccio, Anh Le, Joshua C. Pinkston, and Aaron Yelowitz. 2020b. "Did Social-Distancing Measures in Kentucky Help to Flatten the COVID-19 Curve?" Institute for the Study of Free Enterprise Working Paper 2020-4.

Dave, D.M., Friedson, A.I., Matsuzawa, K., McNichols, D. and Sabia, J.J., 2020a. "Did the Wisconsin Supreme Court Restart the COVID-19 Epidemic? Evidence from a Natural Experiment.” NBER Working Paper No. 27322.

Dave, D., Friedson, A.I., Matsuzawa, K. and Sabia, J.J., 2020b. When do shelter-in-place orders fight COVID-19 best? Policy heterogeneity across states and adoption time. Economic Inquiry, Forthcoming

Dave, D.M., Friedson, A.I., Matsuzawa, K. Sabia, J.J., and Safford, S. 2020c. "Were Urban Cowboys Enough to Control COVID-19? Local Shelter-In-Place Orders and Coronavirus Case Growth.” Journal of Urban Economics, Forthcoming

Dave, D. and Kaestner, R., 2009. "Health insurance and ex ante moral hazard: evidence from Medicare.” International Journal of Health Care Finance and Economics, 9(4), p.367. 
Dustmann, C. and Fasani, F., 2016. “The Effect of Local Area Crime on Mental Health.” The Economic Journal, 126(593), pp.978-1017.

Fineberg, Harvey. 2020. "Rapid Expert Consultation on the Possibility of Bioaerosol Spread of SARS-CoV-2 for the COVID-19 Pandemic" The National Academies of Science, Engineering, Medicine, April 1. Available at: https://www.nap.edu/read/25769/chapter/1\#3

Fisher, K.A., Tenforde, M.W., Feldstein, L.R., Lindsell, C.J., Shapiro, N.I., Files, D.C., Gibbs, K.W., Erickson, H.L., Prekker, M.E., Steingrub, J.S. and Exline, M.C., 2020. Community and close contact exposures associated with COVID-19 among symptomatic adults $\geq 18$ years in 11 outpatient health care facilities-United States, July 2020. Morbidity and Mortality Weekly Report, 69(36), p.1258.

Foster, S. and Giles-Corti, B., 2008. "The Built Environment, Neighborhood Crime and Constrained Physical Activity: An Exploration of Inconsistent Findings.” Preventive Medicine, 47(3), pp.241-251.

Friedson, A.I., McNichols, D., Sabia, J.J. and Dave, D., (2020). "Shelter in Place Orders and Public Health: Evidence from California During the COVID-19 Pandemic.” Journal of Policy Analysis and Management, forthcoming.

Furber, Matt, Audra D. S. Burch and Frances Robles. (2020, May 29). "What Happened in the Chaotic Moments Before George Floyd Died.” The New York Times.

Goldberg, Emma (2020, June 7). "George Floyd Protests Add New Front Line for Coronavirus Doctors” The New York Times

Goodman-Bacon, Andrew. 2018. "Difference-in-Differences with Variation in Treatment Timing.” NBER Working Paper No. 25108.

Gupta, S., Nguyen, T.D., Rojas, F.L., Raman, S., Lee, B., Bento, A., Simon, K.I. and Wing, C. (2020). "Tracking Public and Private Responses to the COVID-19 Epidemic: Evidence from State and Local Government Actions” NBER Working Paper No. 27027.

Harmon, Amy, and Rick Rojas. (2020, June 7) “A Delicate Balance: Weighing Protest Against the Risks of the Coronavirus" The New York Times

Hill, Evan, Ainara Tiefenthäler, Christiaan Triebert, Drew Jordan, Haley Willis and Robin Stein. (2020, May 31). "8 Minutes and 46 Seconds: How George Floyd Was Killed in Police Custody.” The New York Times.

Fisher, K.A., Tenforde, M.W., Feldstein, L.R., Lindsell, C.J., Shapiro, N.I., Files, D.C., Gibbs, K.W., Erickson, H.L., Prekker, M.E., Steingrub, J.S. and Exline, M.C., 2020. Community and close contact exposures associated with COVID-19 among symptomatic adults $\geq 18$ 
years in 11 outpatient health care facilities—United States, July 2020. Morbidity and Mortality Weekly Report, 69(36), p.1258.

Friedson, Andrew I., Drew McNichols, Joseph J. Sabia, and Dhaval Dave. 2020. "Shelter-inPlace Orders and Public Health: Evidence from California During a Pandemic.” Journal of Policy Analysis and Management, Forthcoming.

Janke, K., Propper, C. and Shields, M.A., 2016. “Assaults, murders and walkers: The impact of violent crime on physical activity.” Journal of Health Economics, 47, pp.34-49.

Jakiela, P. and Ozier, O., 2019. "The impact of violence on individual risk preferences: evidence from a natural experiment.” Review of Economics and Statistics, 101(3), pp.547-559.

Khazan, Olga. (2020, June 2). "Why People Loot” The Atlantic.

Kim, Catherine. (2020, May 31). "Images of police using violence against peaceful protesters are going viral” Vox.

Klick, J. and Stratmann, T., 2007. "Diabetes treatments and moral hazard." The Journal of Law and Economics, 50(3), pp.519-538.

Lakdawalla, D., Sood, N. and Goldman, D., 2006. "HIV breakthroughs and risky sexual behavior.” The Quarterly Journal of Economics, 121(3), pp.1063-1102.

Lasry, A., Kidder, D., Hast, M., Poovey, J., Sunshine, G., Zviedrite, N., Ahmed, F. and Ethier, K.A., (2020). "Timing of Community Mitigation And Changes in Reported COVID-19 And Community Mobility-Four US metropolitan Areas." Morbidity and Mortality Weekly Report, 69(15): 451-457.

Lauer, Stephen A., Kyra H. Grantz, Qifang Bi, Forrest K. Jones, Qulu Zheng, Hannah R. Meredith, Andrew S. Azman, Nicholas G. Reich, and Justin Lessler. "The Incubation Period of Coronavirus Disease 2019 (COVID-19) from Publicly Reported Confirmed Cases: Estimation and Application.” Annals of Internal Medicine (2020).

Liao, J., Fan, S., Chen, J., Wu, J., Xu, S., Guo, Y., Li, C., Zhang, X., Wu, C., Mou, H. and Song, C., 2020. Epidemiological and clinical characteristics of COVID-19 in adolescents and young adults. The Innovation, 1(1), p.100001.

Mangrum, D. and Niekamp, P., 2020. College Student Contribution to Local COVID-19 Spread: Evidence from University Spring Break Timing. Available at SSRN 3606811.

Mullahy, J. (1999). It'll only hurt a second? Microeconomic determinants of who gets flu shots. Health Economics, 8(1), 9-24. 
Pan, Xingfei, Dexiong Chen, Yong Xia, Xinwei Wu, Tangsheng Li, Xueting Ou, Liyang Zhou, and Jing Liu. 2020. "Asymptomatic cases in a family cluster with SARS-CoV-2 infection.” The Lancet Infectious Diseases, 20(4): 410-411.

Peterson, Hayley. (2020, May 29). “A Minneapolis Target store was destroyed by looting. Photos show the flooded remains.” Business Insider.

Powell, M. (2020, July 6). “Are Protests Dangerous? What Experts Say May Depend on Who's Protesting What.” The New York Times.

Pratt, J.W., 1964. Risk aversion in the small and in the large. Econometrica, 32(1), pp. 122-136.

Public Health England. 2020. "Guidance on Social Distancing for Everyone in the U.K." Available at: https://www.gov.uk/government/publications/covid-19-guidance-on-socialdistancing-and-for-vulnerable-people/guidance-on-social-distancing-for-everyone-in-theuk-and-protecting-older-people-and-vulnerable-adults

Public Health Agency of Canada. 2020. "Community-Based Measures to Mitigate the Spread of Coronavirus Disease (COVID-19) in Canada.” Available at: https://www.canada.ca/en/public-health/services/diseases/2019-novel-coronavirusinfection/health-professionals/public-health-measures-mitigate-covid-19.html

Resnick, B. (2020, June 6) "What public health experts want critics to know about why they support the protests." Vox.

Roman, C.G. and Chalfin, A., 2008. "Fear of Walking Outdoors: A Multilevel Ecologic Analysis of Crime and Disorder.” American Journal of Preventive Medicine, 34(4), pp.306-312.

Rothe C, Schunk M, Sothmann P, et al. 2020. "Transmission of 2019-nCoV Infection from an Asymptomatic Contact in Germany.” New England Journal of Medicine, 382:970-971

Rothenberg, C., Achanta, S., Svendsen, E.R. and Jordt, S.E., 2016. “Tear gas: an epidemiological and mechanistic reassessment.” Annals of the New York Academy of Sciences, 1378(1), p.96.

Rubin, G.J., Brewin, C.R., Greenberg, N., Simpson, J. and Wessely, S., 2005. "Psychological and behavioural reactions to the bombings in London on 7 July 2005: cross sectional survey of a representative sample of Londoners.” BMJ, 331(7517), p.606.

Sears, James and Villas-Boas, J. Miguel and Villas-Boas, Vasco and Villas-Boas, Sofia, Are We \#StayingHome to Flatten the Curve? (May 25, 2020). Department of Agricultural and Resource Economics. CUDARE Working Papers. Available at SSRN: https://ssrn.com/abstract=3569791. 
Stafford, M., Cummins, S., Ellaway, A., Sacker, A., Wiggins, R.D. and Macintyre, S., 2007. Pathways to obesity: identifying local, modifiable determinants of physical activity and diet. Social Science \& Medicine, 65(9), pp.1882-1897.

Simon, Mallory. (2020, June 5). “Over 1,000 health professionals sign a letter saying, Don't shut down protests using coronavirus concerns as an excuse.” CNN.

Stolzenberg, L., D’Alessio, S.J. and Flexon, J.L., 2019. The Impact of Violent Crime on Obesity. Social Sciences, 8(12), p.329.

State of Minnesota. 2020. "Warrant: State of Minnesota v Derek Michael Chauvin” Available at: https://www.hennepinattorney.org/-/media/Attorney/Derek-Chauvin-CriminalComplaint.pdf

Taylor, Derrick Bryson. (2020, June 9) “George Floyd Protests: A Timeline” The New York Times.

Tsutsui, Y., Benzion, U., \& Shahrabani, S. (2012). Economic and behavioral factors in an individual's decision to take the influenza vaccination in Japan. The Journal of SocioEconomics, 41(5), 594-602.

Wang, Y. and Yang, M., 2013. "Crisis-induced depression, physical activity and dietary intake among young adults: Evidence from the 9/11 terrorist attacks.” Economics \& Human Biology, 11(2), pp.206-220.

Wei, J. and Li, Y., 2016. “Airborne spread of infectious agents in the indoor environment.” American Journal of Infection Control, 44(9), pp.S102-S108.

White House. 2020. “The President’s Coronavirus Guidelines for America.” Available at: https://www.whitehouse.gov/wp-content/uploads/2020/03/03.16.20_coronavirusguidance_8.5x11_315PM.pdf

World Health Organization. 2020. “Q\&A: Similarities and Differences - COVID-19 and Influenza.” Available at: https://www.who.int/news-room/q-a-detail/q-a-similarities-and\%20differences-covid-19-and-influenza

Xie, X., Li, Y., Sun, H. and Liu, L., 2009. Exhaled droplets due to talking and coughing. Journal of the Royal Society Interface, 6(suppl_6), pp.S703-S714.

Yu, E. and Lippert, A.M., 2016. Neighborhood crime rate, weight-related behaviors, and obesity: a systematic review of the literature. Sociology Compass, 10(3), pp.187-207. 
Figure 1. Protests in Cities with Municipal Population of Least 100,000 Persons

May 26

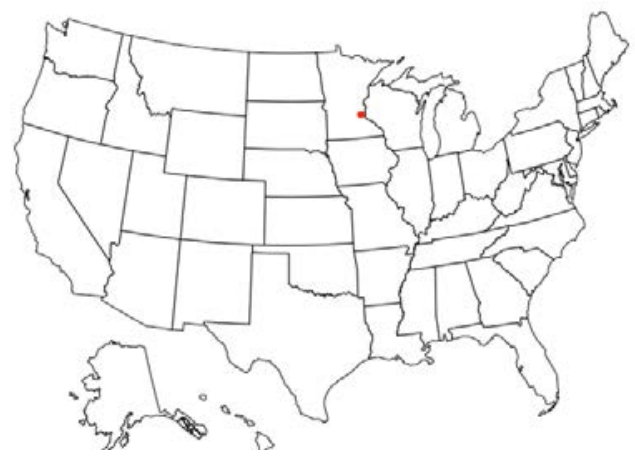

May 28

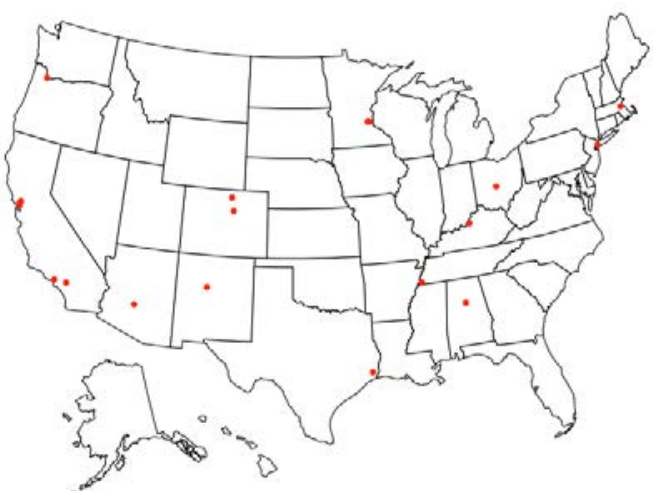

May 29

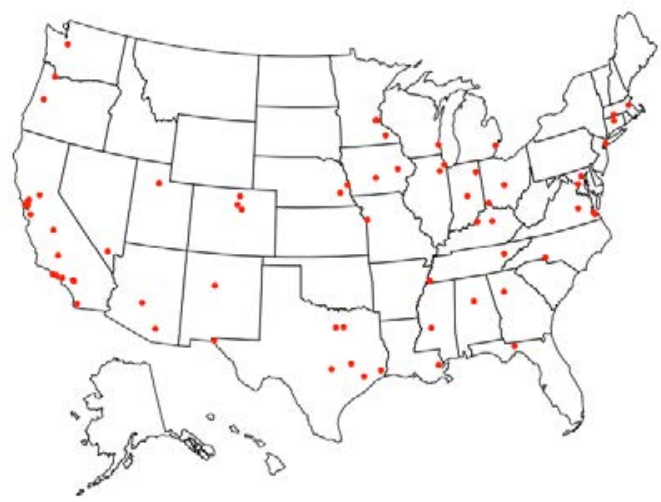

May 30

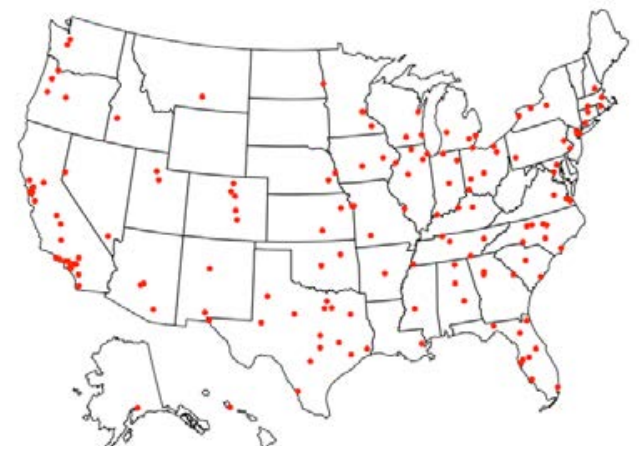

Note: Red dots represent cities that held a protest
May 31
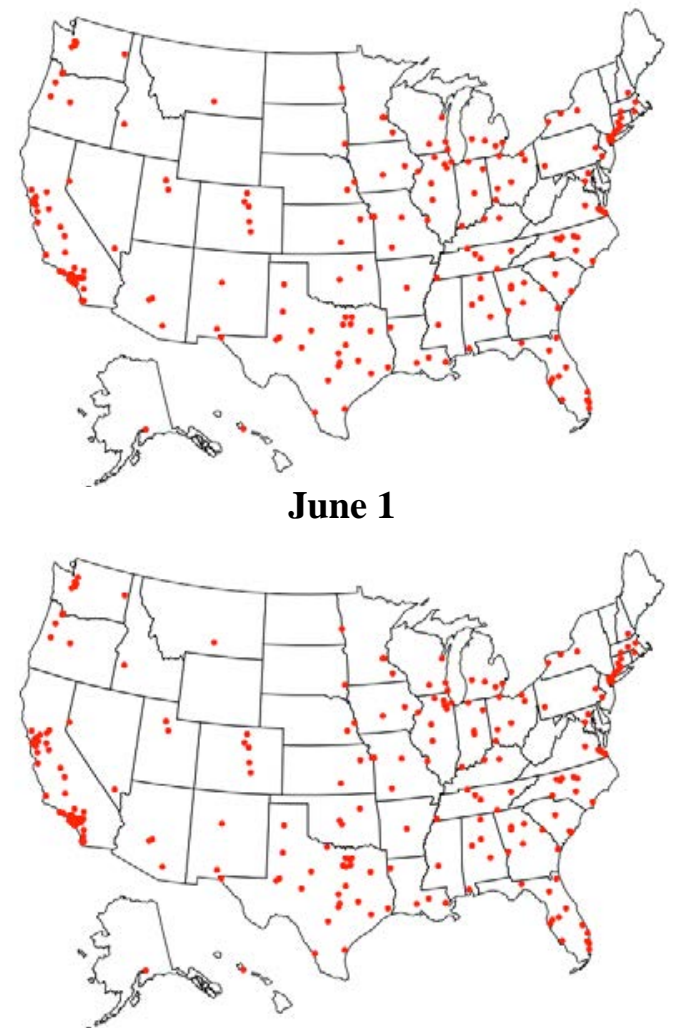

June 7

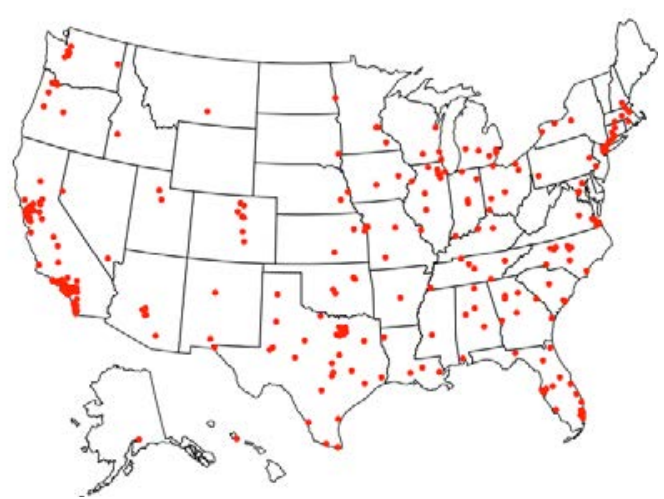

July 7

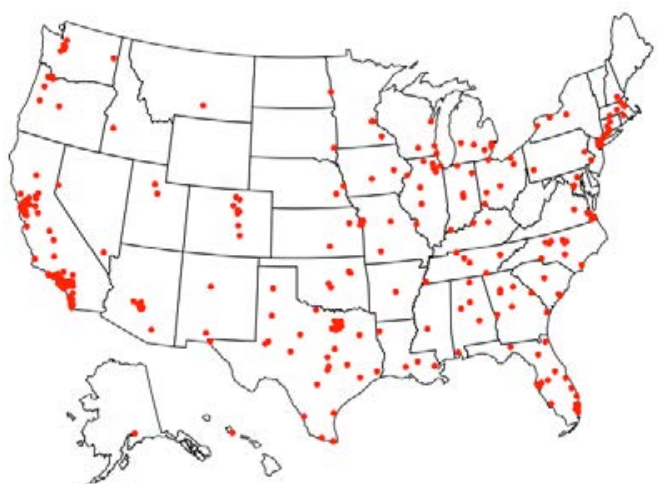




\section{Figure 2. Event Studies Analysis of the Effects of Urban Protests on Social Distancing}

Panel (a): Percent Staying at Home Full-Time

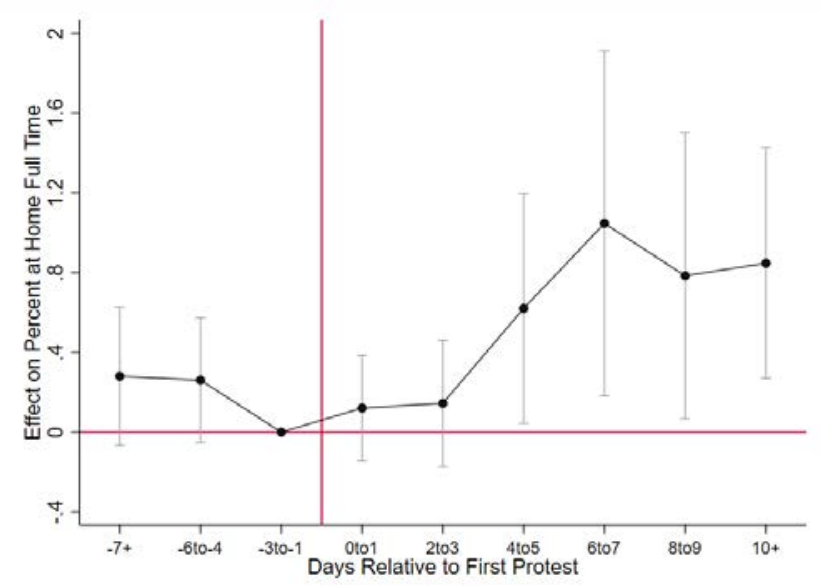

Panel (b): Median Percent of Time at Home

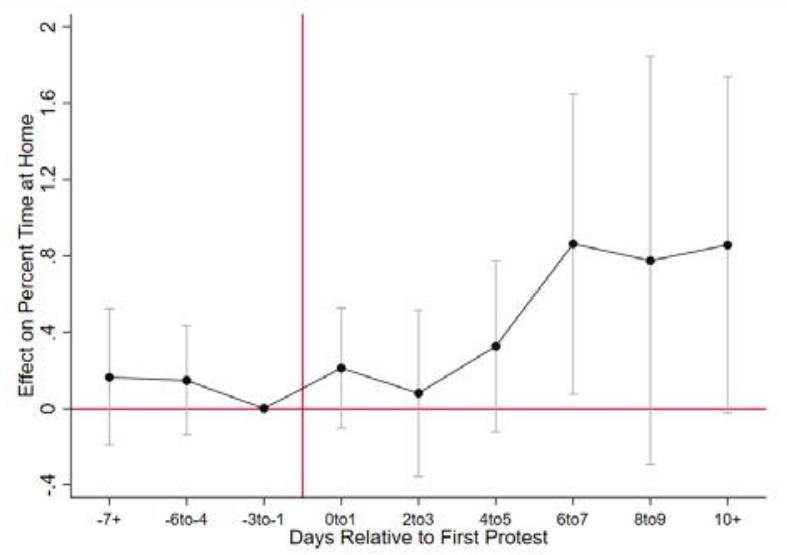

Panel (c): Median Hours at Home

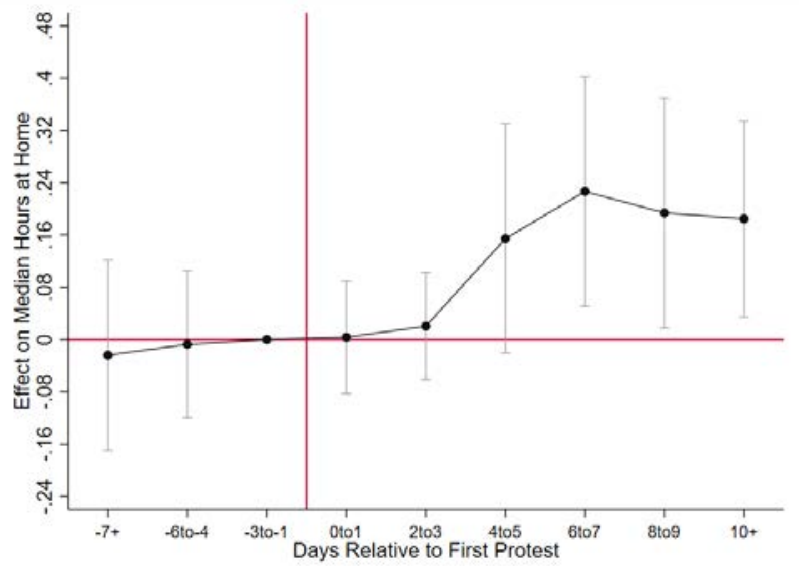

Notes: Estimate is generated using weighted least squares. All models include county and day fixed effects. State-level controls include: log testing rate, indicator for a SIPO, mask mandate, whether food industry reopened, whether retail store reopened, whether personal or pet care services reopened, and whether entertainment or activity reopened. County-level controls include: average temperature and an indicator for whether any precipitation fell. 
Figure 3. Event Studies Analysis of the Effects of Urban Protests on Foot Traffic and COVID-19 Case Growth

Panel (a): Restaurant \& Bar

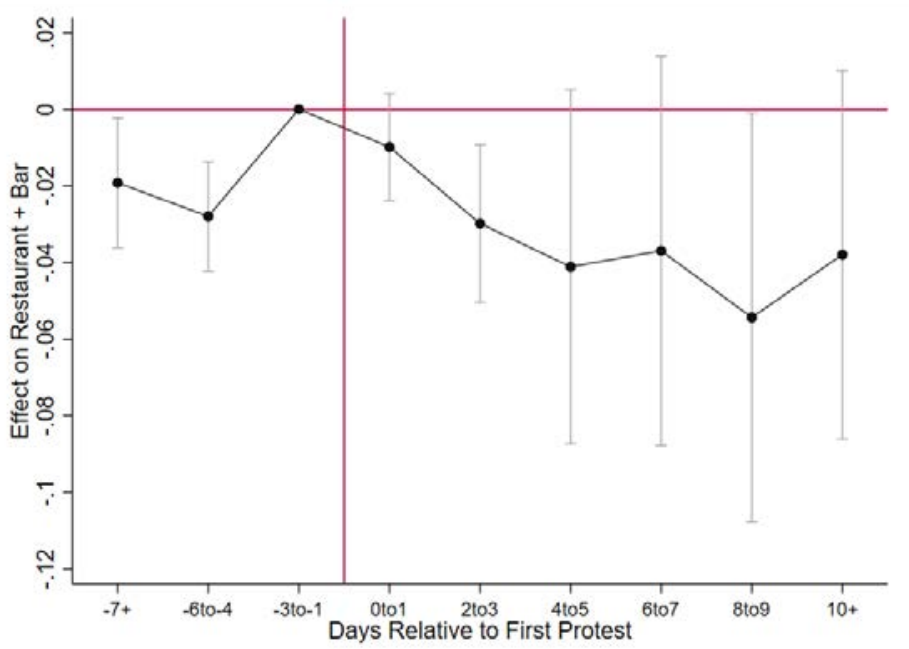

Panel (c): Business Services

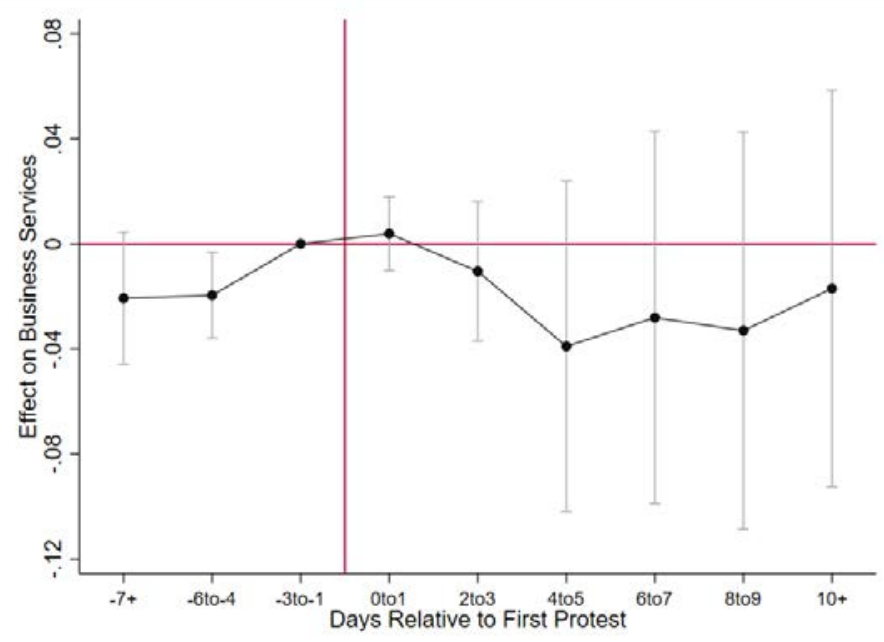

Panel (b): Retail

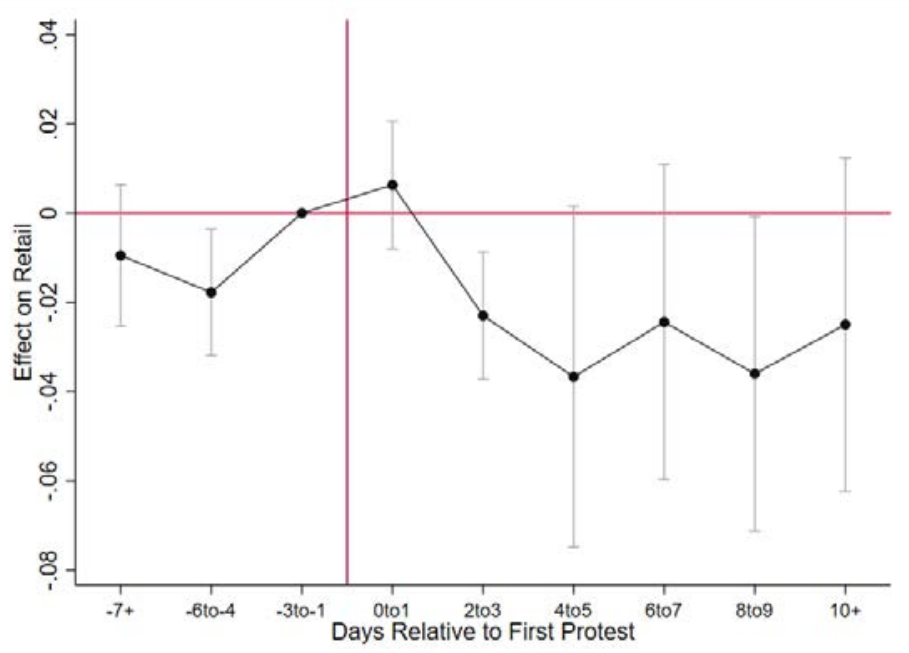

Panel (d): COVID-19 Case Growth Rate

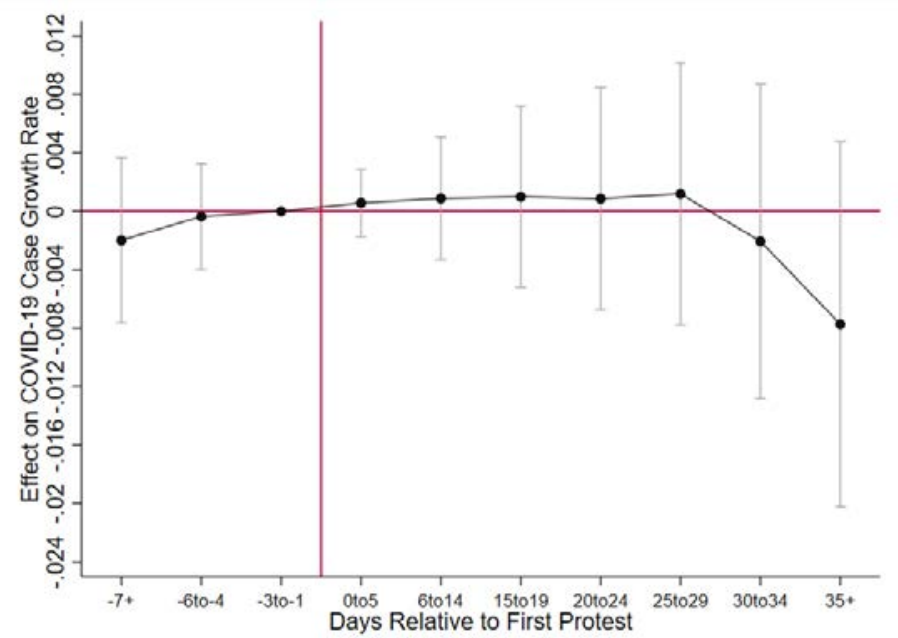

Notes: Estimate is generated using weighted least squares. For foot-traffic, the outcome is the inverse hyperbolic sine of the measures. All models include county and day fixed effects. State-level controls include: log testing rate, indicator for a SIPO, mask mandate, whether food industry reopened, whether retail store reopened, whether personal or pet care services reopened, and whether entertainment or activity reopened. County-level controls include: average temperature and an indicator for whether any precipitation fell. 
Table 1. Difference-in-Differences Estimates of the Effect of Urban Protests on Social Distancing

\begin{tabular}{|c|c|c|c|c|c|c|}
\hline & \multicolumn{2}{|c|}{$\begin{array}{l}\text { Stay-at-Home } \\
\text { Full-Time }\end{array}$} & \multicolumn{2}{|c|}{$\begin{array}{l}\text { Median Percent Time } \\
\text { Spent at Home }\end{array}$} & \multicolumn{2}{|c|}{$\begin{array}{l}\text { Median Hours } \\
\text { Spent at Home }\end{array}$} \\
\hline & (1) & (2) & (3) & (4) & (5) & (6) \\
\hline & \multicolumn{6}{|c|}{ Panel I: Primary Counties } \\
\hline 0-1 Days After Protest & $\begin{array}{c}-0.040 \\
(0.142)\end{array}$ & $\begin{array}{c}0.072 \\
(0.123)\end{array}$ & $\begin{array}{c}0.118 \\
(0.156)\end{array}$ & $\begin{array}{c}0.182 \\
(0.151)\end{array}$ & $\begin{array}{c}-0.021 \\
(0.040)\end{array}$ & $\begin{array}{c}0.005 \\
(0.037)\end{array}$ \\
\hline 2-3 Days After Protest & $\begin{array}{l}-0.087 \\
(0.169)\end{array}$ & $\begin{array}{c}0.099 \\
(0.158)\end{array}$ & $\begin{array}{l}-0.064 \\
(0.209)\end{array}$ & $\begin{array}{c}0.056 \\
(0.214)\end{array}$ & $\begin{array}{l}-0.013 \\
(0.041)\end{array}$ & $\begin{array}{c}0.023 \\
(0.042)\end{array}$ \\
\hline 4-7 Days After Protest & $\begin{array}{c}0.490 \\
(0.336)\end{array}$ & $\begin{array}{c}0.692 * * \\
(0.327)\end{array}$ & $\begin{array}{c}0.322 \\
(0.272)\end{array}$ & $\begin{array}{l}0.448^{*} \\
(0.265)\end{array}$ & $\begin{array}{c}0.132 \\
(0.091)\end{array}$ & $\begin{array}{l}0.176^{*} \\
(0.093)\end{array}$ \\
\hline 8+ Days After Protest & $\begin{array}{c}0.265 \\
(0.344)\end{array}$ & $\begin{array}{l}0.568 * * \\
(0.273)\end{array}$ & $\begin{array}{c}0.347 \\
(0.466)\end{array}$ & $\begin{array}{c}0.527 \\
(0.423)\end{array}$ & $\begin{array}{c}0.096 \\
(0.091)\end{array}$ & $\begin{array}{l}0.158^{*} \\
(0.086)\end{array}$ \\
\hline $\mathrm{N}$ & 6210 & 6210 & 6210 & 6210 & 6210 & 6210 \\
\hline & \multicolumn{6}{|c|}{ Panel II: Primary \& Secondary Counties } \\
\hline 0-1 Days After Protest & $\begin{array}{l}-0.074 \\
(0.137)\end{array}$ & $\begin{array}{c}0.034 \\
(0.119)\end{array}$ & $\begin{array}{c}0.105 \\
(0.151)\end{array}$ & $\begin{array}{c}0.167 \\
(0.146)\end{array}$ & $\begin{array}{l}-0.024 \\
(0.038)\end{array}$ & $\begin{array}{c}0.001 \\
(0.035)\end{array}$ \\
\hline 2-3 Days After Protest & $\begin{array}{l}-0.117 \\
(0.164)\end{array}$ & $\begin{array}{c}0.063 \\
(0.153)\end{array}$ & $\begin{array}{l}-0.073 \\
(0.202)\end{array}$ & $\begin{array}{c}0.044 \\
(0.207)\end{array}$ & $\begin{array}{l}-0.017 \\
(0.039)\end{array}$ & $\begin{array}{c}0.018 \\
(0.040)\end{array}$ \\
\hline 4-7 Days After Protest & $\begin{array}{c}0.437 \\
(0.325)\end{array}$ & $\begin{array}{c}0.624^{*} \\
(0.317)\end{array}$ & $\begin{array}{c}0.320 \\
(0.259)\end{array}$ & $\begin{array}{l}0.437 * \\
(0.252)\end{array}$ & $\begin{array}{c}0.121 \\
(0.086)\end{array}$ & $\begin{array}{l}0.161^{*} \\
(0.089)\end{array}$ \\
\hline 8+ Days After Protest & $\begin{array}{c}0.192 \\
(0.330)\end{array}$ & $\begin{array}{l}0.464^{*} \\
(0.266)\end{array}$ & $\begin{array}{c}0.313 \\
(0.451)\end{array}$ & $\begin{array}{c}0.473 \\
(0.411)\end{array}$ & $\begin{array}{c}0.084 \\
(0.085)\end{array}$ & $\begin{array}{l}0.139 * \\
(0.081)\end{array}$ \\
\hline $\mathrm{N}$ & 7470 & 7470 & 7470 & 7470 & 7470 & 7470 \\
\hline Mean of DV & 35.572 & 35.572 & 89.586 & 89.586 & 12.533 & 12.533 \\
\hline Observable Controls? & No & Yes & No & Yes & No & Yes \\
\hline
\end{tabular}

* Significant at the $10 \%$ level, $* *$ Significant at the $5 \%$ level, *** Significant at the $1 \%$ level

Notes: Estimate is generated using weighted least squares. All models include county and day fixed effects. State-level controls include: log testing rate, indicator for a SIPO, mask mandate, whether food industry reopened, whether retail store reopened, whether personal or pet care services reopened, and whether entertainment or activity reopened. County-level controls include: average temperature and an indicator for whether any precipitation fell. Standard errors, clustered at the county-level, are reported inside the parentheses. 


\section{Table 2. Difference-in-Differences Estimates of the Effect of Urban Protests on Foot Traffic}

\begin{tabular}{|c|c|c|c|c|c|c|}
\hline & \multicolumn{2}{|c|}{ Restaurant \& Bar } & \multicolumn{2}{|c|}{ Retail } & \multicolumn{2}{|c|}{ Business } \\
\hline & $(1)$ & $(2)$ & (3) & (4) & (5) & (6) \\
\hline & \multicolumn{6}{|c|}{ Panel I: Primary Counties } \\
\hline 0-1 Days After Protest & $\begin{array}{l}-0.005 \\
(0.007)\end{array}$ & $\begin{array}{c}-0.006 \\
(0.007)\end{array}$ & $\begin{array}{l}0.012 * \\
(0.007)\end{array}$ & $\begin{array}{c}0.009 \\
(0.007)\end{array}$ & $\begin{array}{c}0.009 \\
(0.008)\end{array}$ & $\begin{array}{c}0.006 \\
(0.008)\end{array}$ \\
\hline 2-3 Days After Protest & $\begin{array}{l}-0.022 * \\
(0.011)\end{array}$ & $\begin{array}{c}-0.026 * * \\
(0.011)\end{array}$ & $\begin{array}{l}-0.014^{*} \\
(0.008)\end{array}$ & $\begin{array}{c}-0.021 * * \\
(0.008)\end{array}$ & $\begin{array}{l}-0.002 \\
(0.015)\end{array}$ & $\begin{array}{c}-0.008 \\
(0.015)\end{array}$ \\
\hline 4-7 Days After Protest & $\begin{array}{c}-0.031 \\
(0.026)\end{array}$ & $\begin{array}{c}-0.037 \\
(0.025)\end{array}$ & $\begin{array}{c}-0.023 \\
(0.021)\end{array}$ & $\begin{array}{l}-0.032 \\
(0.021)\end{array}$ & $\begin{array}{l}-0.026 \\
(0.035)\end{array}$ & $\begin{array}{c}-0.035 \\
(0.034)\end{array}$ \\
\hline 8+ Days After Protest & $\begin{array}{l}-0.042 \\
(0.029)\end{array}$ & $\begin{array}{c}-0.050 * \\
(0.026)\end{array}$ & $\begin{array}{c}-0.026 \\
(0.021)\end{array}$ & $\begin{array}{c}-0.037 * \\
(0.020)\end{array}$ & $\begin{array}{l}-0.023 \\
(0.039)\end{array}$ & $\begin{array}{c}-0.034 \\
(0.038)\end{array}$ \\
\hline $\mathrm{N}$ & 6210 & 6210 & 6210 & 6210 & 6210 & 6210 \\
\hline & \multicolumn{6}{|c|}{ Panel II: Primary \& Secondary Counties } \\
\hline 0-1 Days After Protest & $\begin{array}{c}-0.004 \\
(0.007)\end{array}$ & $\begin{array}{c}-0.005 \\
(0.007)\end{array}$ & $\begin{array}{l}0.013 * \\
(0.007)\end{array}$ & $\begin{array}{c}0.009 \\
(0.007)\end{array}$ & $\begin{array}{c}0.009 \\
(0.008)\end{array}$ & $\begin{array}{c}0.007 \\
(0.007)\end{array}$ \\
\hline 2-3 Days After Protest & $\begin{array}{l}-0.019 * \\
(0.011)\end{array}$ & $\begin{array}{c}-0.023 * * \\
(0.011)\end{array}$ & $\begin{array}{c}-0.012 \\
(0.008)\end{array}$ & $\begin{array}{c}-0.018 * * \\
(0.008)\end{array}$ & $\begin{array}{c}0.001 \\
(0.014)\end{array}$ & $\begin{array}{c}-0.005 \\
(0.014)\end{array}$ \\
\hline 4-7 Days After Protest & $\begin{array}{l}-0.027 \\
(0.025)\end{array}$ & $\begin{array}{c}-0.032 \\
(0.024)\end{array}$ & $\begin{array}{l}-0.020 \\
(0.020)\end{array}$ & $\begin{array}{l}-0.028 \\
(0.020)\end{array}$ & $\begin{array}{l}-0.021 \\
(0.034)\end{array}$ & $\begin{array}{c}-0.029 \\
(0.033)\end{array}$ \\
\hline 8+ Days After Protest & $\begin{array}{l}-0.037 \\
(0.028)\end{array}$ & $\begin{array}{c}-0.043^{*} \\
(0.026)\end{array}$ & $\begin{array}{c}-0.022 \\
(0.020)\end{array}$ & $\begin{array}{c}-0.032 * \\
(0.019)\end{array}$ & $\begin{array}{l}-0.016 \\
(0.037)\end{array}$ & $\begin{array}{c}-0.025 \\
(0.036)\end{array}$ \\
\hline $\mathrm{N}$ & 7470 & 7470 & 7470 & 7470 & 7470 & 7470 \\
\hline Mean of DV & 9.74 & 9.74 & 10.24 & 10.24 & 9.27 & 9.27 \\
\hline Observable Controls? & No & Yes & No & Yes & No & Yes \\
\hline
\end{tabular}

* Significant at the $10 \%$ level, ** Significant at the 5\% level, *** Significant at the $1 \%$ level

Notes: Estimate is generated using weighted least squares. The outcome is inverse hyperbolic sine of the foot-traffic measures. All models include county and day fixed effects. State-level controls include: log testing rate, indicator for a SIPO, mask mandate, whether food industry reopened, whether retail store reopened, whether personal or pet care services reopened, and whether entertainment or activity reopened. County-level controls include: average temperature and an indicator for whether any precipitation fell. Standard errors, clustered at the county-level, are reported inside the parentheses. 
Table 3. Heterogeneity in the Effects of Urban Protests on Social Distancing

\begin{tabular}{|c|c|c|c|c|c|c|}
\hline & \multicolumn{2}{|c|}{$\begin{array}{l}\text { Stay-at-Home Full-Time } \\
(1)\end{array}$} & \multicolumn{2}{|c|}{$\begin{array}{c}\text { Median Percent Time } \\
\text { Spent at Home } \\
(2)\end{array}$} & \multicolumn{2}{|c|}{$\begin{array}{l}\text { Median Hours } \\
\text { Spent at Home } \\
\text { (3) }\end{array}$} \\
\hline & $\mathrm{T}_{\mathrm{C}}=1$ & $\mathrm{~T}_{\mathrm{C}}=0$ & $\mathrm{~T}_{\mathrm{C}}=1$ & $\mathrm{~T}_{\mathrm{C}}=0$ & $\mathrm{~T}_{\mathrm{C}}=1$ & $\mathrm{~T}_{\mathrm{c}}=0$ \\
\hline & \multicolumn{6}{|c|}{$\begin{array}{c}\text { Panel I: Cities with Violent Protests }\left(T_{c}=1\right) \text { vs. } \\
\text { Cities with Peaceful Protests }\left(T_{c}=0\right)\end{array}$} \\
\hline 0-1 Days After Protest & $\begin{array}{c}0.142 \\
(0.129)\end{array}$ & $\begin{array}{l}-0.273 \\
(0.256)\end{array}$ & $\begin{array}{c}0.175 \\
(0.159)\end{array}$ & $\begin{array}{c}0.327 \\
(0.269)\end{array}$ & $\begin{array}{c}0.008 \\
(0.040)\end{array}$ & $\begin{array}{l}-0.001 \\
(0.061)\end{array}$ \\
\hline 2-3 Days After Protest & $\begin{array}{c}0.111 \\
(0.173)\end{array}$ & $\begin{array}{c}0.204 \\
(0.291)\end{array}$ & $\begin{array}{c}0.063 \\
(0.228)\end{array}$ & $\begin{array}{c}0.335 \\
(0.293)\end{array}$ & $\begin{array}{c}0.022 \\
(0.044)\end{array}$ & $\begin{array}{c}0.077 \\
(0.088)\end{array}$ \\
\hline 4-7 Days After Protest & $\begin{array}{c}0.771^{* *} \\
(0.341)\end{array}$ & $\begin{array}{c}0.108 \\
(0.328)\end{array}$ & $\begin{array}{r}0.544^{* *} \\
(0.264)\end{array}$ & $\begin{array}{c}0.196 \\
(0.327)\end{array}$ & $\begin{array}{l}0.192^{*} \\
(0.100)\end{array}$ & $\begin{array}{c}0.115 \\
(0.100)\end{array}$ \\
\hline 8+ Days After Protest & $\begin{array}{l}0.507^{*} \\
(0.281)\end{array}$ & $\begin{array}{c}0.218 \\
(0.389)\end{array}$ & $\begin{array}{c}0.552 \\
(0.428)\end{array}$ & $\begin{array}{c}0.412 \\
(0.466)\end{array}$ & $\begin{array}{l}0.158 * \\
(0.091)\end{array}$ & $\begin{array}{c}0.135 \\
(0.131)\end{array}$ \\
\hline & \multicolumn{6}{|c|}{$\begin{array}{c}\text { Panel II: Cities with Persistent Protests }\left(T_{c}=1\right) \text { vs. } \\
\text { Cities with Temporary Protests }\left(T_{c}=0\right)\end{array}$} \\
\hline 0-1 Days After Protest & $\begin{array}{c}0.109 \\
(0.129)\end{array}$ & $\begin{array}{l}-0.172 \\
(0.273)\end{array}$ & $\begin{array}{c}0.162 \\
(0.160)\end{array}$ & $\begin{array}{c}0.435 \\
(0.279)\end{array}$ & $\begin{array}{c}0.006 \\
(0.040)\end{array}$ & $\begin{array}{l}-0.011 \\
(0.060)\end{array}$ \\
\hline 2-3 Days After Protest & $\begin{array}{c}0.104 \\
(0.168)\end{array}$ & $\begin{array}{c}0.091 \\
(0.304)\end{array}$ & $\begin{array}{c}0.076 \\
(0.224)\end{array}$ & $\begin{array}{c}0.145 \\
(0.305)\end{array}$ & $\begin{array}{c}0.018 \\
(0.043)\end{array}$ & $\begin{array}{c}0.066 \\
(0.093)\end{array}$ \\
\hline 4-7 Days After Protest & $\begin{array}{c}0.711^{* *} \\
(0.345)\end{array}$ & $\begin{array}{c}0.379 \\
(0.354)\end{array}$ & $\begin{array}{c}0.497^{*} \\
(0.268)\end{array}$ & $\begin{array}{c}0.417 \\
(0.355)\end{array}$ & $\begin{array}{l}0.179 * \\
(0.100)\end{array}$ & $\begin{array}{c}0.163 \\
(0.106)\end{array}$ \\
\hline 8+ Days After Protest & $\begin{array}{l}0.518 * \\
(0.281)\end{array}$ & $\begin{array}{c}0.452 \\
(0.392) \\
\end{array}$ & $\begin{array}{c}0.566 \\
(0.426) \\
\end{array}$ & $\begin{array}{c}0.447 \\
(0.484) \\
\end{array}$ & $\begin{array}{l}0.158 * \\
(0.091) \\
\end{array}$ & $\begin{array}{r}0.120 \\
(0.135) \\
\end{array}$ \\
\hline
\end{tabular}




\begin{tabular}{|c|c|c|c|c|c|c|}
\hline & \multicolumn{2}{|c|}{$\begin{array}{l}\text { Stay-at-Home Full-Time } \\
\text { (1) }\end{array}$} & \multicolumn{2}{|c|}{$\begin{array}{l}\text { Median Percent Time } \\
\text { Spent at Home } \\
(2)\end{array}$} & \multicolumn{2}{|c|}{$\begin{array}{l}\text { Median Hours } \\
\text { Spent at Home } \\
\text { (3) } \\
\end{array}$} \\
\hline & $\mathrm{T}_{\mathrm{C}}=1$ & $\mathrm{~T}_{\mathrm{C}}=0$ & $\mathrm{~T}_{\mathrm{C}}=1$ & $\mathrm{~T}_{\mathrm{C}}=0$ & $\mathrm{~T}_{\mathrm{C}}=1$ & $\mathrm{~T}_{\mathrm{C}}=0$ \\
\hline & & & $\begin{array}{l}\text { otest Citi } \\
\text { st Cities }\end{array}$ & $\begin{array}{l}\text { Size }>1 \\
e<1,000\end{array}$ & 1) vs. & \\
\hline \multirow[t]{2}{*}{ 0-1 Days After Protest } & 0.129 & -0.016 & 0.279 & 0.125 & 0.000 & 0.017 \\
\hline & $(0.159)$ & $(0.165)$ & $(0.182)$ & $(0.180)$ & $(0.043)$ & $(0.039)$ \\
\hline \multirow{2}{*}{ 2-3 Days After Protest } & 0.188 & -0.095 & 0.283 & -0.245 & 0.034 & 0.011 \\
\hline & $(0.215)$ & $(0.161)$ & $(0.253)$ & $(0.168)$ & $(0.050)$ & $(0.051)$ \\
\hline \multirow[t]{2}{*}{ 4-7 Days After Protest } & $0.731 * *$ & $0.467^{*}$ & $0.641 * *$ & 0.048 & $0.192 *$ & $0.139 *$ \\
\hline & $(0.357)$ & $(0.256)$ & $(0.270)$ & $(0.222)$ & $(0.102)$ & $(0.079)$ \\
\hline \multirow[t]{3}{*}{ 8+ Days After Protest } & 0.443 & $0.573^{*}$ & 0.568 & 0.127 & $0.139 *$ & $0.171 *$ \\
\hline & $(0.271)$ & $(0.295)$ & $(0.399)$ & $(0.396)$ & $(0.082)$ & $(0.103)$ \\
\hline & \multicolumn{6}{|c|}{ Panel IV: Cities with a Curfew $\left(T_{c}=1\right)$ vs. Cities without a Curfew $\left(T_{c}=0\right)$} \\
\hline \multirow[t]{2}{*}{ 0-1 Days After Protest } & 0.104 & -0.019 & 0.227 & 0.160 & 0.008 & -0.008 \\
\hline & $(0.148)$ & $(0.164)$ & $(0.174)$ & $(0.199)$ & $(0.043)$ & $(0.040)$ \\
\hline \multirow[t]{2}{*}{ 2-3 Days After Protest } & 0.126 & -0.048 & 0.205 & -0.199 & 0.029 & -0.009 \\
\hline & $(0.202)$ & $(0.186)$ & $(0.245)$ & $(0.194)$ & $(0.049)$ & $(0.047)$ \\
\hline \multirow[t]{2}{*}{ 4-7 Days After Protest } & $0.696 * *$ & $0.438^{*}$ & $0.569 * *$ & 0.055 & $0.179 *$ & 0.114 \\
\hline & $(0.349)$ & $(0.250)$ & $(0.265)$ & $(0.217)$ & $(0.097)$ & $(0.079)$ \\
\hline \multirow[t]{2}{*}{ 8+ Days After Protest } & 0.322 & $0.791^{* * *}$ & 0.397 & 0.456 & 0.097 & $0.218 * *$ \\
\hline & $(0.268)$ & $(0.296)$ & $(0.410)$ & $(0.390)$ & $(0.084)$ & $(0.098)$ \\
\hline
\end{tabular}




\begin{tabular}{|c|c|c|c|c|c|c|}
\hline & \multicolumn{2}{|c|}{$\begin{array}{c}\text { Stay-at-Home Full-Time } \\
\text { (1) }\end{array}$} & \multicolumn{2}{|c|}{$\begin{array}{l}\text { Median Percent Time } \\
\text { Spent at Home } \\
(2)\end{array}$} & \multicolumn{2}{|c|}{$\begin{array}{l}\text { Median Hours } \\
\text { Spent at Home } \\
(3) \\
\end{array}$} \\
\hline & $\mathrm{T}_{\mathrm{c}}=1$ & $\mathrm{~T}_{\mathrm{C}}=0$ & $\mathrm{~T}_{\mathrm{c}}=1$ & $\mathrm{~T}_{\mathrm{C}}=0$ & $\mathrm{~T}_{\mathrm{C}}=1$ & $\mathrm{~T}_{\mathrm{c}}=0$ \\
\hline & \multicolumn{6}{|c|}{ Panel V: States with a Mask Mandate $\left(T_{c}=1\right)$ vs. States without a Mask Mandate $\left(T_{c}=0\right)$} \\
\hline 0-1 Days After Protest & $\begin{array}{l}-0.242 \\
(0.169)\end{array}$ & $\begin{array}{l}0.286 * \\
(0.158)\end{array}$ & $\begin{array}{l}-0.012 \\
(0.177)\end{array}$ & $\begin{array}{l}0.311^{*} \\
(0.186)\end{array}$ & $\begin{array}{l}-0.050 \\
(0.044)\end{array}$ & $\begin{array}{c}0.038 \\
(0.042)\end{array}$ \\
\hline 2-3 Days After Protest & $\begin{array}{c}0.040 \\
(0.302)\end{array}$ & $\begin{array}{c}0.104 \\
(0.157)\end{array}$ & $\begin{array}{l}-0.213 \\
(0.221)\end{array}$ & $\begin{array}{c}0.172 \\
(0.262)\end{array}$ & $\begin{array}{l}-0.032 \\
(0.061)\end{array}$ & $\begin{array}{l}0.044 \\
(0.042)\end{array}$ \\
\hline 4-7 Days After Protest & $\begin{array}{c}0.545^{* *} \\
(0.257)\end{array}$ & $\begin{array}{c}0.746^{* *} \\
(0.374)\end{array}$ & $\begin{array}{c}0.130 \\
(0.240)\end{array}$ & $\begin{array}{l}0.535^{*} \\
(0.285)\end{array}$ & $\begin{array}{c}0.148 * * \\
(0.073)\end{array}$ & $\begin{array}{l}0.172 * \\
(0.102)\end{array}$ \\
\hline 8+ Days After Protest & $\begin{array}{c}0.561 \\
(0.360)\end{array}$ & $\begin{array}{l}0.468 * \\
(0.261)\end{array}$ & $\begin{array}{c}0.347 \\
(0.418)\end{array}$ & $\begin{array}{c}0.506 \\
(0.416)\end{array}$ & $\begin{array}{c}0.164 \\
(0.101)\end{array}$ & $\begin{array}{c}0.133 \\
(0.081)\end{array}$ \\
\hline $\begin{array}{l}\mathrm{N} \\
\text { Mean of DV }\end{array}$ & \multicolumn{2}{|c|}{6210} & \multicolumn{2}{|c|}{6210} & \multicolumn{2}{|c|}{6210} \\
\hline
\end{tabular}

* Significant at the $10 \%$ level, ** Significant at the $5 \%$ level, *** Significant at the $1 \%$ level

Notes: Estimate is generated using weighted least squares. All models include county and day fixed effects. State-level controls include: log testing rate, indicator for a SIPO, mask mandate, whether food industry reopened, whether retail store reopened, whether personal or pet care services reopened, and whether entertainment or activity reopened. County-level controls include: average temperature and an indicator for whether any precipitation fell. Standard errors, clustered at the county-level, are reported inside the parentheses. 
Table 4. Difference-in-Differences Estimates of the Effect of Urban Protests on COVID-19 Case Growth

(1)

(2)

0-5 Days After Protest

6-14 Days After Protest

15-19 Days After Protest

20-24 Days After Protest

25-29 Days After Protest

30-34 Days After Protest

35+ Days After Protest

$\mathrm{N}$

Observable Controls?

0-5 Days After Protest

6-14 Days After Protest

15-19 Days After Protest

20-24 Days After Protest

25-29 Days After Protest

30-34 Days After Protest

35+ Days After Protest

$\mathrm{N}$

Observable Controls?

Panel I: Primary Counties

Panel II: Primary \& Secondary Counties
0.0007

(0.0014)

0.0006

$(0.0023)$

0.0004

$(0.0032)$

$-0.0003$

(0.0038)

$-0.0000$

(0.0045)

$-0.0036$

(0.0053)

$-0.0094$

(0.0062)

13446

No

\begin{tabular}{cc}
\hline 0.0008 & 0.0011 \\
$(0.0015)$ & $(0.0013)$ \\
0.0011 & 0.0016 \\
$(0.0024)$ & $(0.0020)$ \\
0.0012 & 0.0018 \\
$(0.0033)$ & $(0.0027)$ \\
0.0010 & 0.0013 \\
$(0.0039)$ & $(0.0032)$ \\
0.0012 & 0.0016 \\
$(0.0045)$ & $(0.0038)$ \\
-0.0021 & -0.0019 \\
$(0.0054)$ & $(0.0046)$ \\
-0.0079 & -0.0077 \\
$(0.0063)$ & $(0.0053)$ \\
11178 & 11178 \\
No & Yes
\end{tabular}

0.0010

$(0.0012)$

0.0012

(0.0019)

0.0010

(0.0026)

0.0000

$(0.0032)$

0.0004

(0.0038)

$-0.0033$

(0.0045)

$-0.0086$

(0.0052)

13446

Yes 
0-5 Days After Protest

6-14 Days After Protest

15-19 Days After Protest

20-24 Days After Protest

25-29 Days After Protest

30-34 Days After Protest

35+ Days After Protest

0-5 Days After Protest

6-14 Days After Protest

15-19 Days After Protest

20-24 Days After Protest

25-29 Days After Protest

30-34 Days After Protest

35+ Days After Protest
Panel III: Heterogenous Effects by Protest Characteristics

$$
\mathrm{T}_{\mathrm{C}}=1
$$

$\mathrm{T}_{\mathrm{C}}=0$

(a): Cities with Violent Protests $\left(\mathrm{T}_{\mathrm{c}}=1\right)$ vs Cities Peaceful Protests $\left(\mathrm{T}_{\mathrm{c}}=0\right)$
$-0.0002$
(0.0013)
0.0018
$-0.0001$
$(0.0017)$
$(0.0021)$
0.0027
$-0.0005$
$(0.0025)$
$(0.0029)$
0.0003
0.0061
$(0.0034)$
0.0014
$(0.0039)$
(0.0036)
0.0056
$-0.0007$
(0.0045)
$-0.0076$
(0.0039)
0.0069
(0.0050)
0.0010
$(0.0050)$
(0.0052)
0.0012
0.0018

(b): Cities with Persistent Protests $\left(\mathrm{T}_{\mathrm{C}}=1\right)$ vs Cities with Temporary Protests $\left(\mathrm{T}_{\mathrm{c}}=0\right)$
0.0007
$(0.0013)$
0.0001
0.0006
$(0.0026)$
(0.0021)
0.0051
0.0006
(0.0039)
(0.0027)
0.0098
0.0004
(0.0066)
(0.0032)
0.0132
0.0017
(0.0085)
(0.0038)
0.0082
$-0.0014$
$(0.0088)$
(0.0045)
0.0062
$-0.0070$
(0.0091)
(0.0053) 
0-5 Days After Protest

6-14 Days After Protest

15-19 Days After Protest

20-24 Days After Protest

25-29 Days After Protest

30-34 Days After Protest

35+ Days After Protest

0-5 Days After Protest

6-14 Days After Protest

15-19 Days After Protest

20-24 Days After Protest

25-29 Days After Protest

30-34 Days After Protest

35+ Days After Protest
$\mathrm{T}_{\mathrm{C}}=1$

$\mathrm{T}_{\mathrm{C}}=0$

(c): Protest Cities with Size $\geq 1,000\left(\mathrm{~T}_{\mathrm{c}}=1\right)$ vs. Protest Cities with Size

$$
<1,000\left(\mathrm{~T}_{\mathrm{C}}=0\right)
$$

$\begin{array}{cc}0.0013 & -0.00003 \\ (0.0012) & (0.0017) \\ 0.0014 & 0.0011 \\ (0.0020) & (0.0027) \\ 0.0012 & 0.0028 \\ (0.0027) & (0.0038) \\ 0.0012 & 0.0017 \\ (0.0034) & (0.0041) \\ 0.0018 & 0.0015 \\ (0.0040) & (0.0049) \\ -0.0012 & -0.0043 \\ (0.0047) & (0.0052) \\ -0.0083 & -0.0068 \\ (0.0054) & (0.0059)\end{array}$

(d): Cities with a Curfew $\left(\mathrm{T}_{\mathrm{c}}=1\right)$ vs. Cities without a Curfew $\left(\mathrm{T}_{\mathrm{c}}=0\right)$

$\begin{array}{cc}0.0004 & 0.0010 \\ (0.0013) & (0.0015) \\ 0.0002 & 0.0024 \\ (0.0021) & (0.0024) \\ 0.0001 & 0.0038 \\ (0.0029) & (0.0034) \\ -0.0001 & 0.0044 \\ (0.0036) & (0.0036) \\ 0.0013 & 0.0040 \\ (0.0041) & (0.0044) \\ -0.0015 & -0.0006 \\ (0.0046) & (0.0047) \\ -0.0082 & -0.0041 \\ (0.0052) & (0.0054)\end{array}$


(e): States with a Mask Mandate $\left(T_{c}=1\right)$ vs. States without a Mask Mandate $\left(T_{c}=0\right)$

0-5 Days After Protest

6-14 Days After Protest

15-19 Days After Protest

20-24 Days After Protest

25-29 Days After Protest

30-34 Days After Protest

35+ Days After Protest
0.0015

(0.0013)

0.0022

$(0.0025)$

0.0028

(0.0036)

0.0013

(0.0049)

0.0028

$(0.0052)$

$-0.0034$

(0.0054)

$-0.0091$

(0.0058)
0.0007

(0.0016)

0.0010

$(0.0022)$

0.0010

$(0.0029)$

0.0014

$(0.0032)$

0.0011

(0.0039)

$-0.0001$

$(0.0047)$

$-0.0066$

$(0.0055)$

$\mathrm{N}$

11178

Mean of DV

0.0212

* Significant at the $10 \%$ level, ** Significant at the 5\% level, *** Significant at the $1 \%$ level

Notes: Estimate is generated using weighted least squares. All models include county and day fixed effects. State-level controls include: log testing rate, indicator for a SIPO, mask mandate, whether food industry reopened, whether retail store reopened, whether personal or pet care services reopened, and whether entertainment or activity reopened. County-level controls include: average temperature and an indicator for whether any precipitation fell. Panel III includes the full set of controls. Standard errors, clustered at the county-level, are reported inside the parentheses. 
Table 5. Difference-in-Differences Estimates of the Effect of Urban Protests on COVID-19 Death Growth

(1)

(2)

0-14 Days After Protest

15-19 Days After Protest

20-24 Days After Protest

25-29 Days After Protest

30-34 Days After Protest

35+ Days After Protest

$\mathrm{N}$

Observable Controls?

0-14 Days After Protest

15-19 Days After Protest

20-24 Days After Protest

25-29 Days After Protest

30-34 Days After Protest

35+ Days After Protest

$\mathrm{N}$

Observable Controls?
Panel I: Primary Counties

\begin{tabular}{cc}
\hline 0.0011 & 0.0011 \\
$(0.0016)$ & $(0.0015)$ \\
0.0020 & 0.0020 \\
$(0.0024)$ & $(0.0023)$ \\
0.0017 & 0.0016 \\
$(0.0028)$ & $(0.0025)$ \\
-0.0011 & -0.0014 \\
$(0.0034)$ & $(0.0031)$ \\
-0.0001 & -0.0005 \\
$(0.0042)$ & $(0.0039)$ \\
-0.0033 & -0.0037 \\
$(0.0048)$ & $(0.0045)$ \\
11106 & 11106 \\
No & Yes
\end{tabular}

Panel II: Primary \& Secondary Counties

0.0012

(0.0015)

0.0012

(0.0015)

0.0020

0.0020

(0.0023)

(0.0022)

0.0020

0.0018

(0.0027)

(0.0025)

$-0.0008$

(0.0032)

$-0.0012$

(0.0029)

$-0.0004$

$-0.0008$

(0.0040)

(0.0037)

$-0.0038$

$-0.0043$

(0.0046)

(0.0043)

13061

13061

Yes 
Panel III: Heterogenous Effects by Protest Characteristics

$\mathrm{T}_{\mathrm{C}}=1$

$\mathrm{T}_{\mathrm{c}}=0$

0-14 Days After Protest

15-19 Days After Protest

20-24 Days After Protest

25-29 Days After Protest

30-34 Days After Protest

35+ Days After Protest

0-14 Days After Protest

15-19 Days After Protest

20-24 Days After Protest

25-29 Days After Protest

30-34 Days After Protest

35+ Days After Protest (a): Cities with Violent Protests $\left(\mathrm{T}_{\mathrm{C}}=1\right)$ vs Cities Peaceful Protests $\left(\mathrm{T}_{\mathrm{C}}=0\right)$
0.0001
$(0.0016)$
0.0019
$(0.0018)$
0.0004
0.0050
$(0.0023)$
0.0010
(0.0039)
(0.0026)
0.0034
$-0.0022$
(0.0032)
$(0.0031)$
0.0018
$-0.0010$
(0.0044)
(0.0039)
$-0.0035$
0.0042
(0.0059)
0.0057
(0.0046)

(b): Cities with Persistent Protests $\left(\mathrm{T}_{\mathrm{C}}=1\right)$ vs Cities with Temporary Protests $\left(\mathrm{T}_{\mathrm{c}}=0\right)$
0.0006
(0.0015)
0.0026
0.0009
(0.0034)
$(0.0023)$
0.0153
0.0015
(0.0101)
(0.0026)
0.0054
$-0.0013$
(0.0047)
(0.0031)
0.0053
$-0.0004$
(0.0058)
(0.0039)
0.0129*
(0.0071)
$-0.0029$
0.0256
(0.0045) 
0-14 Days After Protest

15-19 Days After Protest

20-24 Days After Protest

25-29 Days After Protest

30-34 Days After Protest

35+ Days After Protest

0-14 Days After Protest

15-19 Days After Protest

20-24 Days After Protest

25-29 Days After Protest

30-34 Days After Protest

35+ Days After Protest

$$
\mathrm{T}_{\mathrm{c}}=1
$$

$\mathrm{T}_{\mathrm{C}}=0$

(c): Protest Cities with Size $\geq 1,000\left(\mathrm{~T}_{\mathrm{c}}=1\right)$ vs. Protest Cities with Size

$$
<1,000\left(\mathrm{~T}_{\mathrm{C}}=0\right)
$$

0.0000
$(0.0015)$

0.0021

$-0.0003$

(0.0018)

$(0.0022)$

0.0066

0.0004

$(0.0041)$

(0.0025)

0.0050

(0.0036)

$-0.0022$

$(0.0030)$

$-0.0021$

$(0.0037)$

$-0.0039$

0.0018

$(0.0038)$

0.0077

(0.0056)

0.0070

(0.0044)

(0.0066)

(d): Cities with a Curfew $\left(\mathrm{T}_{\mathrm{C}}=1\right)$ vs. Cities without a Curfew $\left(\mathrm{T}_{\mathrm{C}}=0\right)$
$-0.0003$
(0.0016)
$-0.0004$
$(0.0022)$
0.0021
$(0.0017)$
0.0052
0.0001
$(0.0025)$
(0.0033)
0.0045
$(0.0033)$
$-0.0028$
0.0028
(0.0030)
$-0.0013$
(0.0039)
$(0.0039)$
0.0043
$-0.0043$
(0.0047)
0.0038
(0.0045) 


$$
\mathrm{T}_{\mathrm{c}}=1
$$

$\mathrm{T}_{\mathrm{C}}=0$

(e): States with a Mask Mandate $\left(T_{c}=1\right)$ vs. States without a Mask Mandate $\left(T_{c}=0\right)$

0-14 Days After Protest

15-19 Days After Protest

20-24 Days After Protest

25-29 Days After Protest

30-34 Days After Protest

35+ Days After Protest
0.0014

(0.0016)

0.0001

(0.0023)

0.0009

$(0.0025)$

$-0.0015$

(0.0032)

$-0.0012$

$(0.0041)$

$-0.0046$

(0.0048)
0.0009

(0.0016)

0.0033

$(0.0027)$

0.0017

(0.0029)

$-0.0016$

(0.0034)

$-0.0001$

(0.0042)

$-0.0031$

(0.0048)

$\mathrm{N}$

11106

Mean of DV

0.0124

* Significant at the 10\% level, ** Significant at the 5\% level, *** Significant at the 1\% level

Notes: Estimate is generated using weighted least squares. All models include county and day fixed effects. State-level controls include: log testing rate, indicator for a SIPO, mask mandate, whether food industry reopened, whether retail store reopened, whether personal or pet care services reopened, and whether entertainment or activity reopened. County-level controls include: average temperature and an indicator for whether any precipitation fell. Panel III includes the full set of controls. Standard errors, clustered at the county-level, are reported inside the parentheses. 
Appendix Figure 1: Distribution of Large U.S. Cities with and without Protests

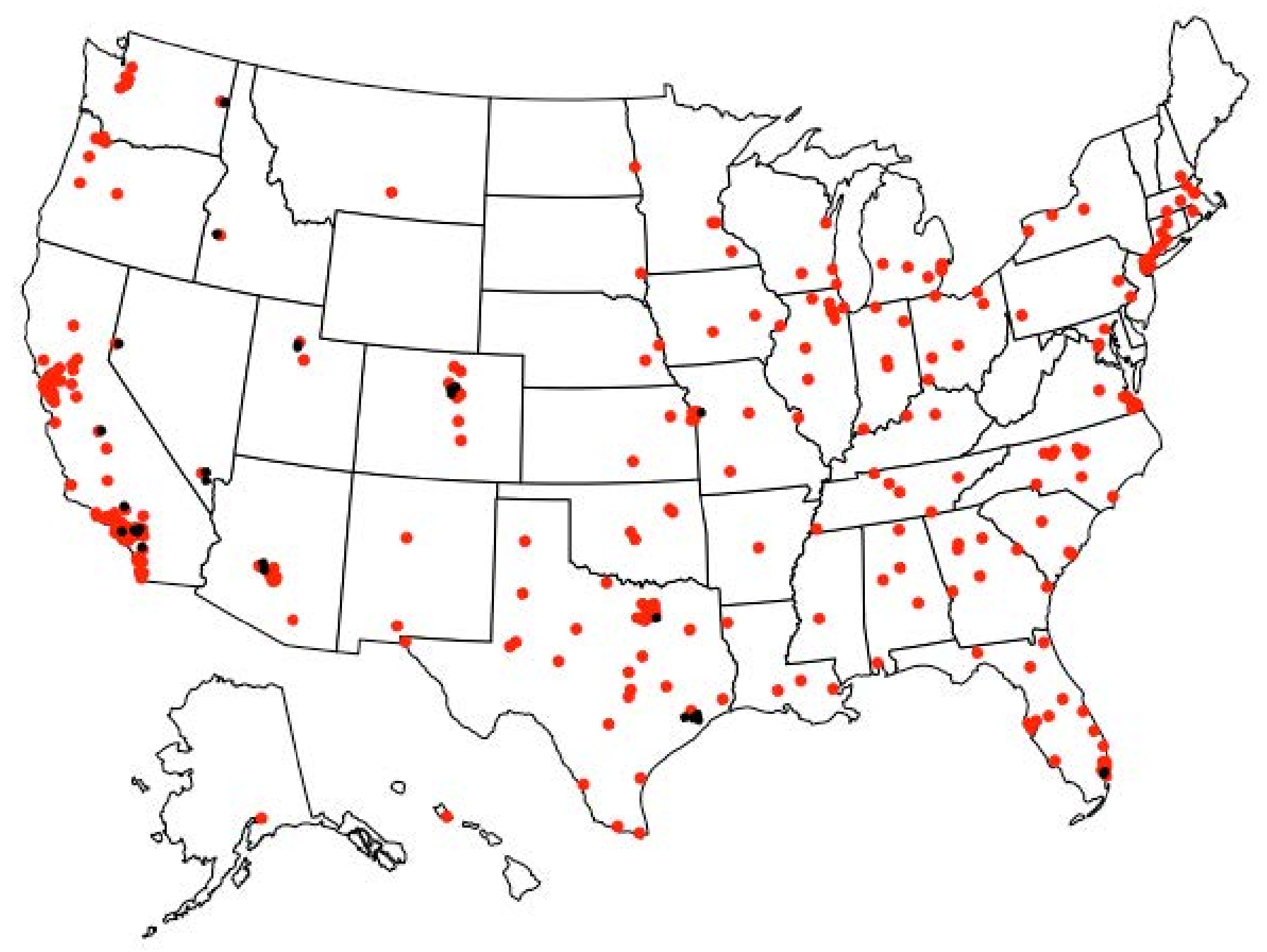

Note: Red dots represent cities with a protests. Black dots represent cities with $>100,000$ population and without a protest. 


\section{Appendix Figure 2. Distribution of Large Cities with Protests, by Whether Accompanied by Media Reports of Violence}

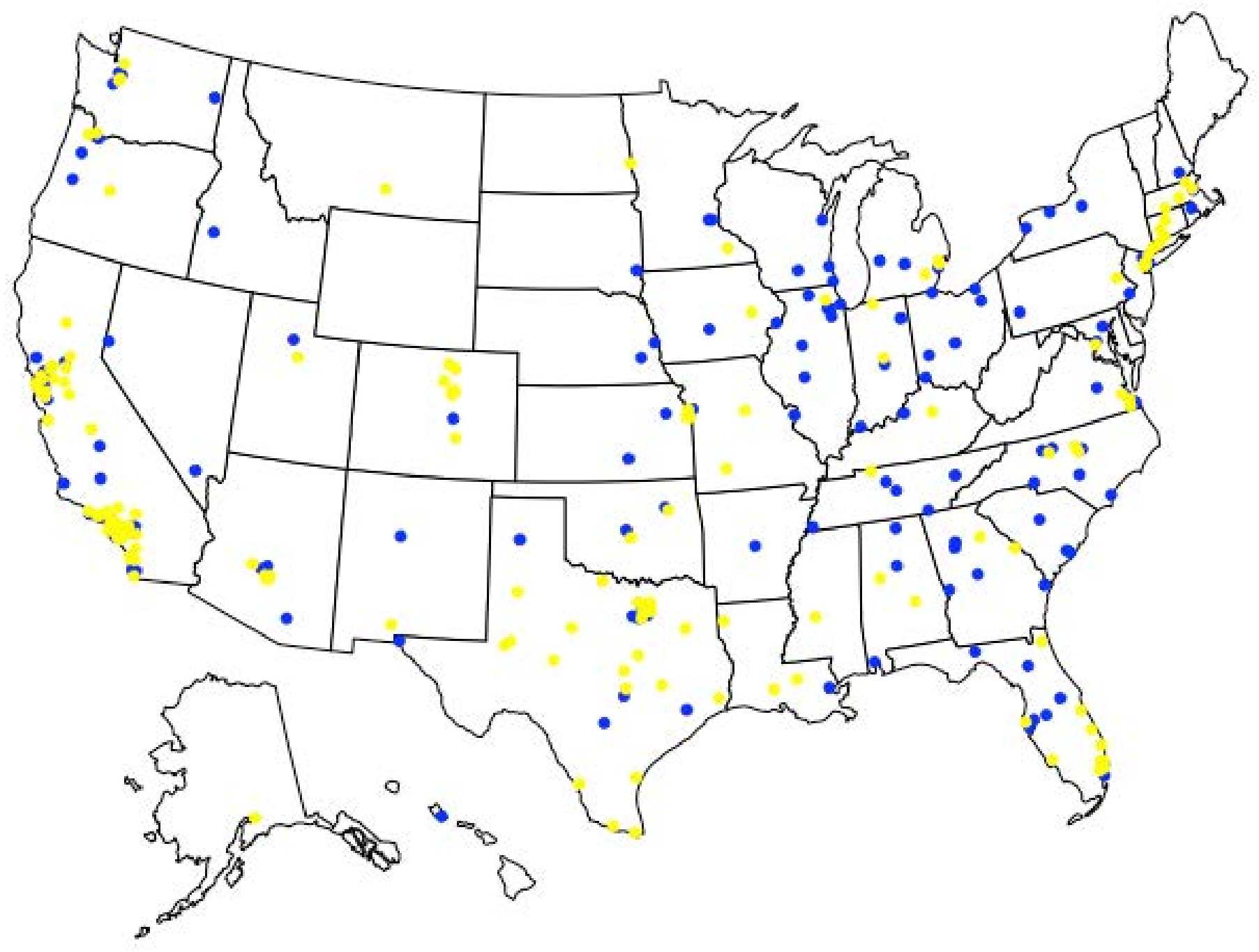

Note: Blue dots represent cities with protests that were accompanied by mainstream media reports of violence. Yellow dots represent cities with protests that were consistently described as peaceful. 
Appendix Figure 3. Distribution of Large Cities with Protests, by Protest Persistence

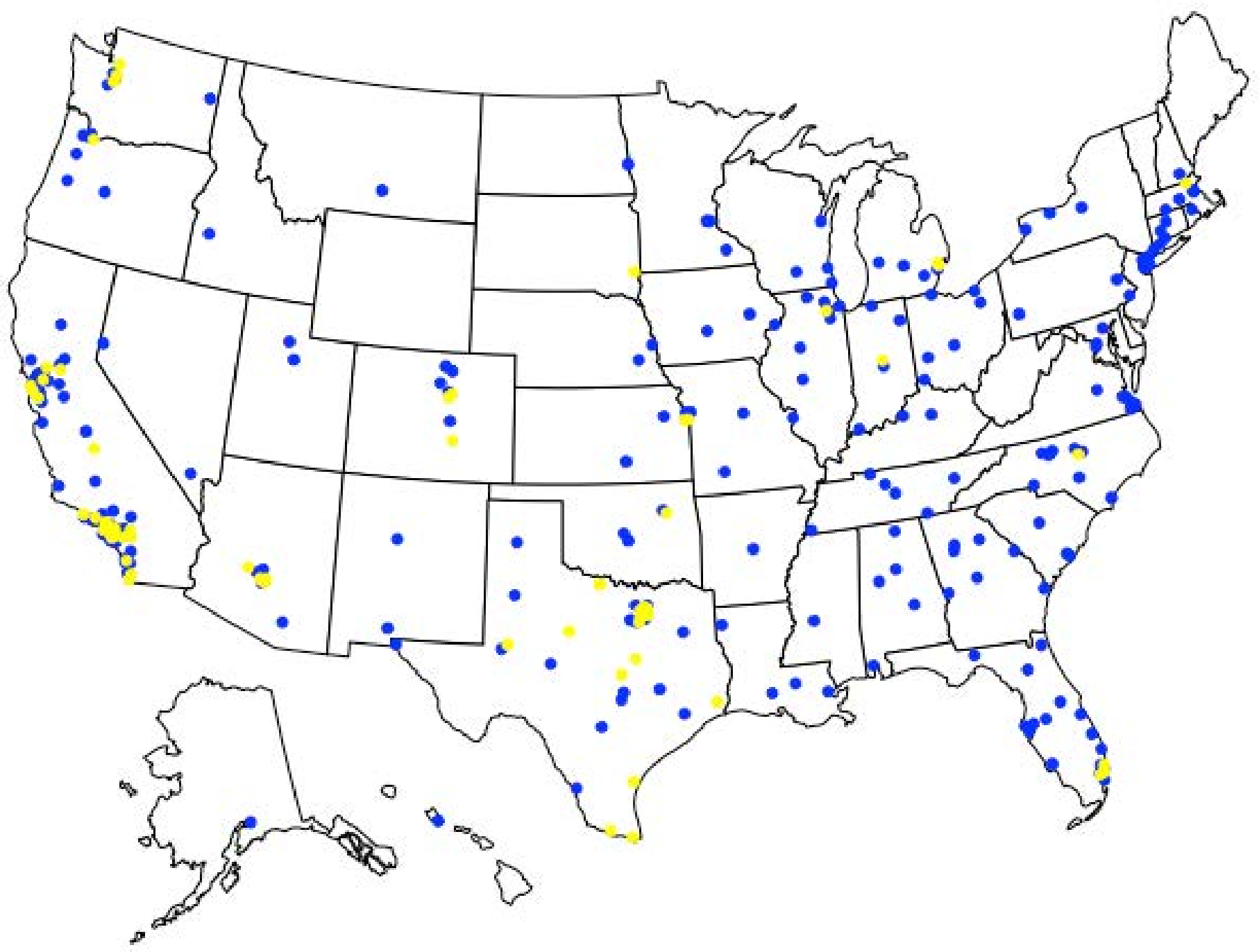

Note: Blue dots represent cities with protests that persisted for three or more days. Yellow dots represent cities with protests that only persisted for one or two days. 


\section{Appendix Figure 4. Distribution of Large Cities with Protests, by Whether Protest Attracted at Least 1,000 Protesters}

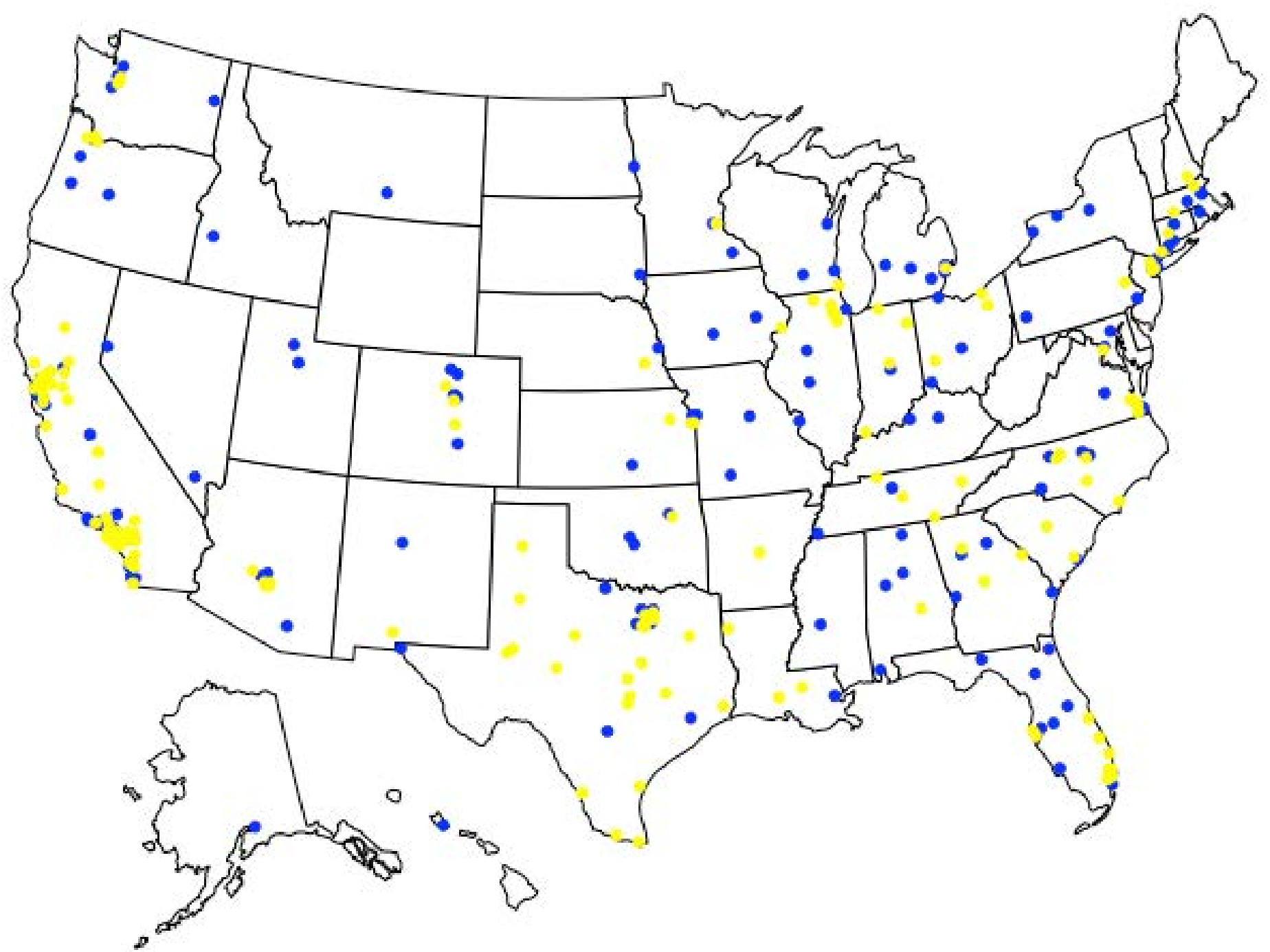

Note: Blue dots represent cities with protests with crowds of over 1,000 people. Yellow dots represent cities with protests with crowds of less than 1,000 people. 
Appendix Figure 5. Distribution of Counties with at Least One Large Urban Protest

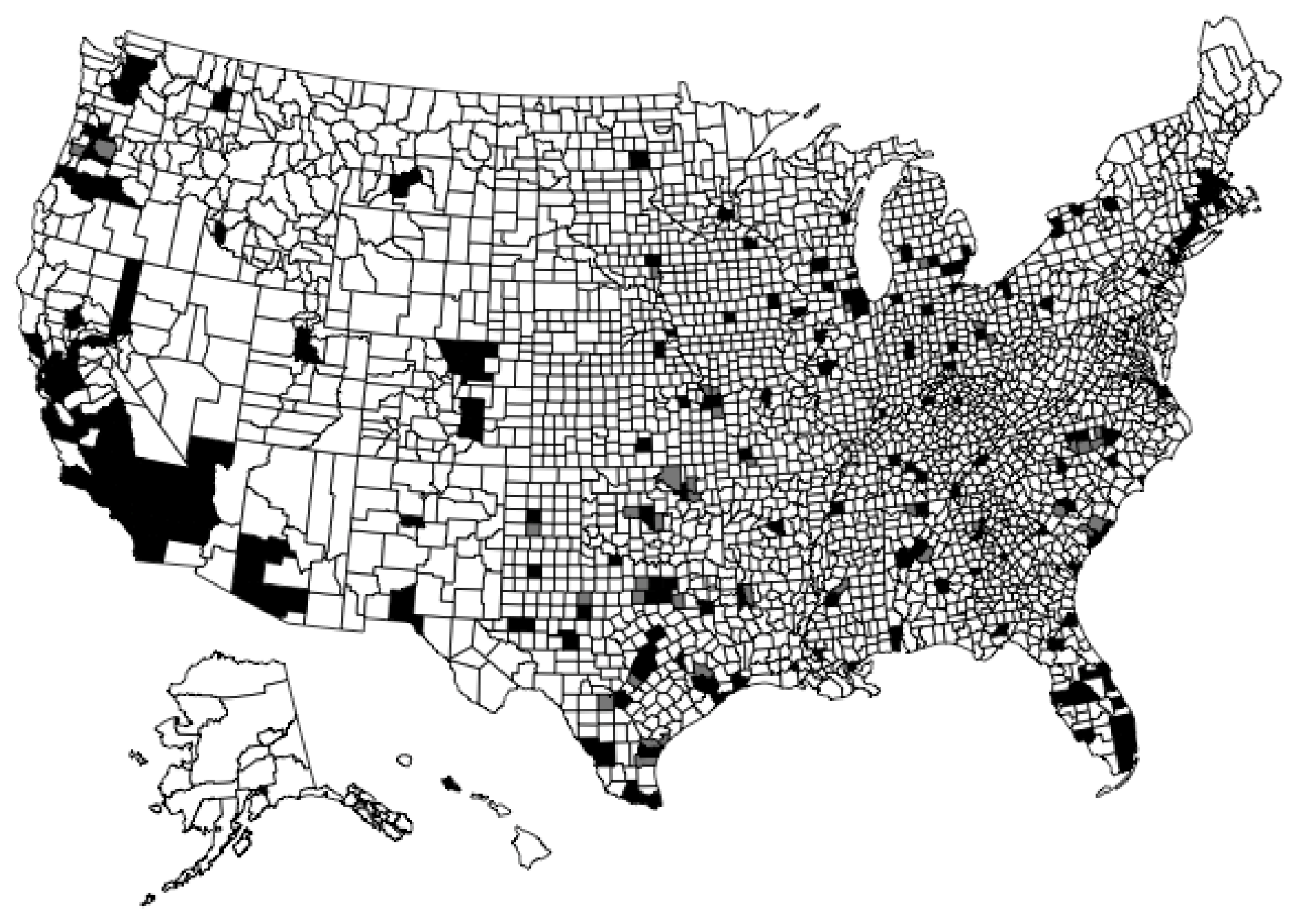

Note: Black shaded counties represent primary counties with a protest. Gray shaded counties represent secondary counties with a protest. 
Appendix Figure 6A. Trends in Social Distancing and COVID-19 Cases

Panel (a): Stay-at-Home Full-Time

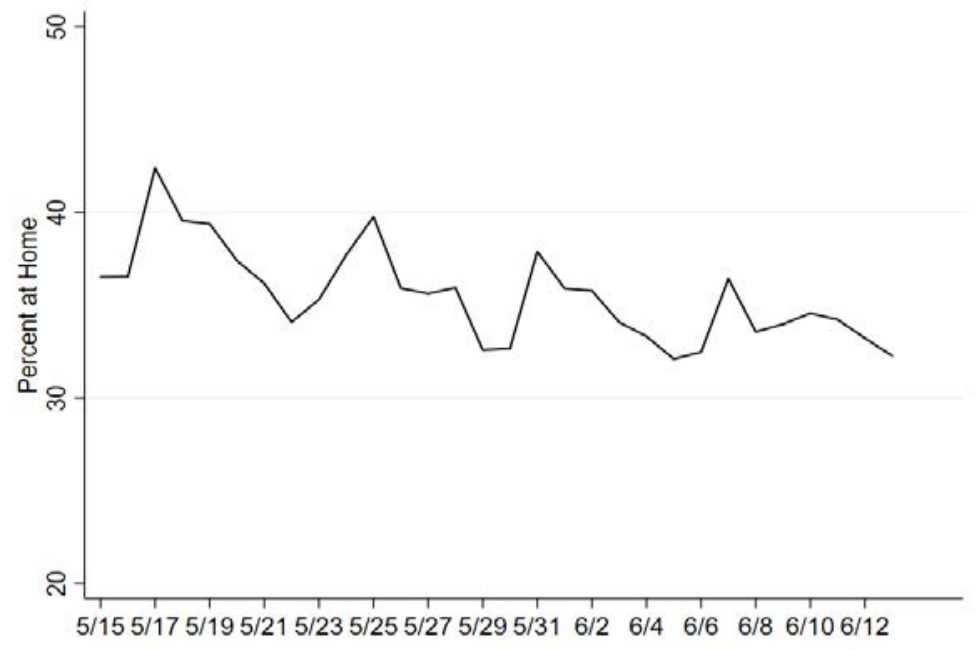

Panel (b): Median Percent Time Spent at Home
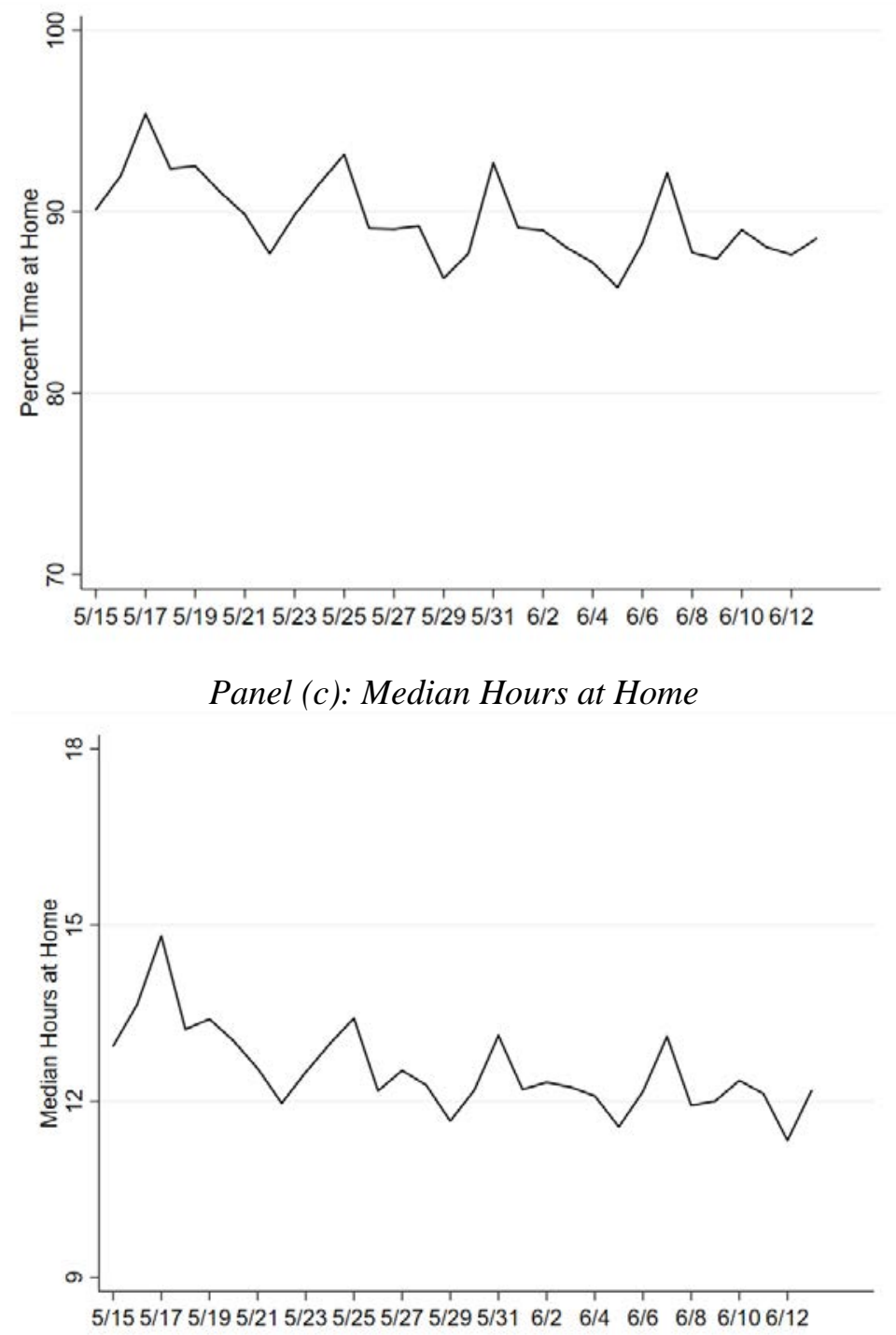


\title{
Appendix Figure 6B. Trends in COVID-19 Cases and COVID-19 Deaths
}

\author{
Panel (a): COVID-19 Cases per 100,000
}

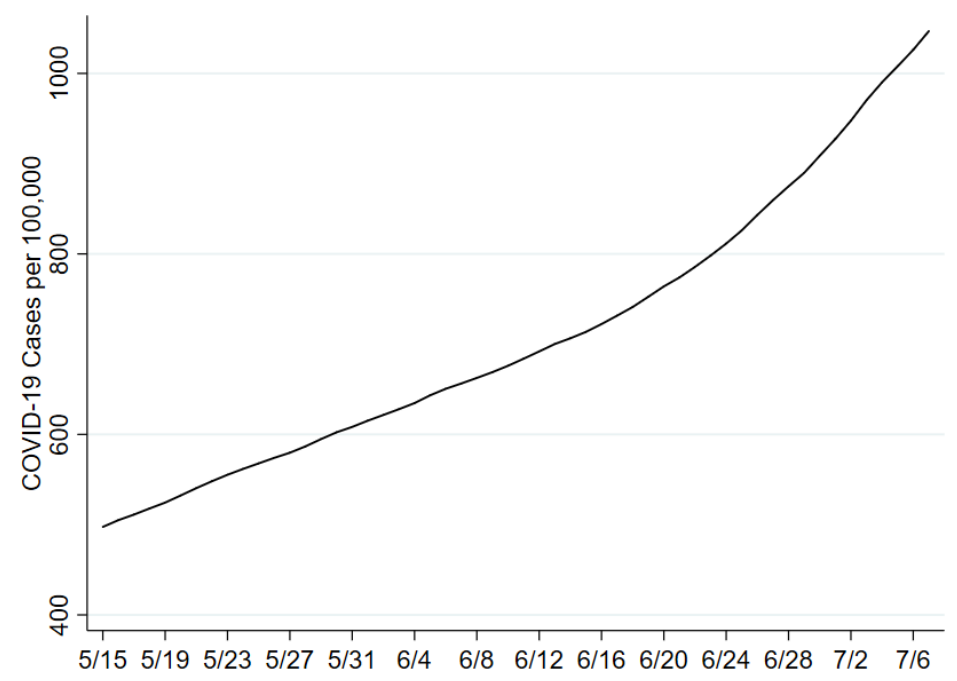

Panel (b): COVID-19 Deaths per 100,000

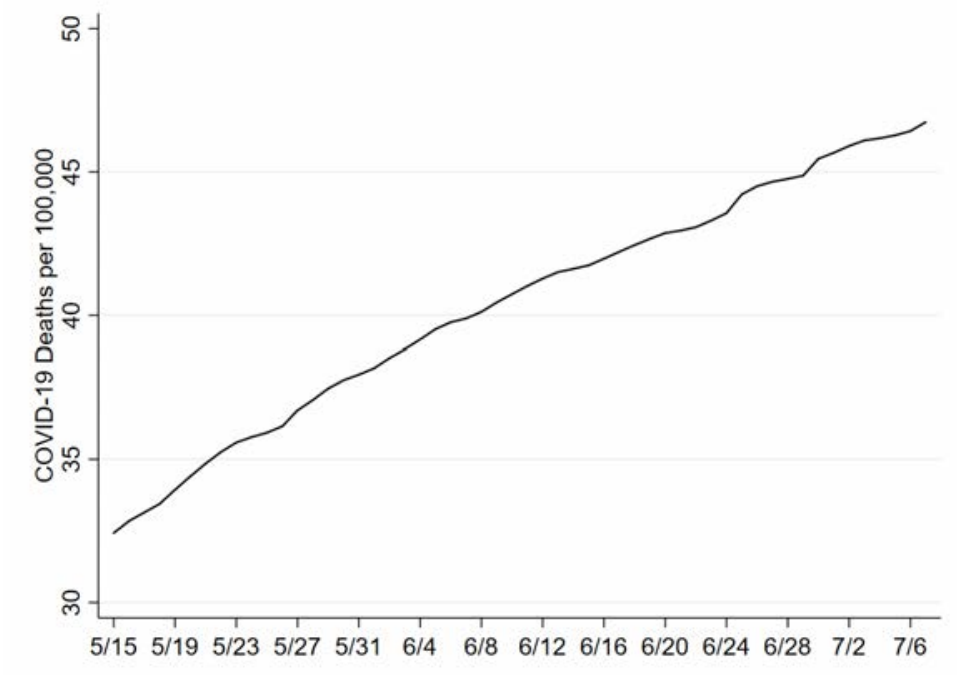




\section{Appendix Figure 7. Event-Study Analysis of Effect of Urban Protests on \% Stay at Home Full-Time, by Protest Characteristics}

Panel (a): Violent

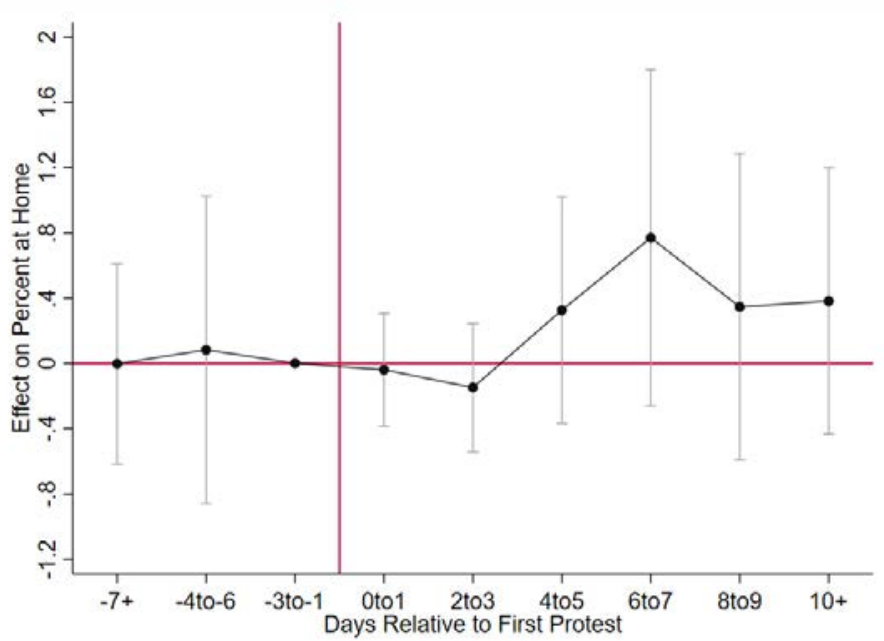

Panel (c): Large Protest

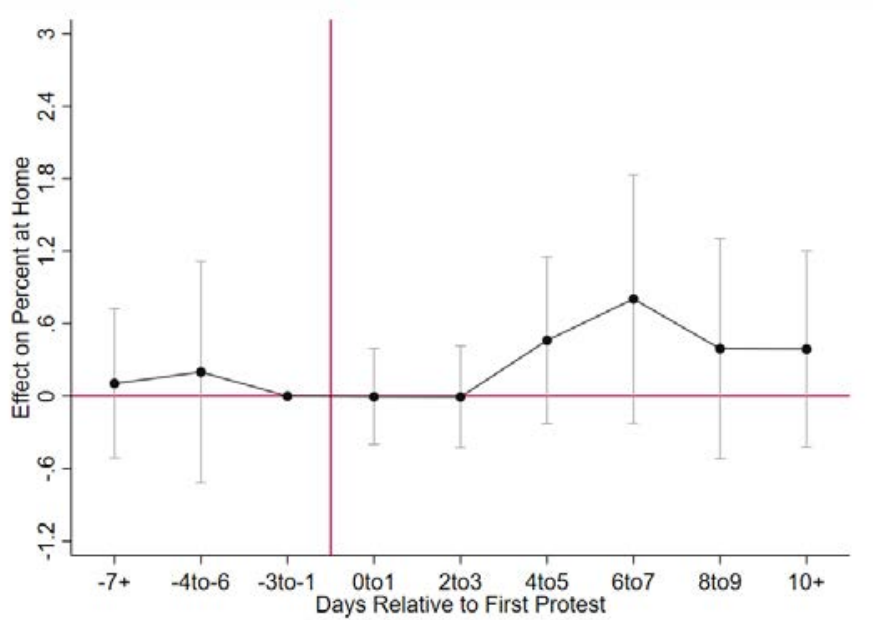

Panel (b): Persistent

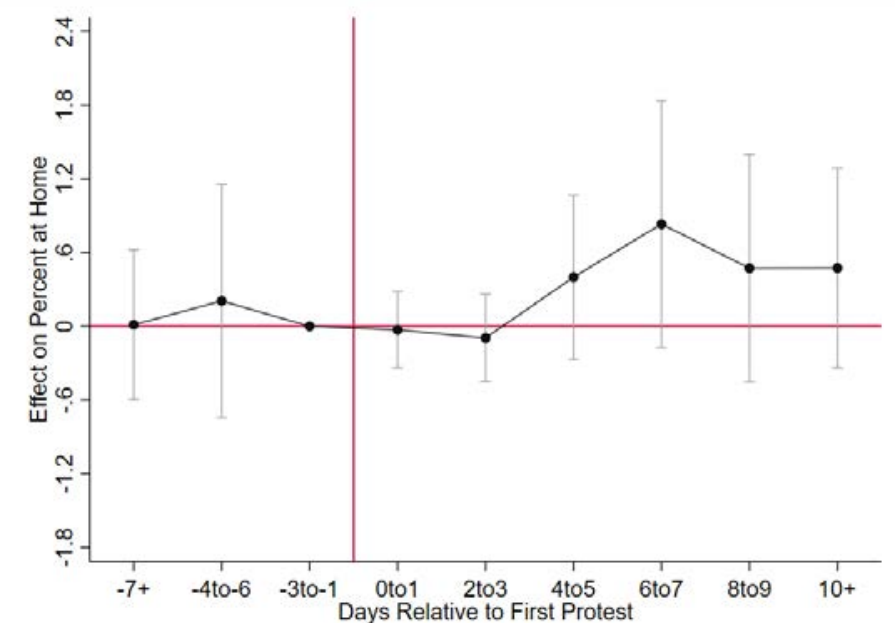

Panel (d): Curfew

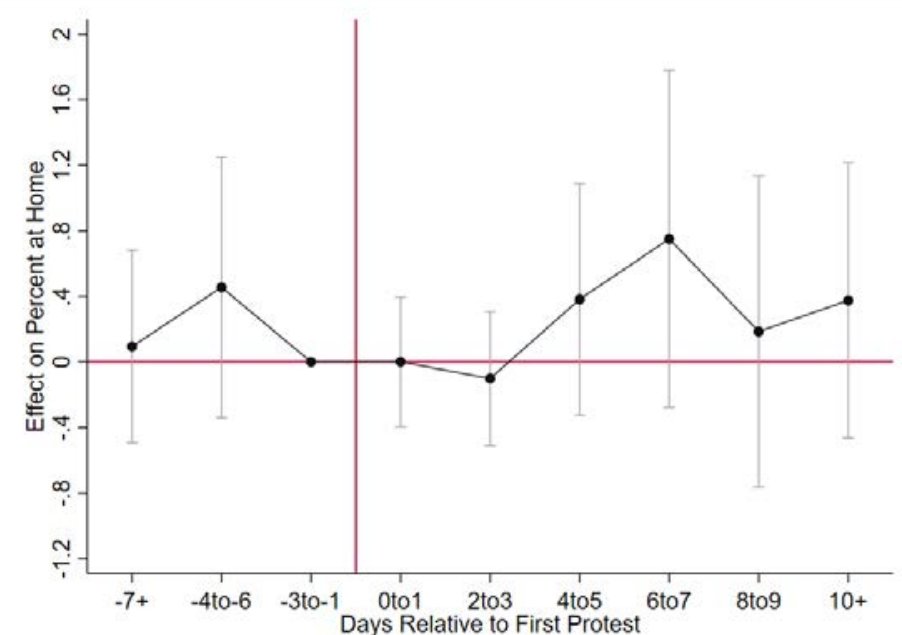

Notes: Estimate is generated using weighted least squares. All models include county and day fixed effects. State-level controls include: log testing rate, indicator for a SIPO, mask mandate, whether food industry reopened, whether retail store reopened, whether personal or pet care services reopened, and whether entertainment or activity reopened. County-level controls include: average temperature and an indicator for whether any precipitation fell. 


\section{Appendix Figure 8. Event-Study Analysis of Urban Protests on COVID-19 Case Growth}
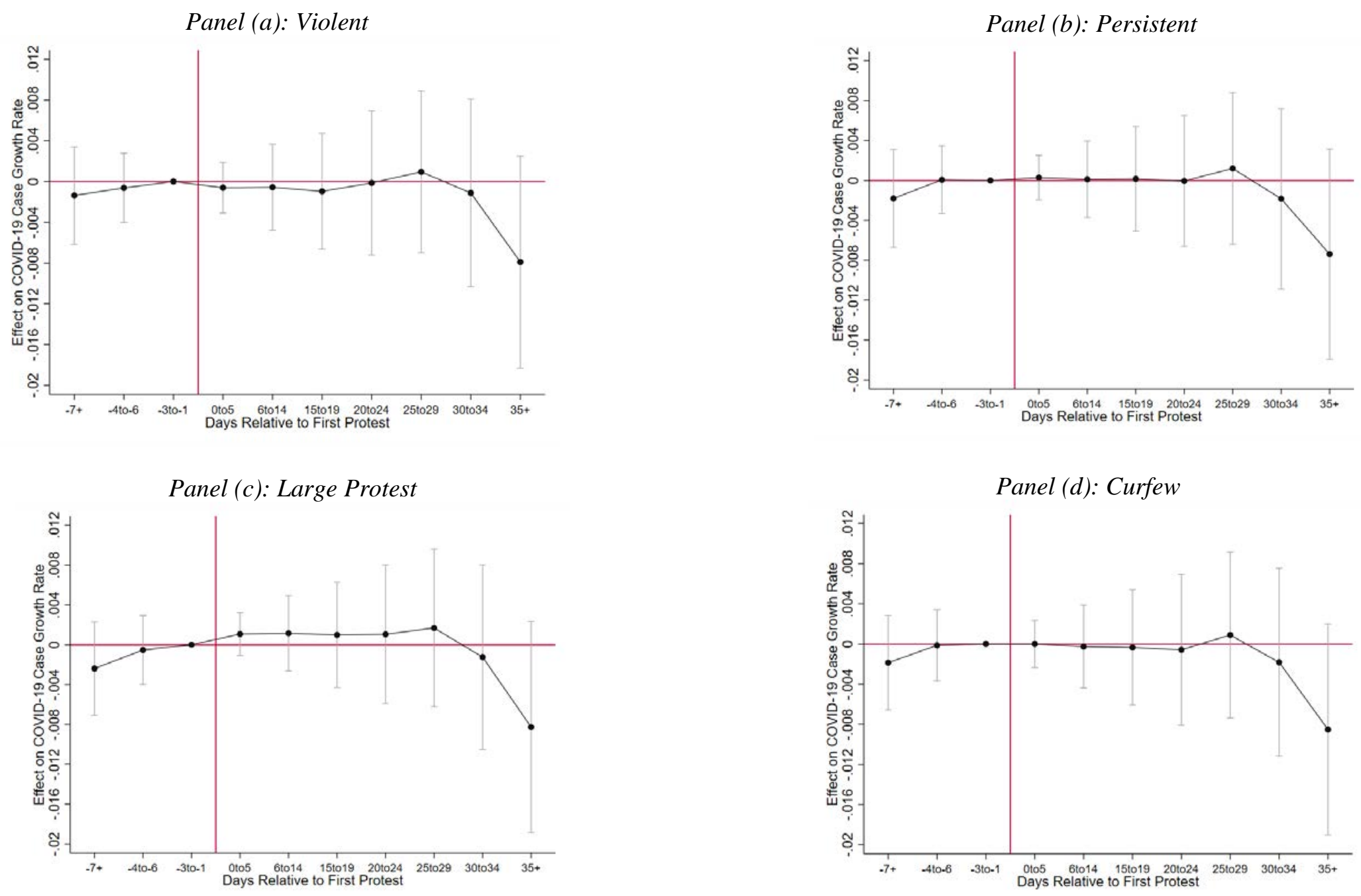

Notes: Estimate is generated using weighted least squares. All models include county and day fixed effects. State-level controls include: log testing rate, indicator for a SIPO, mask mandate, whether food industry reopened, whether retail store reopened, whether personal or pet care services reopened, and whether entertainment or activity reopened. County-level controls include: average temperature and an indicator for whether any precipitation fell. 
Appendix Figure 9. Synthetic Control Estimates of Effects of Urban Protests on COVID-19 Cases Per 100,000 Population for Selected Counties with Early Protest and Strong Pre-trend Match (May 28 or Earlier)
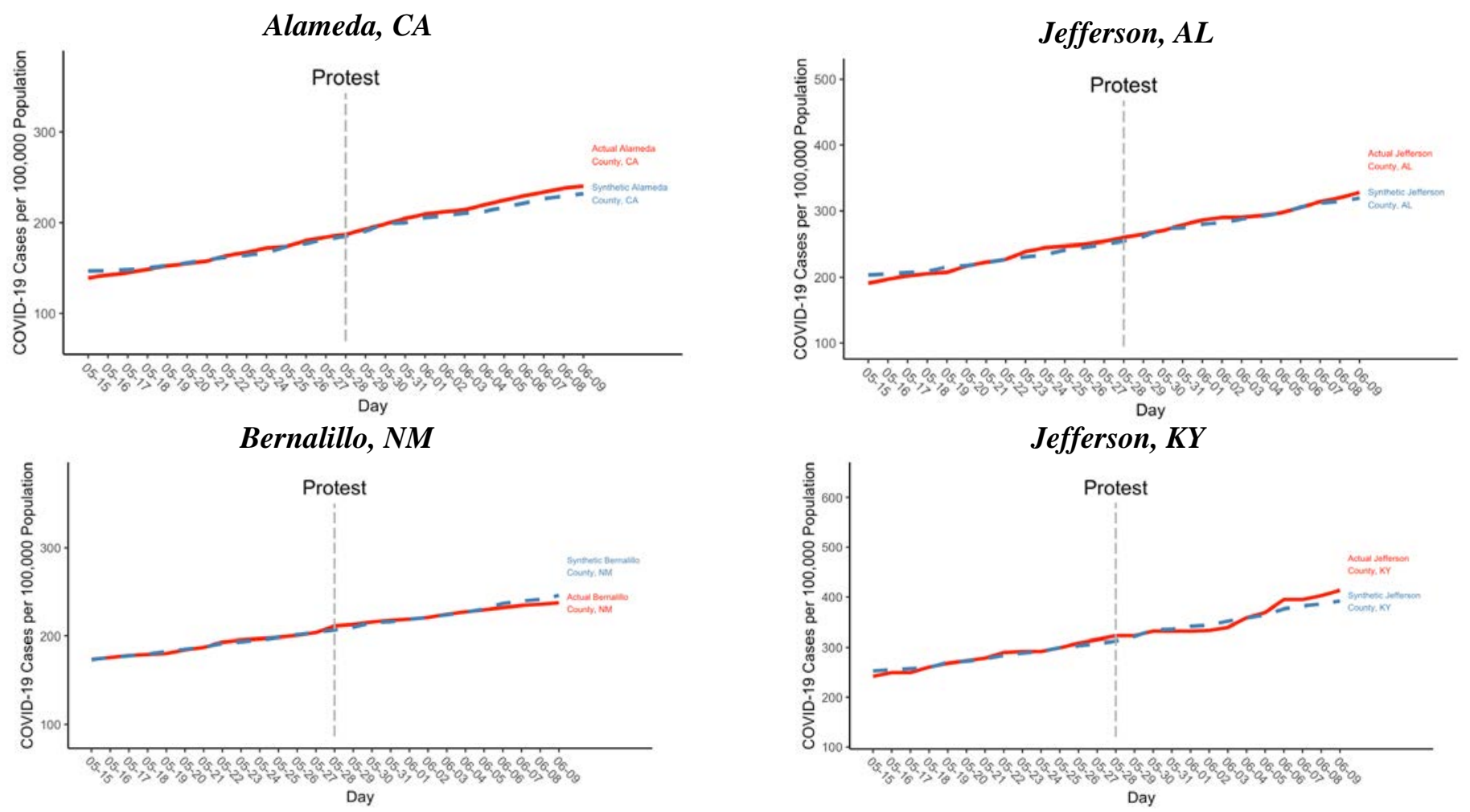

Denver, $\mathrm{CO}$
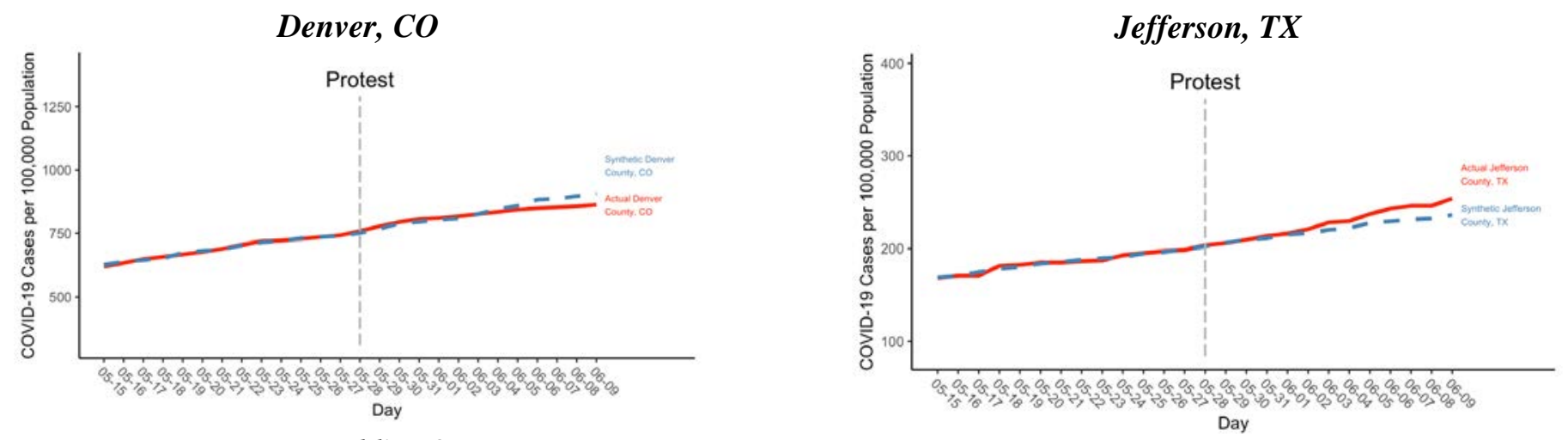

Franklin, $\mathrm{OH}$
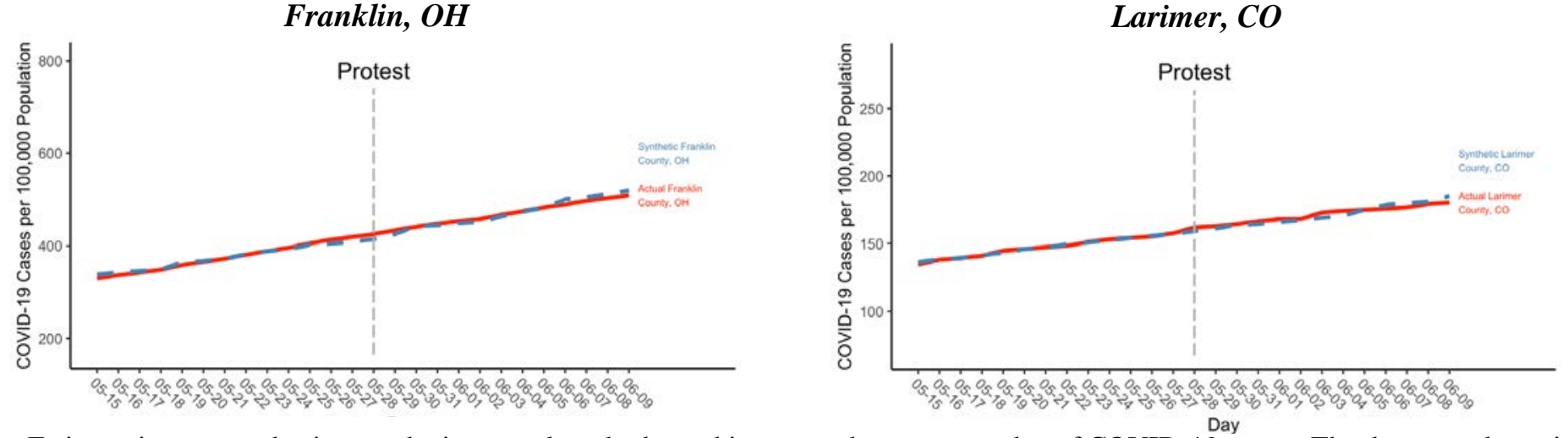

Note: Estimate is generated using synthetic control method matching on each pre-protest day of COVID-19 cases. The donor pool consists of counties where no large (100,000 population) city held a protest or where such a protest took place June 4 or later. 


\section{Appendix Figure 9. Continued}
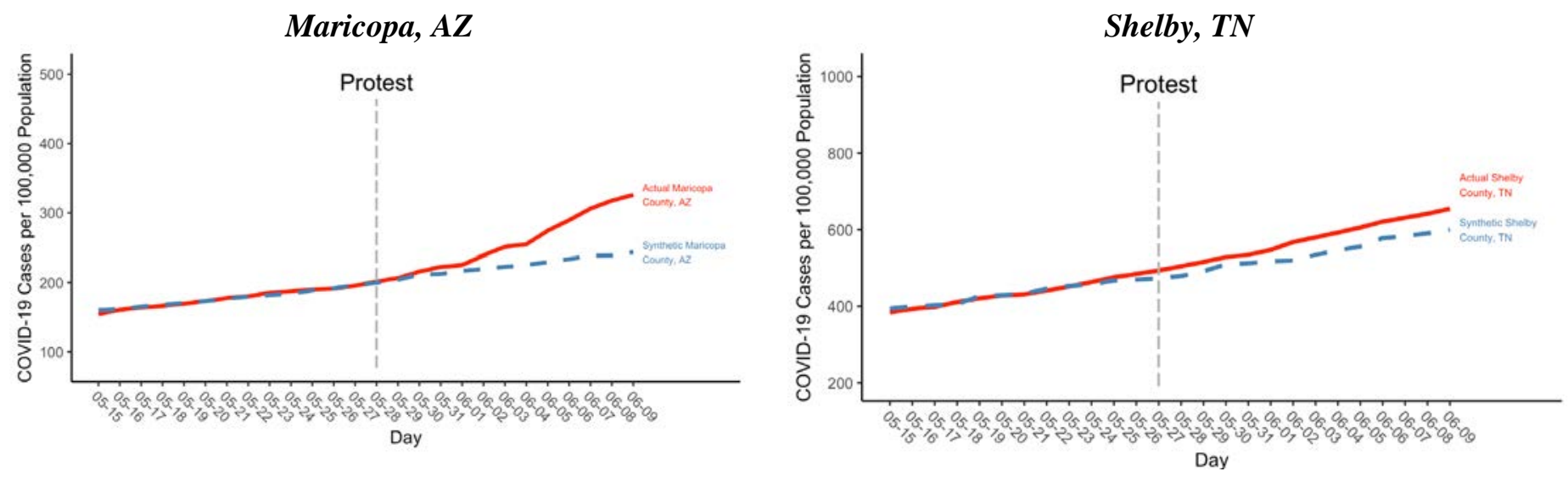

Multnomah, OR
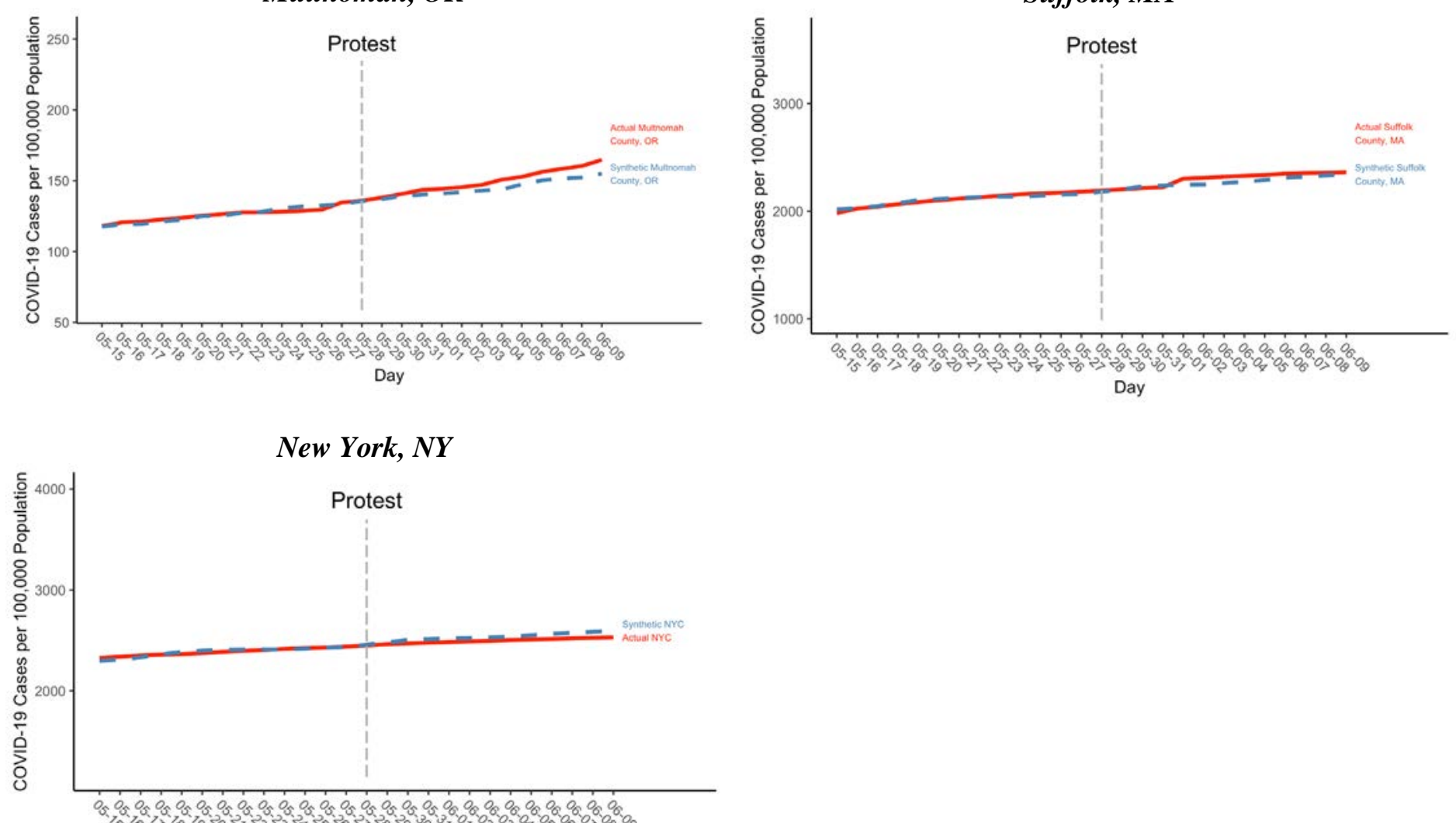

Note: Estimate is generated using synthetic control method matching on each pre-protest day of COVID-19 cases. The donor pool consists of counties where no large (100,000 population) city held a protest or where such a protest took place June 4 or later. 


\section{Appendix Figure 10. Event-Study Analysis of Urban Protests on COVID-19 Death Rate}

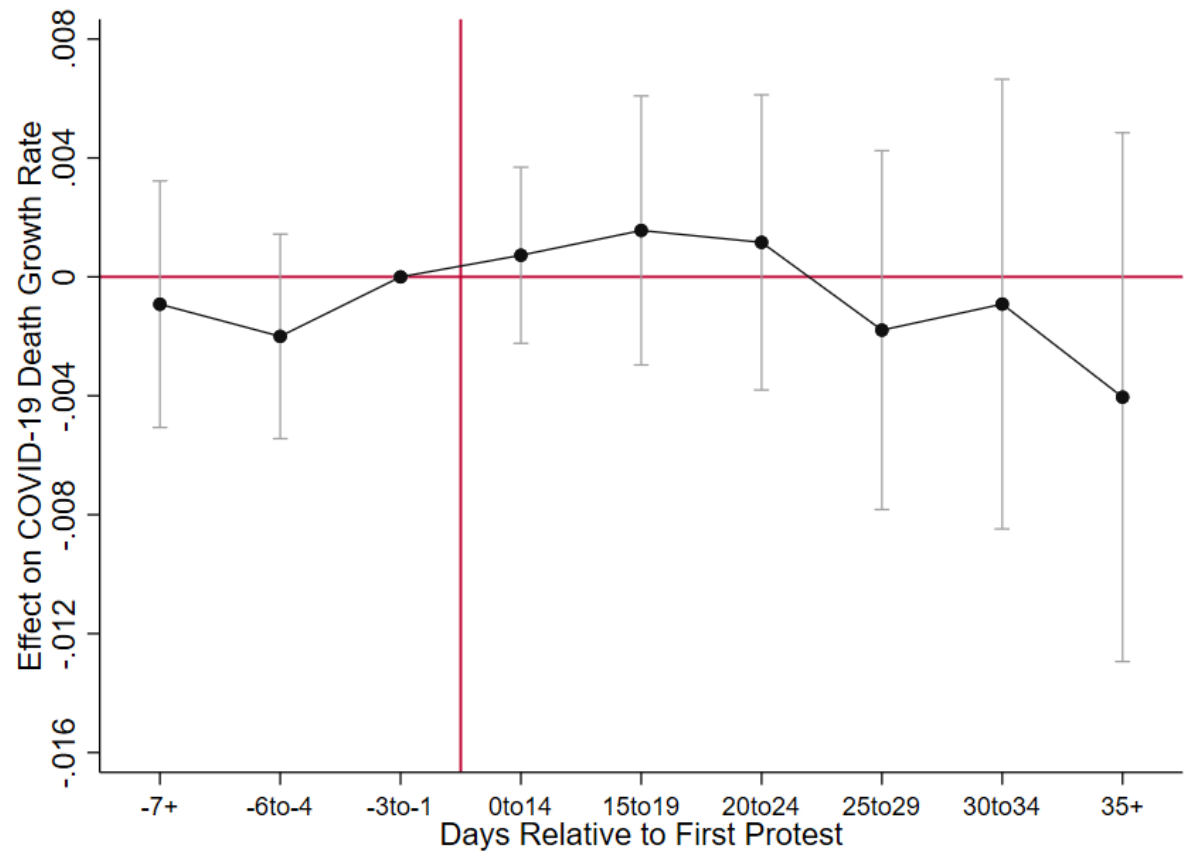

Notes: Estimate is generated using weighted least squares. All models include county and day fixed effects. State-level controls include: log testing rate, indicator for a SIPO, mask mandate, whether food industry reopened, whether retail store reopened, whether personal or pet care services reopened, and whether entertainment or activity reopened. County-level controls include: average temperature and an indicator for whether any precipitation fell. 


\section{Appendix Table 1A. Sensitivity of Difference-in-Differences Estimates of Urban Protests on Social Distancing to Controls for County-Specific Linear Time Trends}

\begin{tabular}{lcc}
\hline & & \\
& Stay-at-Home Full-Time & Median Hours at Home \\
0-1 Days After Protest & $(1)$ & $(2)$ \\
\cline { 2 - 3 } 2-3 Days After Protest & 0.011 & -0.023 \\
& $(0.160)$ & $(0.038)$ \\
4-7 Days After Protest & -0.026 & -0.032 \\
& $(0.182)$ & $(0.062)$ \\
8+ Days After Protest & 0.488 & 0.083 \\
& $(0.493)$ & $(0.146)$ \\
N & 0.192 & -0.007 \\
Controls & $(0.536)$ & $(0.176)$ \\
& & 6210 \\
\hline
\end{tabular}

* Significant at the $10 \%$ level, ** Significant at the 5\% level, *** Significant at the $1 \%$ level

Notes: Estimate is generated using weighted least squares. All models include county and day fixed effects as well as county specific linear time trends. State-level controls include: log testing rate, indicator for a SIPO, mask mandate, whether food industry reopened, whether retail store reopened, whether personal or pet care services reopened, and whether entertainment or activity reopened. County-level controls include: average temperature and an indicator for whether any precipitation fell. Standard errors, clustered at the county-level, are reported inside the parentheses. 


\section{Appendix Table 1B. Sensitivity of Difference-in-Differences Estimates to Inclusion of State- by-Day Fixed Effects}

\begin{tabular}{lcc}
\hline & Stay-at-Home Full-Time & Median Hours at Home \\
& & $(1)$ \\
\cline { 2 - 3 } 0-1 Days After Protest & 0.070 & -0.016 \\
& $(0.111)$ & $(0.030)$ \\
2-3 Days After Protest & -0.215 & -0.065 \\
& $(0.142)$ & $(0.041)$ \\
4-7 Days After Protest & 0.414 & $0.113^{*}$ \\
& $(0.280)$ & $(0.068)$ \\
8+ Days After Protest & $0.469^{*}$ & $0.144^{* *}$ \\
& $(0.239)$ & $(0.069)$ \\
N & & \\
Controls & 6210 & 6210 \\
Yes & Yes \\
\hline sicant at the 10\% level, ** Significant at the 5\% level, *** Significant at the 1\% level
\end{tabular}

* Significant at the $10 \%$ level, ${ }^{* *}$ Significant at the $5 \%$ level, ${ }^{* * *}$ Significant at the $1 \%$ level

Notes: Estimate is generated using weighted least squares. All models include county and day fixed effects. State-level controls include: log testing rate, indicator for a SIPO, mask mandate, whether food industry reopened, whether retail store reopened, whether personal or pet care services reopened, and whether entertainment or activity reopened. County-level controls include: average temperature and an indicator for whether any precipitation fell. Standard errors, clustered at the primary treatment county-level, are reported inside the parentheses. 


\section{Appendix Table 2. Sensitivity of Difference-in-Differences Estimates of Urban Protests on Social Distancing to Inclusion of Border Counties}

\begin{tabular}{lccc}
\hline & Stay-at-Home Full-Time & $\begin{array}{c}\text { Median Percent Time } \\
\text { Spent at Home }\end{array}$ & Median Hours at Home \\
& $(1)$ & $(2)$ & $(3)$ \\
\cline { 2 - 3 } 0-1 Days After Protest & 0.020 & 0.303 & $(0.053)$ \\
& $(0.144)$ & $(0.215)$ & 0.020 \\
2-3 Days After Protest & -0.075 & -0.057 & $(0.043)$ \\
& $(0.165)$ & $(0.189)$ & $0.140 *$ \\
4-7 Days After Protest & $0.470 *$ & $0.426 *$ & $(0.074)$ \\
8+ Days After Protest & $(0.289)$ & $(0.262)$ & $0.130^{*}$ \\
& 0.210 & 0.387 & $(0.070)$ \\
N & $(0.276)$ & $(0.411)$ & 29430 \\
Controls & 29430 & 29430 & Yes \\
\hline
\end{tabular}

* Significant at the $10 \%$ level, ** Significant at the 5\% level, *** Significant at the $1 \%$ level

Notes: Estimate is generated using weighted least squares. All models include county and day fixed effects. State-level controls include: log testing rate, indicator for a SIPO, mask mandate, whether food industry reopened, whether retail store reopened, whether personal or pet care services reopened, and whether entertainment or activity reopened. County-level controls include: average temperature and an indicator for whether any precipitation fell. Standard errors, clustered at the primary treatment county-level, are reported inside the parentheses. 
Appendix Table 3. Heterogeneity in the Effects of Urban Protests on Social Distancing

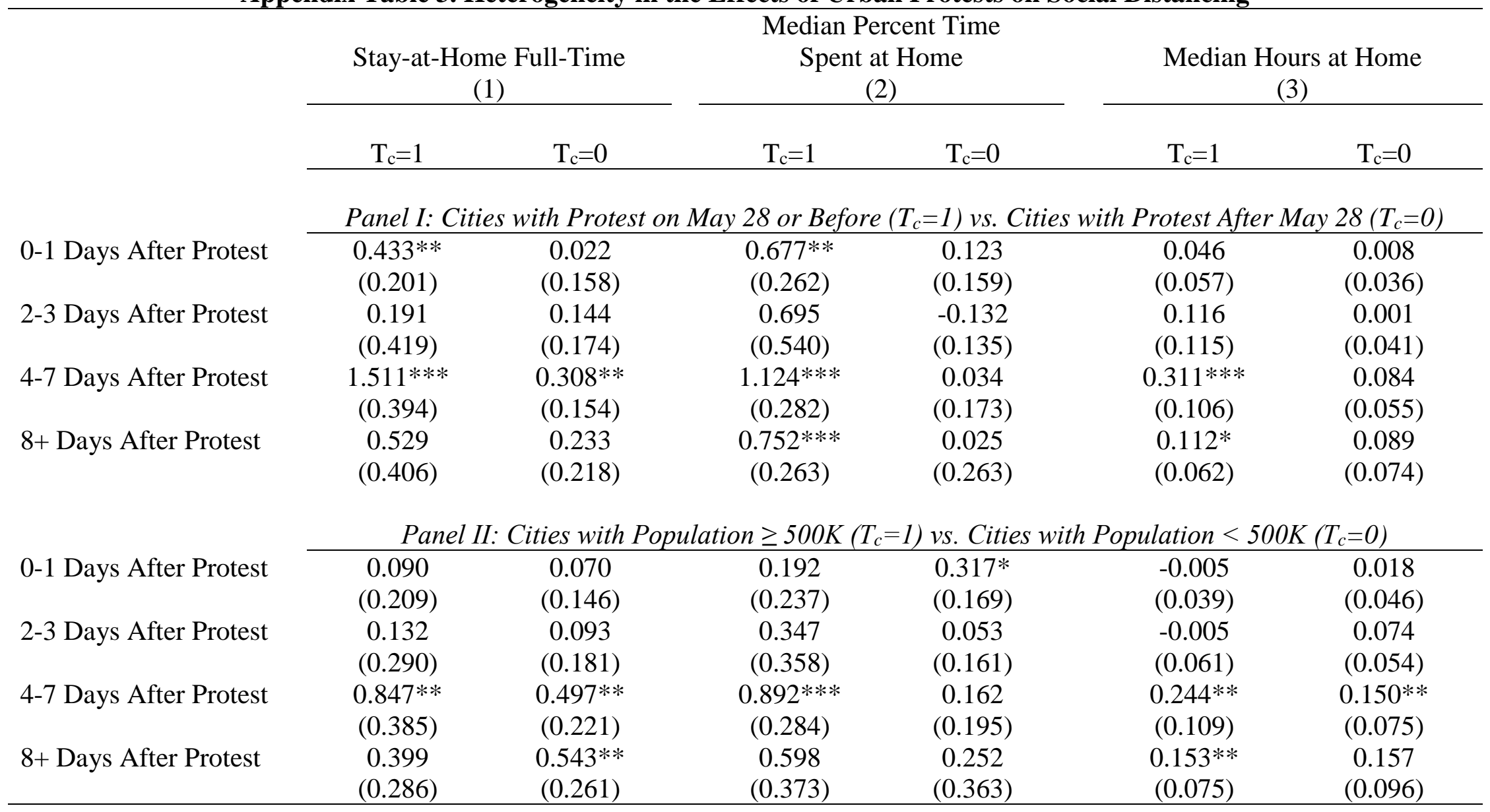




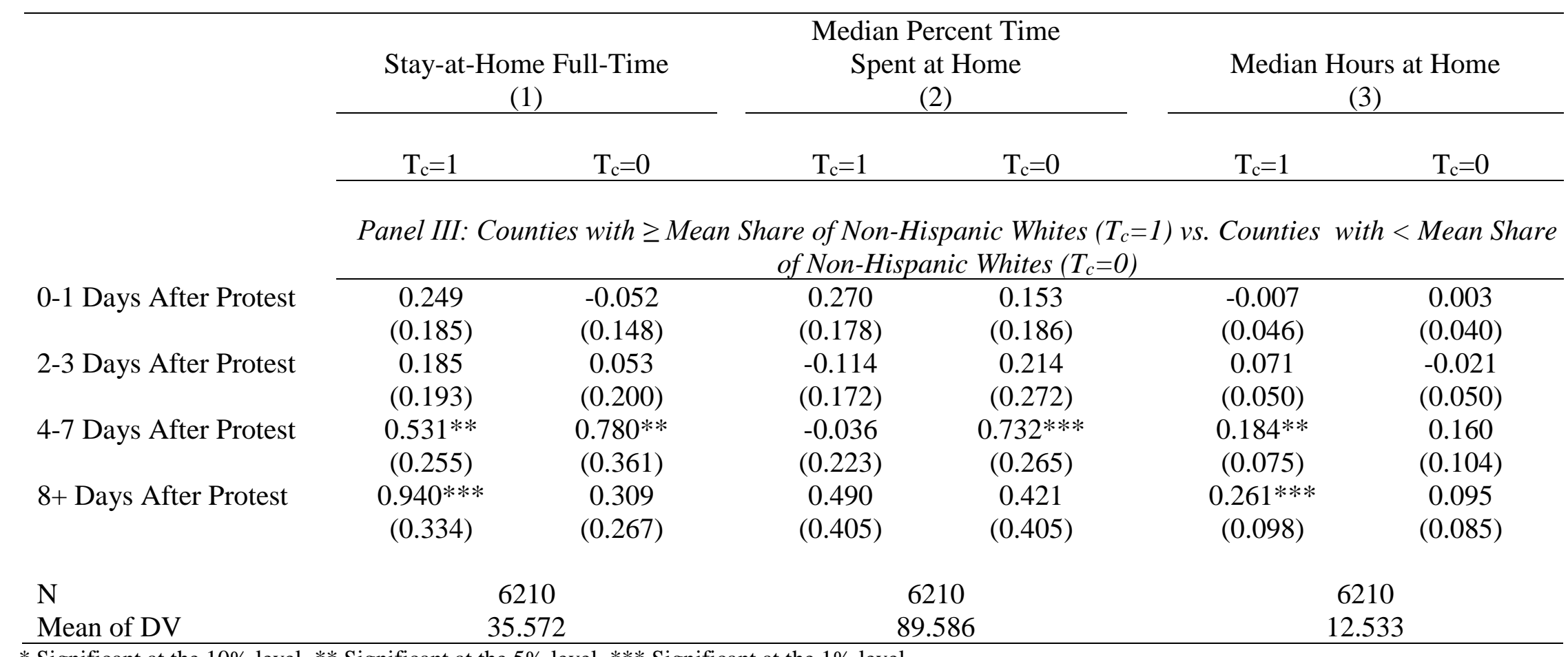

* Significant at the $10 \%$ level, ** Significant at the $5 \%$ level, *** Significant at the $1 \%$ level

Notes: Estimate is generated using weighted least squares. All models include county and day fixed effects. State-level controls include: log testing rate, indicator for a SIPO, mask mandate, whether food industry reopened, whether retail store reopened, whether personal or pet care services reopened, and whether entertainment or activity reopened. County-level controls include: average temperature and an indicator for whether any precipitation fell. Standard errors, clustered at the county-level, are reported inside the parentheses. 
Appendix Table 4. Heterogeneity in the Effects of Urban Protests on Foot Traffic

\begin{tabular}{|c|c|c|c|c|c|c|}
\hline & \multicolumn{2}{|c|}{$\begin{array}{c}\text { Restaurant }+ \text { Bar } \\
(1) \\
\end{array}$} & \multicolumn{2}{|c|}{$\begin{array}{c}\text { Retail } \\
\text { (2) }\end{array}$} & \multicolumn{2}{|c|}{$\begin{array}{c}\text { Business } \\
\text { (3) }\end{array}$} \\
\hline & $\mathrm{T}_{\mathrm{C}}=1$ & $\mathrm{~T}_{\mathrm{C}}=0$ & $\mathrm{~T}_{\mathrm{C}}=1$ & $\mathrm{~T}_{\mathrm{C}}=0$ & $\mathrm{~T}_{\mathrm{C}}=1$ & $\mathrm{~T}_{\mathrm{C}}=0$ \\
\hline & \multicolumn{6}{|c|}{$\begin{array}{c}\text { Panel I: Cities with Violent Protests }\left(T_{C}=1\right) \text { vs. } \\
\text { Cities with Peaceful Protests }\left(T_{c}=0\right)\end{array}$} \\
\hline 0-1 Days After Protest & $\begin{array}{c}0.000 \\
(0.008)\end{array}$ & $\begin{array}{c}-0.024 * * \\
(0.011)\end{array}$ & $\begin{array}{c}0.011 \\
(0.008)\end{array}$ & $\begin{array}{l}-0.002 \\
(0.008)\end{array}$ & $\begin{array}{c}0.011 \\
(0.008)\end{array}$ & $\begin{array}{l}-0.013 \\
(0.014)\end{array}$ \\
\hline 2-3 Days After Protest & $\begin{array}{c}-0.024 * * \\
(0.012)\end{array}$ & $\begin{array}{c}-0.041 * * * \\
(0.016)\end{array}$ & $\begin{array}{c}-0.022 * * \\
(0.009)\end{array}$ & $\begin{array}{l}-0.023^{*} \\
(0.013)\end{array}$ & $\begin{array}{l}-0.012 \\
(0.015)\end{array}$ & $\begin{array}{l}-0.009 \\
(0.023)\end{array}$ \\
\hline 4-7 Days After Protest & $\begin{array}{l}-0.041 \\
(0.027)\end{array}$ & $\begin{array}{l}-0.039 \\
(0.024)\end{array}$ & $\begin{array}{l}-0.036 \\
(0.022)\end{array}$ & $\begin{array}{l}-0.021 \\
(0.020)\end{array}$ & $\begin{array}{l}-0.042 \\
(0.036)\end{array}$ & $\begin{array}{l}-0.021 \\
(0.034)\end{array}$ \\
\hline 8+ Days After Protest & $\begin{array}{l}-0.050 * \\
(0.027)\end{array}$ & $\begin{array}{c}-0.066^{* *} \\
(0.028)\end{array}$ & $\begin{array}{l}-0.034 \\
(0.021)\end{array}$ & $\begin{array}{l}-0.043^{*} \\
(0.023)\end{array}$ & $\begin{array}{l}-0.030 \\
(0.038)\end{array}$ & $\begin{array}{l}-0.041 \\
(0.041)\end{array}$ \\
\hline & \multicolumn{6}{|c|}{$\begin{array}{c}\text { Panel II: Cities with Persistent Protests }\left(T_{C}=1\right) \text { vs. } \\
\text { Cities with Temporary Protests }\left(T_{C}=0\right)\end{array}$} \\
\hline 0-1 Days After Protest & $\begin{array}{l}-0.004 \\
(0.007)\end{array}$ & $\begin{array}{c}-0.026 * * \\
(0.012)\end{array}$ & $\begin{array}{c}0.011 \\
(0.007)\end{array}$ & $\begin{array}{l}-0.012 \\
(0.010)\end{array}$ & $\begin{array}{c}0.011 \\
(0.008)\end{array}$ & $\begin{array}{l}-0.028 \\
(0.019)\end{array}$ \\
\hline 2-3 Days After Protest & $\begin{array}{c}-0.025 * * \\
(0.011)\end{array}$ & $\begin{array}{c}-0.054 * * * \\
(0.019)\end{array}$ & $\begin{array}{c}-0.020 * * \\
(0.008)\end{array}$ & $\begin{array}{c}-0.039 * * \\
(0.016)\end{array}$ & $\begin{array}{l}-0.007 \\
(0.015)\end{array}$ & $\begin{array}{l}-0.035 \\
(0.028)\end{array}$ \\
\hline 4-7 Days After Protest & $\begin{array}{l}-0.041 \\
(0.026)\end{array}$ & $\begin{array}{c}-0.034 \\
(0.025)\end{array}$ & $\begin{array}{c}-0.035 \\
(0.022)\end{array}$ & $\begin{array}{c}-0.026 \\
(0.021)\end{array}$ & $\begin{array}{c}-0.038 \\
(0.036)\end{array}$ & $\begin{array}{l}-0.039 \\
(0.036)\end{array}$ \\
\hline 8+ Days After Protest & $\begin{array}{l}-0.052 * \\
(0.028)\end{array}$ & $\begin{array}{c}-0.065 * * \\
(0.030) \\
\end{array}$ & $\begin{array}{c}-0.038 * \\
(0.021)\end{array}$ & $\begin{array}{c}-0.055^{* *} \\
(0.024) \\
\end{array}$ & $\begin{array}{c}-0.036 \\
(0.039) \\
\end{array}$ & $\begin{array}{l}-0.062 \\
(0.042) \\
\end{array}$ \\
\hline
\end{tabular}




\begin{tabular}{|c|c|c|c|c|c|c|}
\hline & \multicolumn{2}{|c|}{$\begin{array}{c}\text { Restaurant }+ \text { Bar } \\
(1) \\
\end{array}$} & \multicolumn{2}{|c|}{$\begin{array}{c}\text { Retail } \\
(2) \\
\end{array}$} & \multicolumn{2}{|c|}{$\begin{array}{c}\text { Business } \\
\text { (3) } \\
\end{array}$} \\
\hline & $\mathrm{T}_{\mathrm{C}}=1$ & $\mathrm{~T}_{\mathrm{C}}=0$ & $\mathrm{~T}_{\mathrm{C}}=1$ & $\mathrm{~T}_{\mathrm{C}}=0$ & $\mathrm{~T}_{\mathrm{C}}=1$ & $\mathrm{~T}_{\mathrm{C}}=0$ \\
\hline & \multicolumn{6}{|c|}{$\begin{array}{l}\text { Panel III: Protest Cities with Size }>1,000\left(T_{c}=1\right) \text { vs. } \\
\text { Protest Cities with Size }<1,000\left(T_{c}=0\right)\end{array}$} \\
\hline 0-1 Days After Protest & $\begin{array}{c}-0.005 \\
(0.008)\end{array}$ & $\begin{array}{c}-0.009 \\
(0.009)\end{array}$ & $\begin{array}{c}0.012 \\
(0.007)\end{array}$ & $\begin{array}{l}-0.000 \\
(0.008)\end{array}$ & $\begin{array}{c}0.010 \\
(0.008)\end{array}$ & $\begin{array}{l}-0.002 \\
(0.012)\end{array}$ \\
\hline 2-3 Days After Protest & $\begin{array}{c}-0.025^{* *} \\
(0.012)\end{array}$ & $\begin{array}{l}-0.028 * \\
(0.014)\end{array}$ & $\begin{array}{c}-0.019 * * \\
(0.008)\end{array}$ & $\begin{array}{c}-0.026^{* *} \\
(0.011)\end{array}$ & $\begin{array}{l}-0.005 \\
(0.015)\end{array}$ & $\begin{array}{l}-0.019 \\
(0.020)\end{array}$ \\
\hline 4-7 Days After Protest & $\begin{array}{l}-0.036 \\
(0.027)\end{array}$ & $\begin{array}{l}-0.037^{*} \\
(0.022)\end{array}$ & $\begin{array}{l}-0.031 \\
(0.022)\end{array}$ & $\begin{array}{l}-0.035^{*} \\
(0.019)\end{array}$ & $\begin{array}{l}-0.035 \\
(0.036)\end{array}$ & $\begin{array}{l}-0.038 \\
(0.032)\end{array}$ \\
\hline 8+ Days After Protest & $\begin{array}{l}-0.047 * \\
(0.027) \\
\end{array}$ & $\begin{array}{c}-0.061^{* *} \\
(0.026) \\
\end{array}$ & $\begin{array}{l}-0.036^{*} \\
(0.020) \\
\end{array}$ & $\begin{array}{c}-0.049 * * \\
(0.022)\end{array}$ & $\begin{array}{l}-0.031 \\
(0.037) \\
\end{array}$ & $\begin{array}{l}-0.048 \\
(0.040) \\
\end{array}$ \\
\hline & \multicolumn{6}{|c|}{ Panel IV: Cities with a Curfew $\left(T_{c}=1\right)$ vs. Cities without a Curfew $\left(T_{c}=0\right)$} \\
\hline 0-1 Days After Protest & $\begin{array}{c}-0.003 \\
(0.009)\end{array}$ & $\begin{array}{c}-0.016 \\
(0.010)\end{array}$ & $\begin{array}{c}0.012 \\
(0.008)\end{array}$ & $\begin{array}{c}0.000 \\
(0.007)\end{array}$ & $\begin{array}{c}0.012 \\
(0.009)\end{array}$ & $\begin{array}{l}-0.005 \\
(0.011)\end{array}$ \\
\hline 2-3 Days After Protest & $\begin{array}{c}-0.031^{* *} \\
(0.013)\end{array}$ & $\begin{array}{c}-0.021^{*} \\
(0.012)\end{array}$ & $\begin{array}{c}-0.025^{* * *} \\
(0.009)\end{array}$ & $\begin{array}{l}-0.012 \\
(0.010)\end{array}$ & $\begin{array}{c}-0.014 \\
(0.015)\end{array}$ & $\begin{array}{c}0.001 \\
(0.018)\end{array}$ \\
\hline 4-7 Days After Protest & $\begin{array}{l}-0.042 \\
(0.027)\end{array}$ & $\begin{array}{l}-0.027 \\
(0.021)\end{array}$ & $\begin{array}{l}-0.032 \\
(0.022)\end{array}$ & $\begin{array}{l}-0.025 \\
(0.018)\end{array}$ & $\begin{array}{c}-0.037 \\
(0.036)\end{array}$ & $\begin{array}{l}-0.023 \\
(0.031)\end{array}$ \\
\hline 8+ Days After Protest & $\begin{array}{l}-0.046^{*} \\
(0.026)\end{array}$ & $\begin{array}{c}-0.053^{* *} \\
(0.026)\end{array}$ & $\begin{array}{l}-0.030 \\
(0.020)\end{array}$ & $\begin{array}{c}-0.046^{* *} \\
(0.021)\end{array}$ & $\begin{array}{c}-0.023 \\
(0.037)\end{array}$ & $\begin{array}{l}-0.045 \\
(0.039)\end{array}$ \\
\hline
\end{tabular}




\begin{tabular}{|c|c|c|c|c|c|c|}
\hline & \multicolumn{2}{|c|}{$\begin{array}{c}\text { Restaurant }+ \text { Bar } \\
\text { (1) }\end{array}$} & \multicolumn{2}{|c|}{$\begin{array}{c}\text { Retail } \\
(2)\end{array}$} & \multicolumn{2}{|c|}{$\begin{array}{c}\text { Business } \\
\text { (3) }\end{array}$} \\
\hline & $\mathrm{T}_{\mathrm{C}}=1$ & $\mathrm{~T}_{\mathrm{C}}=0$ & $\mathrm{~T}_{\mathrm{C}}=1$ & $\mathrm{~T}_{\mathrm{C}}=0$ & $\mathrm{~T}_{\mathrm{C}}=1$ & $\mathrm{~T}_{\mathrm{C}}=0$ \\
\hline & \multicolumn{6}{|c|}{ States with a Mask Mandate $\left(T_{c}=1\right)$ vs. States without a Mask Mandate $\left(T_{c}=0\right)$} \\
\hline 0-1 Days After Protest & $\begin{array}{c}-0.002 \\
(0.009)\end{array}$ & $\begin{array}{c}-0.010 \\
(0.010)\end{array}$ & $\begin{array}{c}0.018 * * \\
(0.008)\end{array}$ & $\begin{array}{c}0.002 \\
(0.008)\end{array}$ & $\begin{array}{c}0.017 \\
(0.011)\end{array}$ & $\begin{array}{l}-0.001 \\
(0.009)\end{array}$ \\
\hline 2-3 Days After Protest & $\begin{array}{c}-0.028 * * \\
(0.013)\end{array}$ & $\begin{array}{c}-0.025^{*} \\
(0.013)\end{array}$ & $\begin{array}{c}-0.008 \\
(0.012)\end{array}$ & $\begin{array}{c}-0.029 * * * \\
(0.008)\end{array}$ & $\begin{array}{c}0.003 \\
(0.016)\end{array}$ & $\begin{array}{l}-0.015 \\
(0.016)\end{array}$ \\
\hline 4-7 Days After Protest & $\begin{array}{l}-0.021 \\
(0.021)\end{array}$ & $\begin{array}{c}-0.047^{*} \\
(0.027)\end{array}$ & $\begin{array}{c}-0.012 \\
(0.017)\end{array}$ & $\begin{array}{c}-0.042^{* *} \\
(0.021)\end{array}$ & $\begin{array}{l}-0.013 \\
(0.029)\end{array}$ & $\begin{array}{l}-0.046 \\
(0.036)\end{array}$ \\
\hline 8+ Days After Protest & $\begin{array}{l}-0.046^{*} \\
(0.025)\end{array}$ & $\begin{array}{l}-0.050 * \\
(0.026)\end{array}$ & $\begin{array}{l}-0.028 \\
(0.020)\end{array}$ & $\begin{array}{c}-0.038 * * \\
(0.018)\end{array}$ & $\begin{array}{c}-0.028 \\
(0.038)\end{array}$ & $\begin{array}{l}-0.031 \\
(0.035)\end{array}$ \\
\hline $\mathrm{N}$ & \multicolumn{2}{|c|}{6210} & \multicolumn{2}{|c|}{6210} & \multicolumn{2}{|c|}{6210} \\
\hline Mean of DV & \multicolumn{2}{|c|}{35.572} & \multicolumn{2}{|c|}{89.586} & \multicolumn{2}{|c|}{12.533} \\
\hline
\end{tabular}

* Significant at the $10 \%$ level, ** Significant at the $5 \%$ level, *** Significant at the $1 \%$ level

Notes: Estimate is generated using weighted least squares. The outcome is inverse hyperbolic sine of the foot-traffic measures. All models include county and day fixed effects. State-level controls include: log testing rate, indicator for a SIPO, mask mandate, whether food industry reopened, whether retail store reopened, whether personal or pet care services reopened, and whether entertainment or activity reopened. County-level controls include: average temperature and an indicator for whether any precipitation fell. Standard errors, clustered at the county-level, are reported inside the parenthesis. 


\section{Appendix Table 5. Estimated Effect of Urban Protests on Social Distancing, by Pre-George Floyd Death (May 10-24) County-Level COVID-19 Growth Rate}

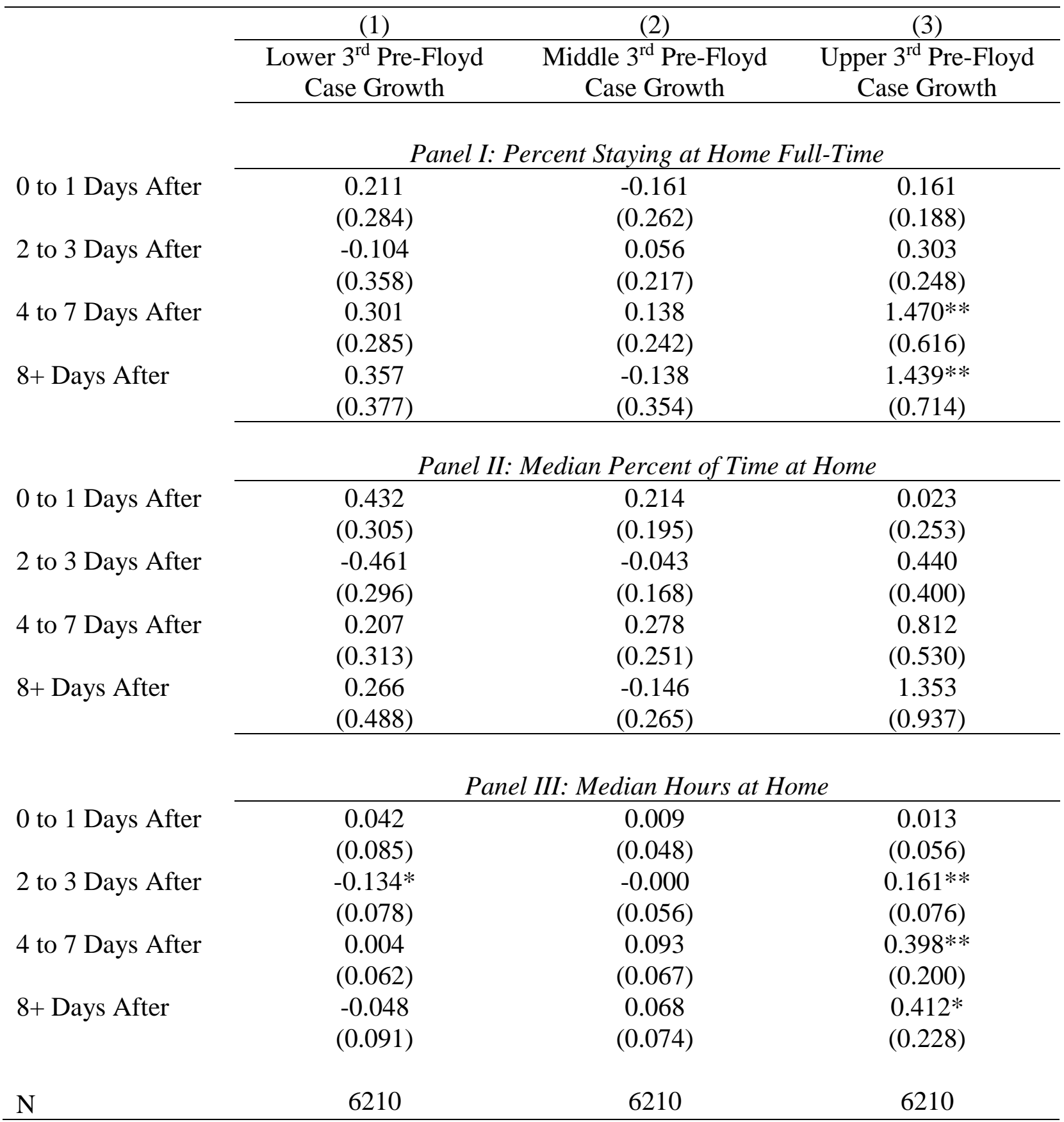

* Significant at the $10 \%$ level, ** Significant at the $5 \%$ level, *** Significant at the $1 \%$ level

Notes: Estimate is generated using weighted least squares. All models include county and day fixed effects. Statelevel controls include: log testing rate, indicator for a SIPO, mask mandate, whether food industry reopened, whether retail store reopened, whether personal or pet care services reopened, and whether entertainment or activity reopened. County-level controls include: average temperature and an indicator for whether any precipitation fell. Standard errors, clustered at the county-level, are reported inside the parentheses. Pre-treatment growth is defined as the change in COVID-19 case rate between May 10 and May 24. 


\section{Appendix Table 6. Sensitivity of Difference-in-Differences Estimates of Urban Protests on Cases to Inclusion of Border Counties}

\begin{tabular}{lc}
\hline & $(1)$ \\
0-5 Days After Protest & 0.0013 \\
6-14 Days After Protest & $(0.0012)$ \\
& 0.0024 \\
15-19 Days After Protest & $(0.0018)$ \\
20-24 Days After Protest & 0.0025 \\
& $(0.0024)$ \\
25-29 Days After Protest & 0.0017 \\
& $(0.0029)$ \\
30-34 Days After Protest & 0.0016 \\
& $(0.0033)$ \\
35+ Days After Protest & -0.0016 \\
& $(0.0038)$ \\
N & -0.0061 \\
\end{tabular}

* Significant at the $10 \%$ level, ${ }^{* *}$ Significant at the $5 \%$ level, ${ }^{* * *}$ Significant at the $1 \%$ level

Notes: Estimate is generated using weighted least squares. All models include county and day fixed effects. State-level controls include: log testing rate, indicator for a SIPO, mask mandate, whether food industry reopened, whether retail store reopened, whether personal or pet care services reopened, and whether entertainment or activity reopened. Countylevel controls include: average temperature and an indicator for whether any precipitation fell. Standard errors, clustered at the primary treatment county-level, are reported inside the parentheses. 


\section{Appendix Table 7A. Sensitivity of Difference-in-Differences Estimates of Urban Protests on Cases to Controls for County-Specific Linear Time Trends}

\begin{tabular}{lc}
\hline & $(1)$ \\
\cline { 2 - 2 } 0-5 Days After Protest & Panel I: COVID-19 Case Growth Rate \\
\cline { 2 - 2 } 6-14 Days After Protest & -0.0007 \\
& $(0.0008)$ \\
15-19 Days After Protest & -0.0010 \\
& $(0.0014)$ \\
20-24 Days After Protest & -0.0013 \\
& $(0.0021)$ \\
25-29 Days After Protest & -0.0012 \\
& $(0.0029)$ \\
30-34 Days After Protest & 0.0001 \\
& $(0.0030)$ \\
35+ Days After Protest & -0.0017 \\
& $(0.0036)$ \\
N & -0.0041 \\
& $(0.0037)$ \\
0-14 Days After Protest & 11178 \\
15-19 Days After Protest & \\
20-24 Days After Protest & Panel II: COVID-19 Death Growth Rate \\
\cline { 2 - 2 } 25-29 Days After Protest & 0.0000 \\
30-34 Days After Protest & $(0.0014)$ \\
35+ Days After Protest & 0.0001 \\
& $(0.0022)$ \\
N & -0.0004 \\
* Significant at the 10\% level ** Significant at the 5\% level *** Significant at the 1\% level & $(0.0024)$ \\
& -0.0033 \\
& $(0.0030)$ \\
& -0.0018 \\
& $(0.0037)$ \\
& -0.0031 \\
& $(0.0043)$ \\
& \\
&
\end{tabular}

* Significant at the $10 \%$ level, ${ }^{* *}$ Significant at the 5\% level, *** Significant at the $1 \%$ level

Notes: Estimate is generated using weighted least squares. All models include county and day fixed effects, as well as county-specific linear time trend. State-level controls include: log testing rate, indicator for a SIPO, mask mandate, whether food industry reopened, whether retail store reopened, whether personal or pet care services reopened, and whether entertainment or activity reopened. County-level controls include: average temperature and an indicator for whether any precipitation fell. Standard errors, clustered at the county-level, are reported inside the parentheses. 


\section{Appendix Table 7B. Sensitivity of Difference-in-Differences Estimates to Inclusion of State- by-Day Fixed Effects}

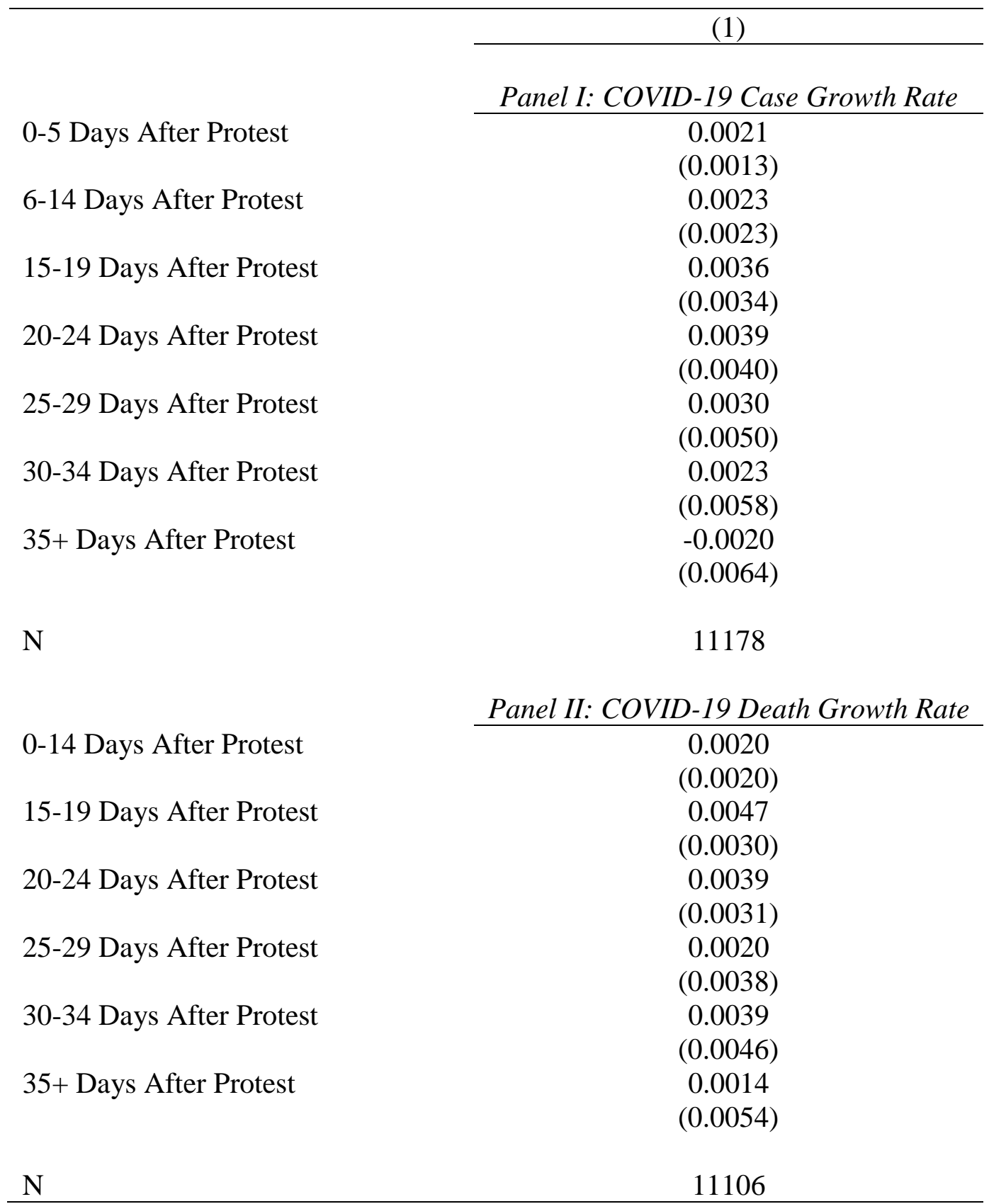

* Significant at the $10 \%$ level, ** Significant at the 5\% level, *** Significant at the $1 \%$ level

Notes: Estimate is generated using weighted least squares. All models include county and day fixed effects. State-level controls include: log testing rate, indicator for a SIPO, mask mandate, whether food industry reopened, whether retail store reopened, whether personal or pet care services reopened, and whether entertainment or activity reopened.

County-level controls include: average temperature and an indicator for whether any precipitation fell. Standard errors, clustered at the primary treatment county-level, are reported inside the parentheses. 


\begin{tabular}{|c|c|c|}
\hline & $\begin{array}{l}(1) \\
\mathrm{T}_{\mathrm{C}}=1\end{array}$ & $\begin{array}{c}(2) \\
\mathrm{T}_{\mathrm{C}}=0\end{array}$ \\
\hline & \multicolumn{2}{|c|}{$\begin{array}{c}\text { Panel I: Cities with Protest on May } 28 \text { or Before }\left(T_{c}=1\right) \text { vs. Cities with } \\
\text { Protest After May } 28\left(T_{c}=0\right)\end{array}$} \\
\hline 0-5 Days After Protest & $\begin{array}{c}0.0014 \\
(0.0022)\end{array}$ & $\begin{array}{l}-0.0001 \\
(0.0012)\end{array}$ \\
\hline 6-14 Days After Protest & $\begin{array}{c}0.0000 \\
(0.0040)\end{array}$ & $\begin{array}{l}-0.0001 \\
(0.0020)\end{array}$ \\
\hline 15-19 Days After Protest & $\begin{array}{l}-0.0010 \\
(0.0049)\end{array}$ & $\begin{array}{l}-0.0002 \\
(0.0029)\end{array}$ \\
\hline 20-24 Days After Protest & $\begin{array}{l}-0.0030 \\
(0.0069)\end{array}$ & $\begin{array}{l}-0.0004 \\
(0.0034)\end{array}$ \\
\hline 25-29 Days After Protest & $\begin{array}{l}-0.0042 \\
(0.0047)\end{array}$ & $\begin{array}{c}0.0016 \\
(0.0043)\end{array}$ \\
\hline 30-34 Days After Protest & $\begin{array}{l}-0.0062 \\
(0.0054)\end{array}$ & $\begin{array}{l}-0.0006 \\
(0.0047)\end{array}$ \\
\hline \multirow[t]{2}{*}{ 35+ Days After Protest } & $\begin{array}{l}-0.0108 \\
(0.0068)\end{array}$ & $\begin{array}{l}-0.0044 \\
(0.0052)\end{array}$ \\
\hline & \multicolumn{2}{|c|}{$\begin{array}{c}\text { Panel II: Cities with Population } \geq 500 K\left(T_{c}=1\right) \text { vs. Cities with } \\
\text { Population }<500 K\left(T_{c}=0\right)\end{array}$} \\
\hline 0-5 Days After Protest & $\begin{array}{c}0.0015 \\
(0.0013)\end{array}$ & $\begin{array}{c}0.0003 \\
(0.0013)\end{array}$ \\
\hline 6-14 Days After Protest & $\begin{array}{c}0.0012 \\
(0.0024)\end{array}$ & $\begin{array}{c}0.0007 \\
(0.0021)\end{array}$ \\
\hline 15-19 Days After Protest & $\begin{array}{c}0.0003 \\
(0.0032)\end{array}$ & $\begin{array}{c}0.0019 \\
(0.0030)\end{array}$ \\
\hline 20-24 Days After Protest & $\begin{array}{l}0.0017 \\
(0.0045)\end{array}$ & $\begin{array}{l}-0.0002 \\
(0.0033)\end{array}$ \\
\hline 25-29 Days After Protest & $\begin{array}{l}-0.0005 \\
(0.0044)\end{array}$ & $\begin{array}{c}0.0018 \\
(0.0042)\end{array}$ \\
\hline 30-34 Days After Protest & $\begin{array}{l}-0.0024 \\
(0.0049)\end{array}$ & $\begin{array}{l}-0.0022 \\
(0.0048)\end{array}$ \\
\hline 35+ Days After Protest & $\begin{array}{l}-0.0095 \\
(0.0065)\end{array}$ & $\begin{array}{l}-0.0057 \\
(0.0054)\end{array}$ \\
\hline
\end{tabular}




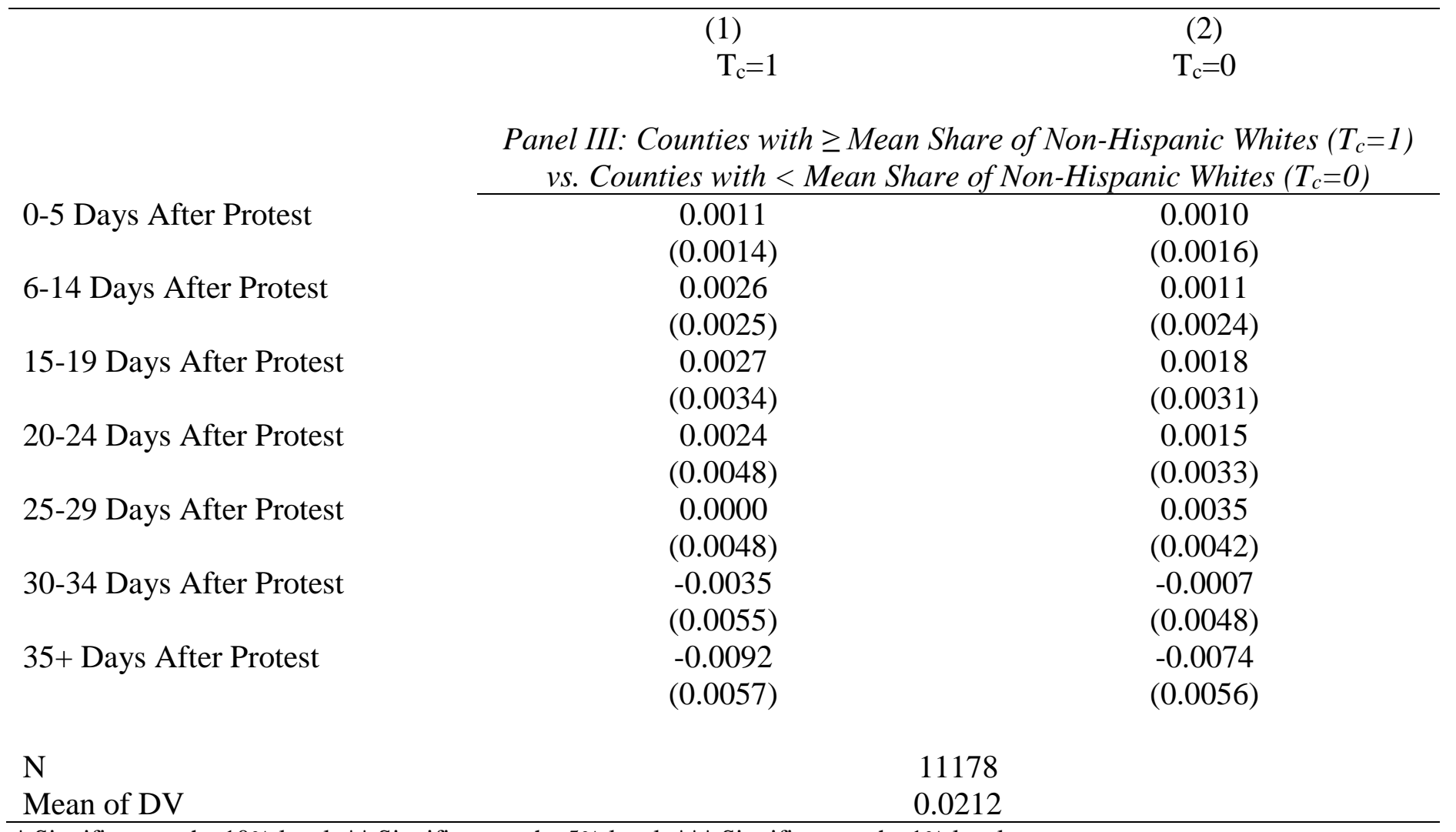

* Significant at the $10 \%$ level, ** Significant at the 5\% level, *** Significant at the $1 \%$ level

Notes: Estimate is generated using weighted least squares. All models include county and day fixed effects. State-level controls include: log testing rate, indicator for a SIPO, mask mandate, whether food industry reopened, whether retail store reopened, whether personal or pet care services reopened, and whether entertainment or activity reopened. County-level controls include: average temperature and an indicator for whether any precipitation fell. Standard errors, clustered at the county-level, are reported inside the parentheses. 


\section{Appendix Table 9. Estimated Effect of Urban Protests on COVID-19 Case Growth Rate, by Pre-George Floyd Death (May 10-24) County-Level COVID-19 Growth Rate}

\begin{tabular}{|c|c|c|c|}
\hline & $(1)$ & $(2)$ & (3) \\
\hline & $\begin{array}{c}\text { Lower } 3^{\text {rd }} \\
\text { Pre-Floyd Case Growth }\end{array}$ & $\begin{array}{l}\text { Middle } 3^{\text {rd }} \\
\text { Pre-Floyd Case Growth }\end{array}$ & $\begin{array}{c}\text { Upper } 3^{\text {rd }} \\
\text { Pre-Floyd Case Growth }\end{array}$ \\
\hline 0 to 5 Days After & $\begin{array}{c}-0.0004 \\
(0.0019)\end{array}$ & $\begin{array}{c}0.0011 \\
(0.0015)\end{array}$ & $\begin{array}{c}-0.0008 \\
(0.0024)\end{array}$ \\
\hline 6 to 14 Days After & $\begin{array}{c}-0.0015 \\
(0.0031)\end{array}$ & $\begin{array}{c}0.0016 \\
(0.0024)\end{array}$ & $\begin{array}{c}-0.0014 \\
(0.0038)\end{array}$ \\
\hline 15 to 19 Days After & $\begin{array}{c}-0.0021 \\
(0.0045)\end{array}$ & $\begin{array}{c}0.0024 \\
(0.0033)\end{array}$ & $\begin{array}{c}0.0000 \\
(0.0049)\end{array}$ \\
\hline 20 to 24 Days After & $\begin{array}{l}-0.0054 \\
(0.0053)\end{array}$ & $\begin{array}{c}0.0031 \\
(0.0029)\end{array}$ & $\begin{array}{c}0.0026 \\
(0.0060)\end{array}$ \\
\hline 25 to 29 Days After & $\begin{array}{c}-0.0055 \\
(0.0060)\end{array}$ & $\begin{array}{c}0.0063 \\
(0.0039)\end{array}$ & $\begin{array}{c}0.0018 \\
(0.0072)\end{array}$ \\
\hline 30 to 34 Days After & $\begin{array}{c}-0.0055 \\
(0.0063)\end{array}$ & $\begin{array}{c}0.0044 \\
(0.0041)\end{array}$ & $\begin{array}{c}-0.0020 \\
(0.0085)\end{array}$ \\
\hline 35+ Days After & $\begin{array}{l}-0.0073 \\
(0.0065)\end{array}$ & $\begin{array}{c}0.0025 \\
(0.0049)\end{array}$ & $\begin{array}{l}-0.0117 \\
(0.0080)\end{array}$ \\
\hline $\mathrm{N}$ & 11718 & 11718 & 11718 \\
\hline
\end{tabular}

* Significant at the $10 \%$ level, ** Significant at the $5 \%$ level, *** Significant at the $1 \%$ level

Notes: Estimate is generated using weighted least squares. All models include county and day fixed effects. Statelevel controls include: log testing rate, indicator for a SIPO, mask mandate, whether food industry reopened, whether retail store reopened, whether personal or pet care services reopened, and whether entertainment or activity reopened. County-level controls include: average temperature and an indicator for whether any precipitation fell. Standard errors, clustered at the county-level, are reported inside the parentheses. Pre-treatment growth is defined as the change in COVID-19 case rate between May 10 and May 24. 


\section{Appendix Table 10. Comparisons of Estimates for Early, Later, and Never-Protest Counties}

\begin{tabular}{lcccc}
\hline & $(1)$ & $(2)$ & $(3)$ & $\begin{array}{c}(4) \\
\text { Early v. Late }\end{array}$ \\
& Pooled & Early v. Never & Late v. Never & 0.0015 \\
0-5 Days After Protest & 0.0011 & -0.0029 & 0.0002 & $(0.0021)$ \\
& $(0.0013)$ & $(0.0038)$ & $(0.0014)$ & 0.0002 \\
6-14 Days After Protest & 0.0016 & -0.0055 & 0.0005 & $(0.0040)$ \\
& $(0.0020)$ & $(0.0045)$ & $(0.0023)$ & -0.0008 \\
15-19 Days After Protest & 0.0018 & -0.0066 & -0.0001 & $(0.0050)$ \\
& $(0.0027)$ & $(0.0062)$ & $(0.0033)$ & -0.0025 \\
20-24 Days After Protest & 0.0013 & -0.0130 & -0.0002 & $(0.0072)$ \\
& $(0.0032)$ & $(0.0076)$ & $(0.0038)$ & -0.0048 \\
25-29 Days After Protest & 0.0016 & -0.0066 & 0.0011 & $(0.0045)$ \\
& $(0.0038)$ & $(0.0074)$ & $(0.0046)$ & -0.0066 \\
30-34 Days After Protest & -0.0019 & -0.0077 & 0.0004 & $(0.0048)$ \\
& $(0.0046)$ & $(0.0089)$ & $(0.0052)$ & -0.0077 \\
35+ Days After Protest & -0.0077 & -0.0144 & -0.0025 & $(0.0047)$ \\
& $(0.0053)$ & $(0.0085)$ & $(0.0059)$ & 10962 \\
\hline
\end{tabular}

* Significant at the $10 \%$ level, ** Significant at the $5 \%$ level, *** Significant at the $1 \%$ level

Notes: Estimate is generated using weighted least squares. All models include county and day fixed effects. State-level controls include: log testing rate, indicator for a SIPO, mask mandate, whether food industry reopened, whether retail store reopened, whether personal or pet care services reopened, and whether entertainment or activity reopened. County-level controls include: average temperature and an indicator for whether any precipitation fell. Standard errors, clustered at the county-level, are reported inside the parenthesis. Counties with first protest on May 28 or before are coded as Early protest county. Counties with first protest on May 29 or after are coded as Late protest county. 